Florida International University

FIU Digital Commons

$10-22-2018$

\title{
The Gendered Long-Term Recovery Priorities of Internally Displaced Persons in Post-Earthquake Haiti
}

Nicki Fraser

Florida International University, nfras001@fiu.edu

Follow this and additional works at: https://digitalcommons.fiu.edu/etd

Part of the Emergency and Disaster Management Commons, Other Public Affairs, Public Policy and Public Administration Commons, and the Public Policy Commons

\section{Recommended Citation}

Fraser, Nicki, "The Gendered Long-Term Recovery Priorities of Internally Displaced Persons in PostEarthquake Haiti" (2018). FIU Electronic Theses and Dissertations. 3924.

https://digitalcommons.fiu.edu/etd/3924

This work is brought to you for free and open access by the University Graduate School at FIU Digital Commons. It has been accepted for inclusion in FIU Electronic Theses and Dissertations by an authorized administrator of FIU Digital Commons. For more information, please contact dcc@fiu.edu. 


\section{FLORIDA INTERNATIONAL UNIVERSITY}

Miami, Florida

A dissertation submitted in partial fulfillment of the

requirements for the degree of

DOCTOR OF PHILOSOPHY

in

PUBLIC AFFAIRS

by

Nicki Fraser 
To: Dean John F. Stack, Jr.

Steven J. Green School of International and Public Affairs

This dissertation, written by Nicki Fraser, and entitled The Gendered Long-term

Recovery Priorities of Internally Displaced Persons in Post-Earthquake Haiti, having been approved in respect to style and intellectual content, is referred to you for judgment.

We have read this dissertation and recommend that it be approved.

$\begin{array}{r}\hline \text { Mevin Grove } \\ \hline \text { Meredith Newman } \\ \hline \text { N. Emel Ganapati-Major Professor }\end{array}$

Date of Defense: October 22, 2018

The dissertation of Nicki Fraser is approved.

Dean John F. Stack, Jr.

Steven J. Green School of International and Public Affairs

Andrés G. Gil

Vice President for Research and Economic Development and Dean of the University Graduate School

Florida International University, 2018 


\section{DEDICATION}

This dissertation is dedicated to my daughter Cristal, who is an exceptional mother to three sons, a loving wife and consummate professional who lovingly assisted me in navigating the academic environment in my 50s. This dissertation is also dedicated to my mother, to my aunt and uncle for their unwavering belief in me, and to my brothers for their humor and support. To the Haitian Community Leaders and NGO directors living in Haiti who commit their lives to serve those affected by the earthquake and strive to create a sustainable recovery environment. To the internally displaced people of Haiti, particularly the women (the "Poto Mitan") who have stayed strong through the years after the earthquake and still maintain their sense of humor and faith in a higher power. I hope that through this research, their voices are heard. 


\section{ACKNOWLEDGMENTS}

I would like to acknowledge my dissertation committee for their expertise and guidance during my research and the writing of this dissertation. To my mentor and dissertation chair, Dr. N. Emel Ganapati, who guided me with patience and tough love through my MPA and Ph.D. journeys. She inspired me through her academic excellence, kindness toward others, and her passion to give a voice to those marginalized by natural and human-made disasters.

To Dr. Meredith Newman, who became my role model as an undergraduate. To Dr. Milena Neshkova, who guided me through the study of citizen participation. To Dr. Kevin Grove, who provided a wealth of cultural insight and knowledge in the Caribbean context. Thank you to the National Science Foundation for their Fellowship opportunity, which provided economic peace of mind the first three years of this journey. Thank you to Dr. Christy McGuire, Dr. Agatha Caraballo \& Dr. Christa Remington, my guides on the side. Finally, I am grateful to the Department of Public Policy and Administration my second home - which provided a supportive environment for a nontraditional student. 


\title{
ABSTRACT OF THE DISSERTATION \\ THE GENDERED LONG-TERM RECOVERY PRIORITIES OF INTERNALLY \\ DISPLACED PERSONS IN POST-EARTHQUAKE HAITI
}

\author{
by
}

Nicki Fraser

Florida International University, 2018

Miami, Florida

\section{Professor N. Emel Ganapati, Major Professor}

Despite a growing body of research on gender and disaster, little is known regarding the long-term recovery priorities and participation of internally displaced women in the longterm recovery process. Focusing on this important scholarly gap in the public administration literature, the overall goal of this study is to understand the long-term recovery processes of populations displaced by the 2010 Haiti earthquake through a gendered lens. The study's specific aims are to: (1) understand the rebuilding priorities of IDPs in Haiti through a gendered lens; (2) determine factors that enable or hinder IDP women's participation in decision-making processes; and (3) assist policymakers, non-governmental organizations, and international aid agencies in addressing the priorities of women IDPs. The dissertation is based on a qualitative research study. Its data collection methods include semi-structured interviews $(n=97)$, focus groups $(n=63)$, participant observation, and a review of diverse secondary sources. Despite some similarities between the recovery priories of women and men IDPs in the short and longterm, women IDPs in Haiti had several additional priorities due to: (1) the traditional roles they play in the household; (2) their perception inside and outside the household as 
passive "victims" that needed help; and, (3) the location and conditions of IDP camps (e.g., increased risks of sexual assaults and violence) within which they lived. Their participation to voice their priorities were limited to participation in informal settings (e.g., camp committee meetings) in camps managed by the government or international aid agencies; and were affected by the following: (1) organizational factors (e.g., diverse range of organizations with diverse organizational cultures); (2) formal institutional factors (e.g., lack of participatory mechanisms customized for IDPs); (3) policymakerrelated factors (e.g., stigma towards the IDPs); (4) IDP related factors (e.g., lack of trust); (5) place-related factors (e.g., lack of access to transportation); and (6) social capitalrelated factors (e.g., women's groups). This study provides useful information to public administration scholars and policymakers who are working to support individuals living in the camps while those individuals rebuild their communities and livelihoods. 


\section{TABLE OF CONTENTS}

CHAPTER

PAGE

I. INTRODUCTION

Overview 1

Findings Summary __ 12

Layout of Dissertation __ 23

II. LITERATURE REVIEW __ 24

Introduction _ 24

Disaster Recovery _ $\quad 26$

IDPs and their Priorities__ 42

IDPs and their Participation in Disaster Recovery___ 43

Chapter Summary__ 55

III. METHODOLOGY

Introduction__ 57

Research Context: Haiti and the 2010 Earthquake__ 57

Case Study Sites__ 63

Data Collection Methods__ 70

Data Management \& Confidentiality___ 81

Data Analysis___ 82

Chapter Summary___ 85

IV. FINDINGS 88

Overview__ 88

Priorities of Men and Women IDPs___ 89

Recap of Priorities Summary__ 110

Priorities from the Perspectives of Policymakers

Factors That Enabled or Hinder Women IDPs' Participation in Recovery 118

Chapter Summary ___ 144

V. CONCLUSIONS _ 146

Overview__ 146

Importance of IDP Participation in the Recovery Process___ 146

Why Haiti was the Ideal Context for Exploring These Issues___ 148

Public Administration and Citizens as IDPs___ 149

Methodology Review __ 150

Gendered Long-term Recovery Priorities of the IDPs in Haiti___ 151 
Institutional and Policy Factors Affecting IDP Women's Participation 154

How Policymakers and Representatives of NGOs Can Address

The Needs of IDP Women 156

Strengths and Limitations of This Research 163

Future Research Directions 165

Closing Thoughts 167 


\section{LIST OF TABLES}

TABLE

PAGE

1. IDP Interview Participants by Location and Gender 77

2. IDP Focus Group Participants by Location and Gender 78

3. IDP Priorities According to Study Policymaker Informants 120

4. Study Participant Priorities 147 


\section{LIST OF FIGURES}

FIGURE

PAGE

1. The Life Cycle of Disaster Management 27

2. Map of Haiti Earthquake of 2010 60

3. Grand'Anse in 2016 after Hurricane Matthew 61

4. A Haitian farmer points to destroyed banana trees after Hurricane Irma 61

5. Pétion-Ville bidonville before the earthquake 64

6. Areas in Haiti affected by the 2010 earthquake 65

7. Boundaries of Delmas 66

8. Boundaries of Pétion-Ville 66

9. The J/P HRO camp in 2011 67

10. Canapé Vert boundaries 68

11. Canaan in 2010 69

12. Canaan in 2016 70

13. Word cloud of most frequently mentioned terms 84

14. Word cloud of top 25 Creole words in 2010 89

15. Cluster analysis illustrating words clustered around "mwen" ("I" or "me") 91

16. Haitian women in the Rebuilding Haiti training program 96 
17. Image of a tap-tap in Haiti

18. IDP Priorities: Similarities 109

19. IDP Priorities: Differences 110

20. Factors affecting IDP participation 120

21. 2010 camp committee letter 131 


\section{ABBREVIATIONS AND ACRONYMS}

\begin{tabular}{|c|c|}
\hline CEDAW & Committee on the Elimination of Discrimination against Women \\
\hline CGC & Common Ground Collective \\
\hline FPE & Feminist Political Ecology \\
\hline GBV & Gender-based violence \\
\hline HUD & Housing and Urban Development (U.S.) \\
\hline ICRC & International Committee of the Red Cross \\
\hline IDB & Inter-American Development Bank \\
\hline IDP & Internally displaced persons \\
\hline IHRC & Interim Haiti Reconstruction Committee \\
\hline IJDH & Institute for Justice and Democracy in Haiti \\
\hline IOM & International Organization for Migration \\
\hline IPV & Intimate partner violence \\
\hline $\mathrm{J} / \mathrm{P} \mathrm{HRO}$ & Jenkins/Penn Haitian Relief Organization \\
\hline KOFAVIV & $\begin{array}{l}\text { Komisyon Fanm Viktim pou Viktims } \\
\text { (Commission of Women for Women) }\end{array}$ \\
\hline LGBTQ & Lesbian, gay, bisexual, transgender, and queer \\
\hline MFM & Mass fatality management \\
\hline $\mathrm{NGO}$ & Non-governmental organization \\
\hline NSF & National Science Foundation \\
\hline ORE & Organization for the Rehabilitation of the Environment \\
\hline PADF & Pan American Development Foundation \\
\hline
\end{tabular}




\section{ABBREVIATIONS AND ACRONYMS (cont'd)}

PHRF People Hurricane Relief Fund

PTSD Post-traumatic stress disorder

U.S. United States

UNDP United Nations Development Program

UNESCO United Nations Educational Scientific and Cultural Organization

UNHCR United Nations High Commission for Refugees

USAID United States Agency for International Development

WB World Bank 


\section{CHAPTER I}

\section{INTRODUCTION}

There wasn't enough assistance from the IOM [International

Organization for Migration]. We feel horrible because of the treatment we have received in Block 7. You (government) forgot all the IDPs [Internally Displaced Persons] and abandoned them in this desert. If we yell loud enough, will that help? We have no food or medical care, others have a hospital, and we don't. Aren't we people too? We need to work and [we need] a school for our children.

A 2010 Letter from Block 7, Camp Corail Committee of Internally Displaced Populations (International Organization for Migration, 2011)

\section{Overview}

Haiti, a densely populated ${ }^{1}$ country of approximately 11 million people (UNESCO, 2017), is in the western part of the island of Hispaniola. It was once known as the "Pearl of the Antilles" (Haiti, 2017). This nickname was the result of rich soil yielding coffee and sugar and beautiful beaches with tranquil blue waters. Strong and resilient slaves inhabited this fertile land after Spanish and French conquerors brought them to the island. Haiti declared its independence in 1804, becoming the first Black

\footnotetext{
${ }^{1}$ According to the World Bank (The World Bank, 2018) as of 2017 Haiti's population density is 398.4 people per square kilometer. For comparison, the population density of the United States is 35.6, and the global average is 58.0.
} 
republic; yet, it continued to struggle for its place in a world fearful of a Black revolt (Dubois, 2012).

Because of this universal fear of a Black revolt in the United States, many international economic and political policies considered to improve the Haitian economic and political environment were detrimental to Haiti's government governance. The United States enforced a trade embargo and refused to recognize the new Black Republic. (Dubois, 2012; Fatton 2011). France's claim of 100 million dollars in reparations took Haiti one hundred years of borrowing from other financial entities to pay off, causing additional debt to the struggling republic (Leger, 1907; Johnson, 1920; Schulz \& Marcella, 1994).

In 1923 , forests covered $60 \%$ of Haiti's terrain, and this geographic landscape allowed its citizenry autonomy over food and fuel production. Since then, chronic erosion, unsustainable and intensive agricultural practices, along with the mountainous terrain contributed to food and fuel scarcity (Rastoje, 2010). By the time of the 2010 earthquake, only $2 \%$ of forests remained. Haiti was a politically exhausted and economically depleted state, no longer known as the "Pearl of the Antilles" but referred to as the "poorest country in the Western hemisphere" (Dubois, 2012; Dupuy, 2010; Fatton, 2011; Schuller, 2012). Despite years of international political, social, and economic aid, Haiti's people and its government were in a state of disarray.

Haiti's history of over 200 years of economic, social and political strife exacerbated its fragile state, and government failures and set the stage for the unprecedented humanitarian disaster caused by the January 12, 2010, Haiti earthquake (Bell 2012; Farmer 2012; Fatton 2011). The epicenter of the earthquake, which measured 
7.0 on the Richter scale, was approximately 25 kilometers west of Port-au-Prince. The earthquake killed an estimated 222,570 people, destroyed or damaged 180,000 homes, and left 3.7 million people adversely affected in some form (World Bank, 2013). It left 1.5 to 2 million people internally displaced (CEPR, 2013; Happel \& Yaffe, 2017; IJDH, 2012; Internal Displacement Organization, 2017; International Organization for Migration, 2018). As Haitians put it, "Tout Ayiti kraze" ("The whole country is no more"; Fatton, 2011, p.164).

Internally Displaced Persons (IDPs in short) are people who - like refugees - flee their homes seeking safety from armed conflicts, violations of human rights or natural or human-made disasters, but - unlike refugees - do so within the boundaries of their home country (Internal Displacement Monitoring Centre, 2017). In the aftermath of the disaster, more than 1,300 government- and NGO-sponsored camps housed the IDPs (World Bank, 2013). Although NGO and government programs closed a majority of these camps, there were 40,000 to 60,000 people living in approximately 31 camps across Port-au-Prince in 2017, seven years after the earthquake (Internal Displacement Organization, 2017). The overall number of IDPs in Haiti continues to rise, with the IOM (2018) currently reporting the total number of IDPs is now close to one million. Several factors contributed to this alarming rise in displacement, namely a 2010 decree by the Dominican Republic's government which excludes Dominican born children of immigrants from Dominican citizenship (Archibald, 2014), followed by two major hurricanes in 2016 (Matthew) and 2017 (Irma). Due to the 2010 Dominican decree and the two recent hurricanes, as of 2018 over 100,000 additional displaced persons are living in camps on the Haitian side of the Haitian-Dominican border. This new wave of 
displaced persons created a humanitarian disaster, which has barely been addressed by the international community or the Haitian or Dominican governments (International Organization for Migration, 2018).

This dissertation focuses on the stories of the IDPs in Haiti. I first came across these stories while reading letters like the one from the Camp Corail Committee presented above. These letters were collected by the International Organizational for Migration (IOM), which had placed suggestion boxes throughout IDP camps in Port- auPrince after the earthquake. The letters captured the overall sentiment of IDPs as being invisible in the eyes of outsiders (C'ést moun invisibles nou ye, or "We are invisible"). It also highlighted the differences in the post-earthquake priorities of women versus men. While women's letters highlighted their family's needs for food and education, for instance, men's letters emphasized the importance of jobs in their lives. I read only a small percentage of the thousands of letters written to the IOM and I was intrigued by the stories of the IDPs.

Soon after reading the IDP letters, my advisor introduced me to a study on social capital and shelter recovery conducted in the aftermath of the 2010 earthquake in Haiti. Entitled RAPID: Re-Housing Urban Haiti after the Earthquake: The Role of Social Capital (referred to hereafter as "the NSF study"), this study was funded by the National Science Foundation (Principal Investigator: N. Emel Ganapati) and undertaken by a group of researchers from Florida International University, University of South Florida and the Haitian Institute of Community Health (Institut Haitien de Santé Communautaire). It focused on three socioeconomically different communes (districts) in or near the Port-au-Prince arrondissement (an administrative division within a city) 
devastated by the 2010 Haiti earthquake: Pétion-Ville, Delmas, and the neighborhood of Canapé Vert within the arrondissement of Port-au-Prince. These communes were originally selected as they were adjacent yet socio-economically diverse communities in Port-au-Prince. All three areas, however, had lower-income areas devastated by the earthquakes, and housed IDPs.

The study's data collection methods included focus groups ( $n=12$ groups with 47 total participants), interviews ( $n=54)$, field observations, and review of secondary sources. The focus groups were conducted in two rounds and were six months apart from one another. A total of four focus groups were conducted in each of the three neighborhoods. Half of all focus groups conducted were with women IDPs, and the other half were with male IDPs. The NSF study completed all data collection activities within a year and a half of the earthquake (May 2010-June 2011).

The NSF study explored the contextual understanding of social capital (social networks) in Haiti through such concepts as of lakou and rekonnét (Rahill et al., 2014). Lakou "refers to clusters of homes in which Haitian families reside, as well as to the extended and multiple-generation family form that is prominent in Haitian culture" (Edmond, Randolph, \& Richard, 2007, p. 19). Rekonnét is the recognition and trust afforded someone based on firsthand experiences (Rahill \& Ganapati, 2017). The study found that IDP's post-earthquake camp environments disrupted their lakou and rekonnét networks as they lost the support of family and friends while being displaced from their home communities to camps. Although social capital helped a group of IDPs who were well connected to the international aid organizations regarding shelter recovery, it reinforced inequalities that existed before the earthquake and created new ones. In some 
IDP communities, these inequalities led to shelter-related conflicts and violence. My dissertation study builds upon and extends the findings of this NSF study (Ganapati \& Rahill, 2017; Mukherji, Ganapati, \& Rahill 2014; Rahill et. al 2014, 2016).

\section{Need for the Study}

The field of disaster management is rich in research covering the phases of preparedness, response, mitigation, and short-term recovery. However, researchers often under-study the critical phase of long-term recovery compared to the other phases. The lack of long-term recovery research is especially true in emergency management literature in the public administration discipline, which almost exclusively focuses on the response phase.

Most disaster researchers and practitioners "view recovery as a process defined by two stages: short- and long-term; steps and sequences that people, organizations, and communities move through at varying rates" (Phillips, 2009, p. 22). The short-term recovery phase transitions a community from response activities to recovery efforts such as managing donations and volunteers, building temporary shelter, and clearing debris within the first weeks following a disaster (Horton, 2012; McEntire, 2012; Phillips, 2009). The long-term recovery phase - from months up to several years post-disaster encompasses multiple dimensions of disaster recovery including debris management along with recovery efforts around environmental, historical and cultural, housing, business, infrastructure and lifelines, social psychological, and public-sector resources (Phillips, 2009).

Researchers posited in a successful long-term recovery process, all stakeholders should actively engage in community planning activities and have access to rebuilding 
and economic opportunities (Comerio, 2017; Enarson, Fothergill, \& Peek, 2006; Jigyasu, 2012). Unfortunately, many post-disasters found the IDPs are often left out of these rebuilding prospects (Blaikie, Cannon, Davis, \& Wisner, 2004; Chandrasekhar, 2012; Chandrasekhar, Zhang, \& Xiao 2014; Kennedy, 2008; Schuller, 2016).

IDP women face additional challenges compared to men during recovery such as gender-based violence (Bell, 2010; Concnnon \& Lindstrom, 2011; Schuller, 2016). Overcrowded shelters or temporary housing facilities put women at greater risk for male aggression (Zahran et al., 2009). Researchers also attribute the rise of post-disaster domestic and gender-based violence to stress, loss, and trauma (Aldrich, 2010; Cullen \& Ivers, 2010; Enarson, Fothergill, \& Peek, 2007; Fischer, 2009; Goldscheid, 2007; Seager, 2006). The loss of community and familial support as well as the lack of protection exacerbate already precarious conditions for women. Yet, we know little about the shortand long-term recovery priorities of IDPs based on gender.

Another topic that has not been fully researched is the set of factors that hinder or enable women IDPs' participation and voice during the long-term recovery process. Some studies have focused on factors that hinder or enable IDP public participation in post-disaster contexts (e.g., Ganapati \& Ganapati, 2009; Schuller, 2016), but studies that focus exclusively on IDP women's participation issues are rare. The broader literature on gender and participation provides some insights (Apaza, 2015; Arnstein, 1969;

Chandrasekhar, 2012; Choguil, 1996). Some studies suggest, for instance, that voice and participation for women may be perceived as selfish and as abandoning family responsibilities given societal roles and responsibilities expected of women (Gilligan, 1993). Other studies have highlighted that women participate more in informal grassroots 
organizations rather than in formal organizations, which leads to their further marginalization (Gilligan, 1993; Ruddick, 1989). Still, other studies have found that women and men manifest voice (and participation) differently. According to Ruddick (1989), women often speak and act in altruistic, maternal, peaceful and communal ways, placing the well-being of the community as their primary focus, whereas men speak authoritatively and act more in an individualistic manner.

In post-disaster contexts, "gender-based exclusion may occur at multiple levels, ranging from transnational policy formation to the ground-level implementation of relief efforts" (Horton, 2012, p. 300). Women, especially those who are socioeconomically and politically insecure (they have fewer opportunities for participation), are the most affected, are the least visible in recovery policies, and are often left more impoverished than before the disaster (Enarson, Fothergill, \& Peek, 2007; Fordham, 2012; Fothergill, 2002; Reigner et al., 2008).

This dissertation attempts to fill these gaps in the scholarly literature by focusing on the short- and long-term priorities and participation of women IDPs during the recovery period.

\section{Study Goals and Aims}

Inspired by the stories of the IDPs and aiming to fill in the gap in the literature, the overall goal of this dissertation is to understand the long-term recovery processes of IDPs in Haiti through a gendered lens. The dissertation is informed by the literature on public administration, disaster emergency management, and feminist political ecology. It seeks to address three specific aims. 
Specific Aim \#1: To understand the long-term rebuilding priorities of the IDPs and the reasons behind such priorities through a gendered lens. This aim focuses on what the differences are between the long-term rebuilding needs of women versus men, and why women place priorities on certain issues over others during the recovery period.

Specific Aim \#2: To determine factors that enable or hinder women IDPS participation in decision-making during recovery processes. This aim deals with factors that either give women opportunities or that hinder them from expressing their unique needs and priorities in the rebuilding process.

Specific Aim \#3: To assist Haitian policymakers as well as representatives of non-governmental organizations (NGOs) and international aid agencies in addressing women IDPs priorities. The intended outcomes of this aim can provide policy recommendations for various actors involved in the post-disaster recovery process, helping them to understand and address the priorities of women IDPs.

\section{Significance of the Study}

According to the Sendai report (2016) - a disaster risk reduction framework (2015-2030) that formulated guidelines for countries and agencies to mitigate, prepare, respond to, and recover from disasters - the number of disasters from 2005 to 2015 affected more than 1.5 billion people (United Nations Office for Disaster Risk Reduction, 2017). According to the United Nations Office for Disaster Risk Reduction (UNISDR, 2017), global disasters during this period such as Hurricane Katrina in the United States (2005), Cyclone Nargis in Myanmar (2008), earthquakes in Haiti and Chile (2010), and the earthquakes in Japan and Christchurch, New Zealand (2011) resulted in \$1.3 trillion USD in economic losses and disproportionately impacted the long-term recovery of 
women, children, and the internally displaced persons. The United States' Federal Emergency Management Agency (FEMA) reported in 2018 that Hurricanes Harvey, Irma, Maria, and the California wildfires affected more than 25 million people - almost $8 \%$ of the United States population. Therefore, the field of disaster management plays a critical role within the United States and on the global stage (Comerio, 2017; Esnard, 2017; Phillips, 2017; Rahill \& Ganapati, 2017).

Within the field of disaster management, the importance of this particular study is multifaceted. First, the IDPs in Port-au-Prince continue to suffer from discrimination due to their 2010 post-earthquake displacement (CEPR, 2013; Reini, 2010), which creates systematic, institutionalized economic barriers to their rebuilding efforts (Corbet, 2014). For example, IDPs experience predatory lending practices (Gender Action Network, 2013), do not have access to affordable housing options (UNESCO, 2017), and lack political representation in local governments (Amnesty International, 2017; Haiti Libre, 2017; Schwartz, 2018). By focusing on the IDPs in Haiti, this study will inform policymakers about the priorities of IDPs. Second, research has demonstrated that there is a lack of coordination between the short-term recovery goals of humanitarian aid agencies and the long-term recovery goals of development organizations (Farmer, 2012; Horton, 2012; Padgett \& Warnecke, 2011). This study will help aid agencies link the short-term and long-term policies targeting the IDPs. Third, recovery efforts and programs undertaken by governments and NGOs often fail to recognize gender differences and tend to marginalize women (Enarson \& Meyreles, 2004; Goldscheid, 2007; Green, Havelin, \& Zitleman, 2011). This study has implications for Haitian and donor country government officials as well as for international aid agency representatives 
who may be interested in integrating IDP women's priorities into the long-term recovery process and with involving them in decision-making around that recovery. Fourth, women in Haiti are in an indeterminate state of shelter and economic insecurity, which creates an environment in which rape and other violence against women proliferate (Bell, 2012; Fordham, 2012; Horton, 2012; Schuller, 2016). This study will benefit women IDPs by bringing their unique post-disaster challenges to light, amplifying their voice and by helping them address issues that matter to them during their post-disaster recovery processes.

\section{Research Methods}

To achieve the overall goal and aims of the study, I conducted semi-structured interviews $(n=43)$ with the IDPs, community leaders and international and Haitian officials involved in policy making with respect to the IDPs. I conducted the interviews from 2017 to 2018 primarily via telephone, speaking in the preferred language of the interviewees and according to the socially acceptable norms in Haiti (e.g., speaking in French with government officials or in Haitian Creole with IDPs). After acquiring the informed consent of the participants, I documented the interviews with written notes or audio recordings. I then transcribed the audio-recorded interviews verbatim. Including these interviews and the interviews of the NSF study, I analyzed qualitative data from 97 interviews, at which point I reached theoretical saturation (Bowen, 2008; Morse, 1995). In addition, I analyzed data from the focus groups from the NSF study ( $\mathrm{n}=12$ groups with 47 total participants), field observation and review of secondary sources (e.g., scholarly articles; reports of international organizations; news articles, blogs, and websites highlighting policies and programs targeting women IDPs and their priorities). I analyzed 
the data I collected using the qualitative analysis software NVivo 11 Pro. As themes emerged through word searches, word clouds, and word trees, I coded and analyzed the transcripts and other documents.

\section{Findings Summary}

The analysis of data from the interviews, focus groups, field observation and secondary sources collected for this dissertation and for the NSF project revealed the following findings with respect to the three specific aims of this study:

\section{The long-term rebuilding priorities of the IDPs and the reasons behind such}

priorities through a gendered lens. According to my informants, despite some similarites between the recovery priories of women and men IDPs in the short- (food security, sanitation/cleanliness, returning home and to pre-disaster community) and long-term (access to secure shelter), women had several additional priorities due to: (1) the traditional roles they play in the household (a reproductive role as a mother and nurturer and productive role as a caregaver and income generator); (2) their perception inside and outside the household as passive "victims" that needed help; and, (3) the location (away from the center) and conditions of IDP camps (e.g., increased risks of sexual assaults and violence in IDP camps, cholera outbreak) within which they lived. I elaborate below on the common priorities of women and men, women- and men- only priorities and the IDP priorites as perceived by the policymakers.

Common Priorities. Women and men IDPs had more shared rebuilding priorities in the immediate aftermath of the disaster (e.g., food security, sanitation/cleanliness, returning home, and returning to their pre-disaster communities), compared to their shared long-term rebuilding priorities (e.g., access to secure shelter). In the long-term, 
however, their priorities diverged more, becoming more gender-specific. Women and men IDP's mutual emphasis on food security is understandable given that they were all affected by the earthquake and had to think about their families' immediate basic needs first. The emphasis on sanitation/cleanliness had more to do with the poor sanitary conditions of the camps during short-term recovery. The emphasis on returning home and to their pre-disaster communities highlighted the importance of the loss of their social networks (e.g., being away from their pre-disaster neighbors and living next to strangers in the camps that they do not necessarily trust) and attachment to their pre-disaster homes and communities, irrespective of gender.

Common Priorities That Require A More Nuanced, Gender-Based Understanding. Although some priorities of women and men IDPs (protection and income generation) seemed to be similar both in the short- and long-term, they required a more nuanced and deeper understanding from policymakers in terms of the dimension of the problem each group wanted to be addressed and the solutions that they wanted to see. In terms of protection, women IDPs had genuine concerns about their bodily integrity in the face of sexual assault and violence threats in IDP camps. Men IDPs were more concerned about the protection of their private property against robbery. In their discussions of protection, the women used the term rape ( $k a j o k)$, whereas the male informants never used this term.

In terms of income generation, women IDPs preferred self-employment. Men, who considered themselves as the primary bread winner of the household, desired jobs outside their household. Women IDPs' preference for self-employment was in part due to their reproductive role as a mother and nurturer and due to their productive role as a caregiver and income generator inside the household. In Haiti, women are generally 
responsible for food selection and preparation as well as for the care and feeding of children (Finch, 2010; Global Food Security, 2013; Seager, 2005). They also provide for their children's educational needs, tuition, books and uniforms very often by running a small business (très petite entreprises) which may consist of buying and selling produce or clothes, and cooking meals to sell.

Female-Only Priorities. Female IDPs' unique priorities, not necessarily prioritized by men, were related to the education of their children, healthcare (both in terms of physical and mental health) and transportation, especially young, child bearing women. Their gender-specific emphasis on education was understandable given their reproductive role in the household. Their priority of healthcare was closely related to the unique threats their children and they faced in the aftermath of the earthquake (e.g., cholera, sexual assault, PTSD). Although men IDPs also suffered from some of the same illnesses their children and women suffered (e.g., cholera), they may not have mentioned it as one of their top priorities since they culturally considered illness as a weakness, reserved for "weak" women. Their emphasis on transportation reflected two factors: their productive role as an income generator (many needed transportation for purchasing and selling goods in the market) and the distant location of IDP camps following evictions from more central areas. Men IDPs may not have mentioned transportation as a priority in part because they had less of a need for transportation and in part because they had more transportation options. In addition to these three women-specific priorities, women were genuinely concerned about their perception as passive victims that needed help as opposed to men's perception. Such perception had to do with cultural norms and expectations with respect to women in the Haitian culture. 
Male-Only Priorities. Men IDPs' only unique priority, not necessarily prioritized by women, was related to their desire to be politically active.

Priorities from The Perspectives Of Policymakers. Policymakers' perspectives of IDP priorities were similar to that of the perspectives of the IDPs. They mentioned sanitation, security and income producing activities as the top three priorities. Some international policymakers thought that the Haitian government was exaggerating instances of violence in IDP camps to ask for more funding from the international NGOs.

\section{To determine factors that enable or hinder IDP women's participation in}

decision-making during recovery processes. Women IDPs (50\%) voiced their priorities to decision makers less than men IDPs $(60 \%)$ both in short- and long-term recovery. Still, however, women IDPs who lived in formal camps made efforts to participate in decisionmaking processes in recovery. However, their participation was not in formal participatory settings (e.g., U.N. Cluster meetings). Rather, it was limited to participation in informal settings (e.g., camp committee meetings) at the neighborhood level, which was closer to them. There were six broad factors that affected women IDPs' participation in decision making processes in the post-earthquake context to inform authorities about their priorities: (1) organizational factors (e.g., diverse range of organizations with diverse organizational cultures); (2) formal institutional factors (e.g., lack of participatory rules and regulations customized for IDPs); (3) policymaker-related factors (e.g., stigma towards the IDPs); (4) IDP related factors (e.g., lack of trust); (5) place-related factors (e.g., lack of access to transportation); and, (6) civic networks-related factors (e.g., women's groups). I explain each of these factors below: 
Organizational Factors. Haiti is a failed state which cannot even provide its citizens with basic services. Hence, besides the Haitian government, there were a number of international and national NGOs attending to the needs of IDPs during the recovery period. The diversity of recovery actors itself made it difficult for the IDP women to participate, especially those who lived in informal camps (e.g., those that were not managed by the Haitian government or the international NGOs), as they did not know who to turn to for their specific problems.

Formal Institutional Factors. Institutional factors were both barriers and enablers with respect to women IDPs' participation in decision making processes in recovery. For instance, as a failed state, the Haitian government did not have any formal mechanisms in place to be in contact with or involve the IDPs in decision making processes. It did not guarantee rights to the IDPs either. Furthermore, institutions that were developed for recovery were not reflective of women IDP's unique needs and strengths (e.g., Haiti's PDNA vs Nepal's PDNA which emphasized the need for a gendered approach to recovery). The international NGOs, on the other hand, made efforts to establish formal mechanisms to allow for IDPs to voice their concerns. The most notable such mechanisms were the U.N. Cluster Meetings and the IDP camp committees. The Cluster Meetings were open to the public. Yet, they were not very inclusive of the IDPs in general, in part because they were mostly held in English or French (that are not spoken by the masses) and in part because they were held in places that were difficult to access and even intimidating (e.g., heavily guarded UN Base). Hence, most U.N. Cluster meetings were attended by representatives from the Haitian government and the international or national NGOs, without a single IDP or a community leader. As for the 
IDP camp committees, although they were established due to requests of the international NGOs, they mainly included male representatives, some of whom used their leadership role in the community for sexual "favors" to IDP women who were trying to make ends meet. Still, however, women IDPs who lived in formal camps were able to voice their concerns in camp committee meetings (although they thought nothing came out of their participation). Women IDPs who lived in informal camps did not even have much of that opportunity. They were mainly limited to participating in church meetings.

Policymaker-Related Factors. There were several policymaker-related barriers. First, Haitian policymakers, who are mostly wealthy, educated (usually outside Haiti), and politically connected men, treated the IDPs - both women and men - as invisibles. They seemed to be more concerned about getting funding from donors than serving the Haitian people, and about looking good in the eyes of donors by showing that they were doing something with the IDPs. The IDPs who lived in informal camps not managed by international NGOs also felt invisible in the eyes of international aid agency representatives. Second, there were few women in positions of power in the Haitian government who could have voiced the concerns of women IDPs. Third, there was stigma attached to the IDPs in general and to women IDPs in specific. Both Haitian and international policymakers believed that IDPs, irrespective of gender, preferred to stay in the camps to take advantage of the aid provided to them through donors even though returning to their pre-disaster home and community was one of IDPs' top priorities as shown earlier. Some even depicted the IDPs in informal camps as deplorables, which mainly consisted of prostitutes and criminals. Hence, they focused more on evicting them rather than trying to involve them to solve their problems. As for women IDPs, the 
policymakers viewed them more as passive victims who needed help, rather than as survivors. Fourth, international policymakers did not believe that IDPs had much to offer for their programs due to their "strange" beliefs and customs (e.g., voodoo). Hence, they did not bother to involve them in decision making processes. Fifth, the policymakers in general (both Haitian and international) seemed to be more interested in dictating what IDPs should want, as opposed to making a genuine effort to listen to them.

IDP-Related Factors. There were also IDP related factors that hindered women IDPs' participation. First, the IDPs did not trust the Haitian policymakers in part since they had genuine concerns about what they did with the money donated to Haiti after the earthquake. It was mostly "us vs. them." Second, they had more trust in the international NGOs that were providing for their needs. They also thought, however, nothing changed even after they voiced their concerns to these agencies. In addition, they felt abondoned by those agencies that left the country soon after the earthquake. Third, women's reproductive, productive and community roles did not leave them much time for participation. They had to attend to their families' basic needs. Fourth, some women felt threatened when they spoke up. They even faced risks of violence when they voiced their concerns. Fifth, women IDPs thought more value were given to men than women in the society.

Place-Related Factors. Another barrier that affected women IDPs' participation was their lack of access to affordable transportation, especially those that were evicted from more central areas and were forced to live in the outskirts of Port au Prince.

Social Capital-Related Factors. One of the factors that enabled women IDPs' participation was civic networks designed exclusively for women (e.g., those that 
provided small loans to women). Some of these organizations, however, were closed down as their funding dried up, and their leaders went into hiding due to fears of violence against them.

3. To assist Haitian policymakers as well as representatives of non-governmental organizations (NGOS) and international aid agencies in addressing women IDPs' priorities. Policymakers and community leaders in this study agreed that the Haitian government needs an expanded grassroots approach to long-term recovery, which should involve the hundreds of small- and medium-sized community organizations dedicated to housing as well as job creation initiatives. One of the lawyers spoke of a "rights-based approach" to recovery; that is, protecting IDP civil, land, and political rights. All the NGO informants in this research agreed that the Haitian government needs to involve IDPs and others affected by these disasters in their long-term recovery. Haitian women have the knowledge, capacity, and resilience to grow their livelihoods and family wealth. What they lack, however, is the global and local financial and political support to do so. Haitians prefer to be self-sustaining and, given the opportunity, to experience economic freedom.

\section{Study Contribution to the Literature}

The study contributes to the literatures on public administration, gender and disasters, as detailed below.

Contributions to the Public Administration Literature. First, the study contributes to the public administration literature on emergency management by focusing on disaster recovery itself. Most public administration studies on emergency management focus on the response phase (short-term recovery), without paying much attention to the long-term 
recovery processes. The notable exceptions are Comfort, Waugh, and Cigler (2012), Ganapati (2012; 2013), and Ganapati and Rahill (2017).

Second, most public administration studies on emergency management deal with organizations and often turn a blind eye to the gender dimensions of different phases of disasters at the community level. The exceptions are Ganapati (2012; 2013). Examining issues through a gendered lens in disaster contexts is important since women and men have often different priorities in short- and long- term. Similarly, various factors are at play that hinder or enable women and men's participation in service providing organizations' decision-making processes.

Third, the study's third contribution to the public administration literature relates to its unique findings on participation in failed or fragile states. Most participation studies in public administration were conducted in the context of U.S. or other developed countries. With its focus on Haiti, this is one of the first studies that sheds light on participation in a fragile state. Participation is uniquely different in such states since there are often hundreds of organizations with diverse organizational cultures that provide the services that the government is unable to provide to its citizens and since there is limited or no contact between the public servants and a majority of the people (as international or domestic NGOs fill in the service provision gaps left by the government).

Fourth, there are barriers or enabling factors that affect people's participation that go beyond the boundaries of organizations that serve the public. Most of the public participation literature in public administration focuses on how laws and regulations, trust in government or in the public, the type and timing of participatory mechanisms or the social construction of the public by policymakers affects participation (Agarwal, 2001; 
Cornwall, 2003; Ganapati \& Ganapati, 2009; Hetherington \& Husser, 2012; Pyles, 2015). There is limited research (Guo \& Neshkova, 2012) that highlights the importance of factors that relate to the public itself (e.g., women's traditional reproductive and productive roles, unique risks women face in post-disaster contexts; Chandrasekhar, 2012; Choguil, 1996) or that relate to the place where they live (e.g., the distance of their post-disaster neighborhoods to the city center; Chandrasekhar, Zhang, \& Xiao, 2014) or to social networks (e.g., networks that address women's unique needs and capabilities; Ganapati, 2012).

Fifth, this study focuses on informal mechanisms of participation. Participation literature in public administration mainly focuses on formal mechanisms of participation, such as public meetings (Ebdon, 2000; Fung, 2004) that are typically attended by socioeconomically better off and educated people. This literature does not offer much insights on informal participatory mechanisms that might be more welcoming of women and other disadvantaged groups at the neighborhood level (e.g., camp committees). A more in-depth understanding of these informal mechanisms is important for ensuring a better representation of the public in formal participatory mechanisms and for finding out how these successful mechanisms can be formalized or scaled up to higher levels (e.g., national level).

Sixth, this research explores the social construction of the public in the eyes of policymakers. Public administration literature on participation presents social construction of the public as a factor that affects participation. This study complements that literature by showing that that there is no one uniform public. Rather there is a variety of publics (Dewey, 1927), who are constructed differently. In the case of Haiti, 
the public was reconstructed by government and NGO officials based on the designation of informal and formal camps. The informal camp designation negated the existence of those IDPs and created an invisible public.

Contributions to the Gender and Disaster Literatures. This study has three additional contributions to the disaster and gender literatures with respect to the priorities of those displaced by a disaster. First, the study shows that surveys may not be the right data collection method in post-disaster contexts as different genders may refer to a different dimension of a problem when they are talking about a particular problem. How one defines the problem is important as it shapes how s/he would want that particular problem to be solved. Furthermore, the same term might have different meanings for different people depending on their situation and priorities. For instance, if a survey asks people to mark their top three priorities, both men and women might select security and protection as one of those priorities. However, while men might prefer security patrol in IDP camps due to their emphasis on protection of their private property, women might prefer to have separate spaces for women and men (including separate toilets with locls on the inside), adequate lighting or access to legal aid, medical assistance or counseling due to their emphasis on protection of their bodily integrity in the face of increased sexual assault and violence.

Second, the disaster literature suggests that people affected by disasters envision to rebuild their communities as it was before the disaster. This study confirms that disaster survivors' desire to go back to their pre-disaster communities is irrespective of gender. Both women and men have desires to have their lives back in their pre-disaster 
homes and pre-disaster communities. Such desire is one of the few shared priorities for women and men displaced by a disaster.

Third, this study shows that women have several additional priorities during short- and long-term recovery. This is not only because of the traditional reproductive and productive roles they are expected to play in the household in both non-disaster and disaster times, as highlighted by the gender literature, but also because how they are perceived as passive victims and because of the the location (away from the city) and conditions of IDP camps where they live (e.g. sexual assaults and violence) in the postdisaster context.

\section{Layout of Dissertation}

The overall goal of this study was to understand the long-term recovery processes of IDPs in Haiti through a gendered lens. Chapter II - the Literature Review summarizes and critiques relevant research from the fields of public administration, disaster management, feminist political ecology, and citizen participation. This examination sought insights about the inclusion of IDPs. In Chapter III, the Methodology outlines why Haiti was chosen as the site for this case study. This chapter also reviews the data collection methods and analysis tools used for this study. Chapter IV, the Findings chapter, evaluates and analyzes informant responses, and places these responses in context with other research. Finally Chapter V, the Conclusion, recaps the overall aims of the dissertation and its findings, closing with a discussion of policy implications for the Haitian government and the NGOs and s suggestions for future research. 


\section{CHAPTER II}

\section{LITERATURE REVIEW}

\section{Introduction}

The field of disaster management is rich in research covering the phases of preparedness, response, mitigation, and short-term recovery. Yet, the extant literature has left the critical phase of long-term recovery ${ }^{2}$ relatively understudied (Jordan \& Javernick, 2012; Rubin, 2009). Despite a growing number of studies on gender and disaster (Enarson \& Fordham, 2002; Enarson et al., 2007; Fothergill, 2002; Horton, 2012; McEntire, 2010; Schuller, 2014), we know little regarding the differences in the longterm recovery needs and priorities between men and women who are internally displaced, or about the processes that support or hinder internally displaced women's participation in the long-term recovery process. Even within the broader disaster literature, disaster recovery remains poorly understood (Philips, 2009; Smith \& Wenger, 2006), in part due to its long-term and multi-faceted nature (Ganapati \& Mukherji, 2014).

To address the aforementioned gap in the literature, this chapter first discusses the relevant literature on disaster management and briefly reviews the "life cycle" or phases of disaster management: preparedness, mitigation, response, and recovery (Phillips, 2009). These phases allow governments, agencies, communities, and individuals to organize specific activities and strategies for potentially minimizing the after-effects of disasters. Second, this review presents Phillips' (2009) dimensions of the recovery phase of disaster management. Within the different dimensions of recovery, IDPs often find

\footnotetext{
${ }^{2}$ In disaster management literature, the phase is also referred to as "reconstruction." This research study uses the terms "long-term recovery" and "reconstruction" interchangeably.
} 
themselves forgotten and voiceless (Schuller, 2016). Third, I examine the literature espousing the integration of a gender-based approach in the post-disaster long-term recovery phase of IDPs specific to women. Due to women's unique roles and responsibilities as well as to the unique challenges women face in post-disaster contexts (e.g., domestic violence, sexual assault), women are likely to have different needs and priorities than men during the long-term disaster recovery phase (Aloudat $\&$ Christensen, 2010; Blaikie, Cannon, Davis, \& Wisner, 2004; Bradshaw, 2013; Enarson \& Morrow, 1998; Schuller, 2016). Here again, the literature under represents the long-term recovery challenges of IDP women. Lastly, I explore IDP participation in their recovery with an emphasis on women, and the factors that enable or hinder their participation. Bradshaw (2013) posited that "participation is a mechanism for change, as a means to build consensus and empower individuals" (p. 147). Although researchers (Chandrasekhar, 2012; Chandrasekhar, Zhang, \& Xiao, 2014; Olshansky \& Chang, 2009) acknowledge participation of different stakeholders in a post-disaster recovery context (government, citizens, international agencies, NGOs), the participation of IDPs to voice their priorities are often overlooked (Ariza, 2017; Brun, 2003; International Organization for Migration, 2018). Concannon and Lindstrom (2011) advocate a "human rights-based approach" to participation where the internally displaced are guaranteed the right to liberty, housing, education, and civil rights. According to Concannon and Lindstrom (2011), the human rights-based approach focuses on the most marginalized and disadvantaged, ensuring their access to sustainable long-term recovery. 


\section{Disaster Recovery: One of the Least Studied and Least Understood Phases of Disaster Management}

Before discussing the disaster management phases, a clarification of the term “disaster" is warranted. This dissertation uses Quarantelli’s (1999) description of a disaster as an event having human impact that is disruptive to a community's ability to function socially, economically, or politically, and whereby damaged infrastructure displaces the community's citizens. The four phases of the disaster life cycle (further examined below) are mitigation, preparedness, response, and recovery. Quarantelli (1999) suggested that the concept of recovery means different things to different people, including rebuilding, reconstruction, restoration, rehabilitation, and restitution. Smith and Wenger (2006) found the field of disaster recovery represented one of the most poorly understood and least researched phases of disaster management. According to Gloria Rubin (2009) "long-term recovery was, and still is, the neglected element of disaster management" (p. 2). Bradshaw (2013) found that researchers disagree as to whether longterm recovery is an opportunity to rebuild the "old" buildings, processes, and societal structures or to transform them. Long-term recovery and reconstruction may present an opportunity to transform gender roles (Enarson \& Morrow, 1998).

The life cycle of disaster management. In 1978, the United States National Governors Association identified a four-phase model, which organized the activities that constituted "the life cycle of disaster management" (Phillips 2009, p. 30; see Figure 1). Those phases are mitigation, preparedness, response, and recovery. 


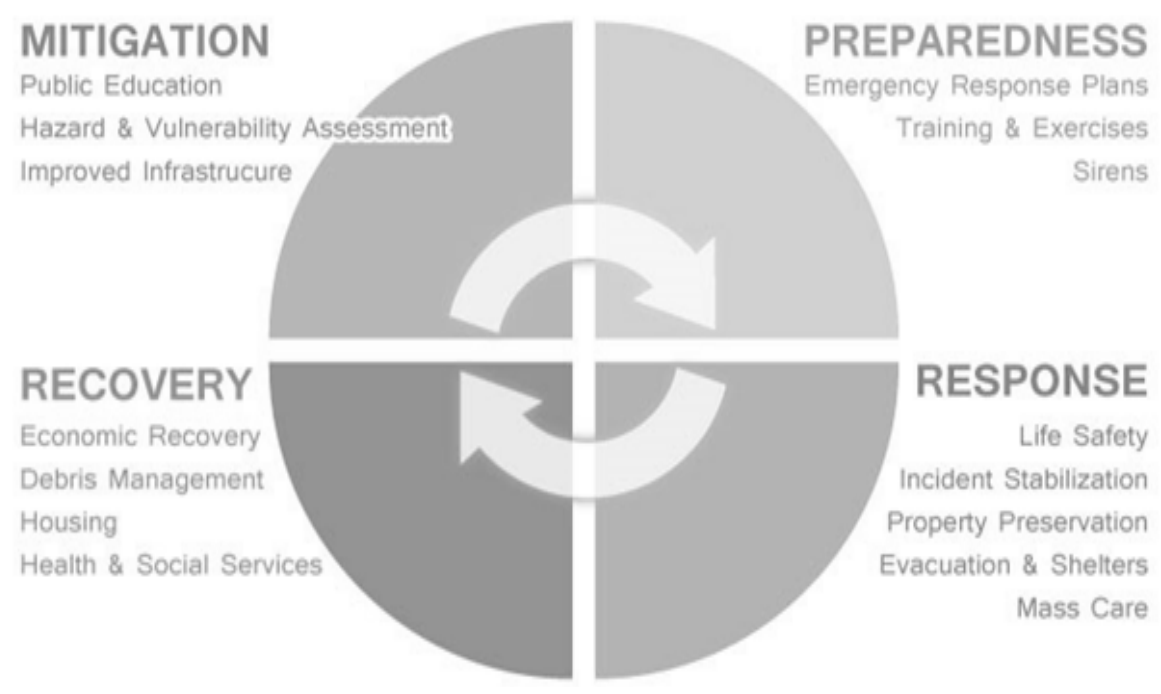

Figure 1. The Life Cycle of Disaster Management (Phillips, 2009, p. 30).

Bradshaw (2013) suggested that these stages represent a progression of activities that build upon each other and often overlap. When a government or community educates its citizenry (mitigation) via training and evacuation (preparedness), the goal is to stem the loss of life and property (response) and to ease the potential shelter, economic, and health issues (recovery).

During the mitigation phase, the goal is to reduce the impact of future disasters whether natural or human-made. Hazard and vulnerability assessments are the critical first steps during mitigation. Diverse fields define the concept of vulnerability differently. Wisner, Blaikie, Cannon, and Davis (2005) utilized the vulnerability theory's definition of the concept as groups or individuals most susceptible to injury, death, economic disruption, and property loss. Researchers in the disaster management field who specialize in gender issues view vulnerability as the diminished capacity to anticipate, overcome, and recover from a human-made or natural disaster (Bradshaw \& Fordham, 2013; Cutter, 2006; Enarson, 2007). Phillips (2009) points out that structural mitigation 
activities comprising the assessment of levees, dams, and seawalls are vital components of disaster mitigation.

The preparedness phase constitutes the planning, education, and coordination of a (local and national) government's citizens and the built environment. Preparation may entail leaving home, seeking shelter in communal facilities, and securing enough water, nonperishable food, and medications for a certain length of time. This phase may present challenges for distinct groups - particularly the poor, women, the elderly, and the disabled in both developed and underdeveloped countries - where warning systems are inconsistent and economic and cultural barriers exist. Ariyanbandu (2009) pointed out that despite cyclone early warning systems, some women in Bangladesh did not evacuate until permitted to do so by their husbands due to religious observance. Before Hurricanes Andrew and Katrina, researchers (David, 2008; Esnard \& Sapat, 2014; Green, Havelin, \& Zitleman, 2011) concluded that many groups consisting of women, the elderly, the disabled, and more impoverished families did not have the funds to evacuate. According to Phillips (2009), "both mitigation and preparedness phases are intended to enhance life safety and reduce the impact on people and property. Should these activities fail, varying degrees of response and recovery activities will be required" (p. 20).

The United States Federal Emergency Management Agency (FEMA, 2018) stipulates the response phase as encompassing the activities that promote life safety, such as deploying emergency services, search and rescue, and securing property. Disaster response, sometimes called "disaster relief," focuses on immediate and short-term needs. Effective, efficient, and timely response relies on preparedness measures, including the development of the response capacities of individuals, communities, organizations, 
countries, and the international community. Often the response and short-term recovery phases extend into each other, encompassing activities such as accessing food, water, medical supplies, and shelter provisions.

The recovery phase has both short-term and long-term components. The shortterm recovery phase encompasses processes such as managing donations and volunteers, provisioning temporary shelter, and clearing debris, which transition a community from the response phase to the long-term recovery phase (FEMA, 2018; Phillips, 2009). Phillips (2009) stated, "The magnitude of a disaster can also delay recovery efforts and may require the majority of disaster funds available to a community. The line between short-term recovery and long-term recovery is never clear" (p. 75).

\section{The road to long-term recovery: "Back to normal" or "Building back better"?}

Quarantelli (1999) suggested that the term long-term recovery implied an attempt to bring the post-disaster situation to some level of acceptability. Researchers found that advantages or disadvantages to diverse groups and communities are inherent in the longterm recovery phase. This phase denotes different concepts to distinct groups and communities. Long-term recovery may be an opportunity to return to a pre-disaster environment or "back to normal" (Bradshaw, 2013; Enarson \& Morrow, 1998). Joshi and Bhatt (2007) contested the term "back to normal" given the pre-disaster environment for many marginalized communities was inequitable. During the long-term recovery phase, survivors refer to "back to normal" as returning home or at least to their community and re-establishing family dynamics and livelihoods (Comerio, 2017; Esnard, 2017).

Platt (2017) suggested that although citizens, governments, and agencies desire rapid recovery in the post-disaster environment, recovery is not only about speed. Rather, 
both the quality of long-term recovery and the idea of "building back better" - a strategy coined by President Clinton when he spoke of recovery in Aceh after the 2004 tsunami must be considered. The challenge in long-term recovery, argue Cunningham (2012), and Mannakkara and Wilkinson (2014), becomes the question of for whom "back to normal" and "building back better" strategies were designed?

Fan (2013), in her comparison of post-disaster recovery policies in Aceh (earthquake and tsunami in 2004), Myanmar (Cyclone Nargis in 2008), and Haiti (earthquake in 2010), determined that there were factors necessary to "build back better" in the long-term recovery phase. She argued that long-term change in the "building back better" strategy is about tranforming power and political relations in the affected society. She further argued "building back better" has multiple technical and political dimensions, each of which is interpreted differently by various actors - citizens, governments, NGOs, and international aid agencies.

Citizens seek to actively engage and participate in long-term recovery by attending community planning sessions and by participating in surveys and in government or NGO needs assessment meetings. These citizen actors expect opportunities to rebuild their homes as well as to earn opportunites and access to education and healthcare (Agarwal, 2001; Apaza, 2015; Finch, Emrich, \& Cutter, 2010). Governments attempt to rebuild infrastucture, provide for its citizens' needs, maintain political relevance, and pursue investors to spur economic development (Cigler, 2009; Col, 2007; Comfort, Waugh, \& Cigler, 2012). In contrast, NGOs and international agencies may be more concerned with the short-term recovery provision of shelter, food, 
water, emergency healthcare, and donor expectations (Johnston, 2018; Quigley, 2016; Quigley \& Ramanauskas, 2016; Schwartz, 2012, 2017).

Most disaster researchers agree that for recovery to be successful, all actors must play active roles in the process (Blaikie, Cannon, Davis, \& Wisner, 2004; Chandrasekhar, Zhang, \& Xiao, 2014; Esnard \& Sapat, 2014; Kweit \& Kweit, 2004). Phillips (2009) wrote, "This participatory process (recovery) must address individual and community quality of life, economic vitality, social and intergenerational equity and sustainable environmental quality" (p. 51). In many countries during the post-disaster recovery, women still cope with male-dominated relief agencies and bureaucratic inefficiencies, which hinder women's active participation (Horton, 2012; Reigner et al., 2008). Fischer (2009) proposed that when officials cease to view women as helpless victims, their skills and talents can be utilized in the recovery process. Researchers concluded that when local and national officials overcome conventional hierarchal attitudes and discriminatory gendered policies, post-disaster recovery can become successful developmental interventions (Agarwal, 2001; Bradshaw, 2013; Buvinic, 1999; Lund \& Vaux, 2009; Soares \& Mullings, 2009; Yonder et al., 2009).

\section{Dimensions of recovery.}

According to Phillips (2009), recovery phase encompasses eight dimensions: housing recovery, business recovery, debris management, infrastructure and lifeline reestablishment, environmental recovery, historical and cultural resource preservation, social psychological recovery, and public-sector management. This research adds two more dimensions to recovery as women may place higher priorities in healthcare and education of their children: health care sector recovery and education sector recovery. 
The goals for activities within each of these dimensions are to rebuild or build anew the various social, political, and economic capital of stakeholders in a community (Aldrich, 2010; Bradshaw, 2004; Cutter et al., 2003; George, 2013: Rodriguez, Trainor, \& Quarantelli, 2006).

Depending on the severity of the disaster and the economic resources available, communities and individuals may move through the various recovery dimensions at different rates (Mileti, 1999; Quarantelli, 1999; Wisner, Blaikie, Cannon, \& Davis, 2005).

Housing recovery. According to Quarantelli (1982), housing recovery is subdivided into short-term disaster housing (encompassing emergency shelter, temporary shelter, and temporary housing), and permanent housing. The housing recovery discussion in this review focuses on the transition from temporary shelter to permanent housing. Quarantelli (1982) concluded that the pre-disaster housing conditions, government planning, and funding allocations predicted permanent housing stock availability. Comerio (1997) argued, "Housing is the single greatest component of all disaster losses regarding economic value and buildings damaged" (p. 176). Researchers examined housing recovery (Comerio, 2017; Finch, Emrich, \& Cutter 2010; Fothergill, 2004; Ganapati \& Ganapati 2008; Shah, 2013) and found that gender issues are not always considered. Phillips (2009) contended that "gender distinctions along with age, income, and cultural divisions make housing recovery challenging” (p. 193).

Chakraborty, Tobin, and Montz (2005) recommended careful consideration be given to the characteristics of local populations when rebuilding. The housing rebuilding process is different when viewed from an urban versus rural perspective, particularly when considering its intersection with gender. Women's and men's livelihood 
opportunities change based on where they live (Elliot, 2006). The rebuilding of rural housing after the 2010 Pakistan floods was slower than in urban areas, causing many families to migrate to urban areas in search of adequate housing and economic opportunities (Kirsch et al., 2014). Disasters create additional socioeconomic housing inequities, such as when lower-income affordable housing is replaced with higher-end housing and businesses (Bell, 2010; Blimn-Pike, Phillips, \& Reeves, 2006; Brun, 2003). Green, Havelin, and Zitleman (2011) cited Hamelin (2007):

Katrina left 25,000 public housing residents without a home even though they estimated that over $80 \%$ of public housing was structurally undamaged. The Housing Authority of New Orleans and the Department of Housing and Urban Development locked public housing residents out of their homes to pursue a plan of demolition and redevelopment aimed to create better communities by removing over two-thirds of the public housing population from their homes and replacing them with richer people. (p. 310)

Post-Katrina, grassroots organizations evolved to address the emerging housing inequity issues. The Peoples Hurricane Relief Fund (PHRF) proved to be a successful model for building a multinational mass movement. They stopped the demolition of public housing sites in New Orleans through the Coalition to Stop Demolition, arguing that the U.S. government through the Department of Housing and Urban Development (HUD) denied many of the residents of public housing the right to return to their homes. Comerio (2017) argued that government assistance, leadership, and adaptability combined with community involvement are essential elements in the housing recovery process. 
Business and livelihood systems recovery. Researchers tend to focus on organized business concerns of both large and small companies yet exclude the numerous ways women generate revenue to support their families. Women tend to establish homebased businesses such as beauty salons, daycare, and babysitting assistance (Bell, 2012; Enarson, 2002; Hossein, 2012), which disappear once a disaster strikes, and the family dwelling no longer exists. Goldscheid (2007) noted that when she compared post-disaster compensations of those directly affected by $9 / 11$ to those of Hurricane Katrina, socioeconomically different women survivors were treated unequally. For example, the better educated 9/11 women survivors were able to access financial assistance, loans, and grants to rebuild their businesses to a degree that was not available to less educated women.

Regnier et al. (2008) examined two field case studies in Aceh (Indonesia) and Tamil Nadu (India), where a well-established European NGO carried out economic relief and micro-entrepreneurship rehabilitation from 2005 to 2007. They found that "Contrary to humanitarian agencies in charge of emergency relief, only a few development agencies and NGOs were able to deliver a rapid rehabilitation of microeconomic activities existing locally before the disaster" (p. 410). The most effective strategies were those that empowered communities to develop microcredit, micromarketing, and micro-financial initiatives specific to their needs. Regnier et al. (2008) found several coastal fishing villages in India that employed women who successfully used micro strategies designed for sustainable growth. Danes and colleagues (Danes, Lee, Amarapurkar, Stafford, \& Haynes, 2009) found that U.S. women business owners were more accepting of financial 
aid towards rebuilding their businesses post-disaster, and therefore experienced a more positive impact from assistance compared to men who owned businesses.

Debris management and body recovery. Phillips (2009) wrote, "Debris management is more than the removal of trash or destroyed buildings, it becomes a critical part of the process of managing public health, both the psychological and physical aspects, across the disaster-affected community" (p. 101). Researchers (Chen, Chen, Au, Ling Feng, \& Qian Chen, 2014; Cerda, et al., 2013; Farooqui, et al., 2017) found incidences of post-traumatic stress disorder (PTSD) rose after a disaster, asserting that PTSD symptoms manifested themselves differently depending on the race, gender, preearthquake economic status, and marital status of the survivor. The PTSD symptoms may include, but are not limited to: sleep deprivation, survivor guilt, depression, increased alcohol and drug use, increases in domestic violence and rape. In a post-disaster environment woman have a higher incidence of PTSD than men. This high rate may be due to the lack of spousal and family support, living in tents or political and socioeconomic constraints post-disaster (Farooqui, et al., 2017).

The process of debris removal, demolition, and clearing allows stakeholders the opportunity to recycle, reuse, and restore their environment. The short- and long-term strategies for debris management pave the way for other dimensions of recovery, without which residents cannot rebuild and businesses cannot reopen. Many debris removal and clearing activities were initiated and facilitated by community grassroots organizations during Hurricane Katrina (David, 2010; Katz, 2013), the Indonesian earthquake and tsunami in 2004, the 2010 flood in Pakistan (Kirsch, Wadhwani, Sauer, Doocy, \& Catlett, 2012), and the earthquake in Haiti in 2010 (McEntire, Sadiq, \& Gupta, 2012). 
One of the most crucial short-term strategies in disaster management is the recovery of bodies and personal belongings. McEntire et al., (2012) asserted:

There are many challenges associated with mass-fatality incidents and body removal. Lack of resources needed, decomposing bodies viewed as health risks (contrary to the truth), lack local expertise in $\mathrm{MFM}^{3}$, non-existing pre-death data (racial and gender issues badly disfigured bodies and list of deceased unavailable. (p. 7)

Infrastructure and lifelines recovery. Research shows that women and men have unequal access to infrastructure and lifeline recovery after disasters (Blaikie, Cannon, Davis, \& Wisner, 2004; Cutter, 2006). Bradshaw and Fordham (2013) found that in most disasters (e.g., Bangladesh in 1991, Nicaragua and Honduras in 1999, Sri Lanka in 2004, Hurricane Katrina areas in 2005, and Haiti in 2010), women and girls suffered a "double disaster": the loss of tangible goods (infrastructure, services, and trade) coupled with intangible losses (gender-based violence, early marriage, slavery or prostitution). The infrastructure, utilities, communication networks, information systems, and public transportation systems are interconnected lifelines necessary to the successful recovery of small and large communities. Information systems and communication can either slow down or speed up the recovery process. Women who are absent from early disaster warning systems are more likely to die than men. Skutsch (2004) and Ikeda (1995) found that information leading up to the 1991 Bangladesh cyclone was transmitted by men to other men in public spaces yet omitted women. This lack of pre-cyclone detail

\footnotetext{
${ }^{3}$ Mass Fatality Management
} 
dissemination was a key factor behind the death toll for women being five times that of men. In contrast, Buvinic (1999) concluded that when women are trained and responsible for early communication and warning systems, community losses are reduced, as evidenced in Honduras after Hurricane Mitch in 1998, where there were no reported storm-related deaths.

Researchers found the post-Katrina recovery of public sector services such as fire and police departments as well as sewer and water systems for poorer wards in New Orleans lagged far behind more affluent areas of the city (Katz, 2008; Raskin, Kjar, \& Butt, 2008). Before the hurricane, most women from the economically depressed wards depended on public transportation and public housing. This reconstruction lag in public sector services impacted the long-term recovery opportunites of many New Orleans communities and impeded the return of many lower-income women and their families (Fothergill \& Peek, 2015; Green, Havelin, \& Zitleman, 2011). Recovery, also seen as a participatory process through government accountability, stimulates individual and community ownership of recovery programs while also lending credibility to the usage and outcomes of program funds.

Environmental recovery. Phillips (2009) referred to environmental recovery "as the activities that salvage, restore, and replenish community resources" (p. 135). Gordon (2013) found after the 2011 Christchurch earthquake, women worked to beautify their surroundings and create cohesive communities. Drolet et al. (2015) posited that women in post-disaster Pakistan were active participants in the reconstruction process by taking on roles and responsibilities usually held by men such as building houses and replanting and harvesting the fields. 
Rodriguez, Wachtendorf, and James (2006) found the 2004 Indian Ocean tsunami resulted in considerable damage to the ecosystems in India and Sri Lanka. Coastal erosion was extensive throughout the most impacted coastlines in India; coral reefs, mangroves, and other types of vegetation along the coastlines bore a significant share of the tsunami's impact. The tsunami transformed the landscape and ecosystems whereby fishers ${ }^{4}$ and those working in the agricultural sectors experienced a negative impact on their livelihoods. Katz's (2008) argument regarding the geographic impacts of disaster and recovery in New Orleans has a global application: "Geography is always socially produced... environmental infrastructure, health care, education, housing, and social justice - that were pivotal to the well-being of New Orleans and its differentiated population before the storm, and have been all the more so in recovery" (p. 19).

Historical and cultural resources recovery. The preservation of a community's historical and unique attributes is an essential component of the recovery process. Hummon (1986) wrote, "places are environmental contexts with real consequences for people, creating a sense of community identity and shared heritage" (p. 162). A disaster requires a physical and social relocation along with a renegotiation of community identity. This relocation also threatens a community's and individual's ties with their ancestors and with their desires for legacies to pass on to their children (Phillips, 1996). David (2010) examined cultural trauma during the recovery period after Hurricane Katrina in 2005 and found that many socioeconomically diverse grassroots women's groups actively championed the rebuilding and restoration of many parts of New Orleans.

\footnotetext{
${ }^{4}$ Academically accepted gender-neutral term for women and men who fish.
} 
For example, Verderbe (2009) found that some of these grassroots organizations fought against the state Neighbourhood Conservation District Committee (NCDC), which despite its name viewed building conservation as "a last resort" (p. 262).

Social psychological recovery. Psychologists tell us that massive events with extensive loss of life are likely to lead to personal trauma. Post-traumatic stress disorder (PTSD) is the most commonly occurring mental health disorder after a natural disaster (Chen et al., 2014). Aloudat and Christensen (2012) wrote, “Often pre-disaster experiences determine post-disaster reactions of the individual, family, and the community, surviving or witnessing disasters may produce different biological stress reactions" (p. 570). In their study after the 2008 Wenchuan earthquake in China, Chen et al. (2014) found that being female was a risk factor for PTSD symptoms. The increased risk of PTSD for women following disasters may be because when faced with disasters, women are more likely than men to reveal their vulnerability and are more inclined to express their true feelings. Women affected by disasters are also more likely to view the world as dangerous, to blame themselves for the trauma, and to have a more negative self-image (Tolin \& Edna, 2006). Enarson and Morrow (1998) point to the burdens of caregiving as contributors to stress, fatigue, and overall declines in women's emotional well-being during disasters. Women often suffer from physical and emotional exhaustion in the post-disaster recovery period (Cook, 1993), and those who assume the traditional roles of homemaker and caretaker are most at risk of losing their sense of self after a disaster, as they tend to put the family's needs before their own.

Healthcare recovery. Researchers found that women survivors frequently experience adverse reproductive health outcomes ranging from unsanitary camp 
environments, lack of access to feminine products, lack of medical facilities, and limited medical staff and full relief shelters (Bradshaw \& Fordham, 2013; Buvinic, 1999; Cullen \& Ivers, 2010; Luke, 2012). Yumarni, Amaratunga, and Haigh (2014) determined following the 2006 Central Java earthquake in the Yogyakarta province of Indonesia that women who were old, disabled, or pregnant suffered because they lacked access to public services, particularly health care. Goodman (2016) determined that the increases in infant and maternal mortality after disasters in Turkey, New Orleans, and Haiti were due to trauma caused by their post-disaster environments. The rise in the violence against women including in intimate partner violence in these post-disaster environments created an additional healthcare crisis for women and girls who were unable to access medical care. (Blimn-Pike, Phillips, \& Reeves, 2006; Gabriel et al., 2016).

In 1992, the UN Committee on the Elimination of Discrimination Against Women (CEDAW) defined gender-based violence as "violence perpetrated against women because of their gender. It includes acts that inflict physical, mental or sexual harm or suffering, threats of such acts, coercion and other deprivations of liberty" (para. 2). Bradshaw and Fordham (2013) posited that women often faced a "double disaster" stemming from a drop in their socioeconomic wellbeing and an increase in violence and sexual violence. Laudisio (1993) found after Hurricane Andrew in Miami that calls to local helplines reporting spousal abuse increased by 50\%. Similarly, following the 2004 Indian Ocean tsunami, domestic violence and sexual assault escalated in Sri Lanka (Hyndman, 2008). And in Haiti, Horton (2012) found that dangerous post-disaster economic conditions led to an increase in the sexual exploitation of women and girls. 
Education recovery. "Disasters may disrupt children's education process and diminish educational outcomes" (Fothergill \& Peek, 2015, p. 22). Despite the positive outcomes of education - educated women and girls are healthier, are more economically independent, and provide better healthcare for themselves and their families globally (Seager, 2009) - research indicates that post-disaster education needs are often relegated to the bottom of long-term recovery priority checklists. In 2010, a UN General Assembly directive mandated that the protection of schools in emergencies should be a key priority for the international community. Education played a vital role in preventing gender-based violence, exploitation, human trafficking, and child labor (UN General Assembly, 2010). UNESCO (2017) reaffirmed the reasons why education was crucial to recovery success for children and women. The report stated that education was not only a human right for children, youth, and women, but that it also served as a tool in the prevention of harm and exploitation such as forced labor, prostitution, criminal activities, and drug abuse. For the long-term recovery process, education provides the community with a sense of normalcy, tackling psychosocial issues such as violence and gender disparities. Fothergill and Peek (2015) theorized that many children in post-Katrina environments, especially those children attending new schools, inspired adults with their capacity to adapt and connect with others.

Public sector recovery. Recovery can become an opportunity for public officials to lay new foundations for a better community and to prove their worth as public-sector leaders. Governmental leaders must weigh the challenges such as- how to serve diverse citizens effectively and efficiently while maintaining positive attitudes for their staff and for the community at large. Public accountability of recovery funds through performance 
auditing is critical for the recovery process to be considered successful by all stakeholders (Labadie, 2008). Recovery, also seen as a participatory process through accountability, stimulates individual and community ownership and lends credibility to the allocation and outcomes of program funds. In this recovery dimension, the presence of women as managers or as political leaders is nonexistent in recovery literature.

\section{Overview of the dimensions of recovery.}

The internally displaced - principally women - are often excluded from the longterm recovery process due to gaps between the short-term and long-term recovery phases (Bradshaw \& Fordham, 2013; Padgett \& Warnecke, 2011). Humanitarian agencies concerned with the immediate response - saving lives, search and rescue, the provision of food, shelter and medical services - as part of the short-term recovery period rarely coordinate with the affected government and development agencies for a sustainable long-term recovery (Phillips, 2009; Schuller, 2016). This lack of coordination leaves a gap which excludes many marginalized groups such as women, the elderly, and lesbian, gay, bisexual, transgender, and queer (LGBTQ) communities from participating in their community’s long-term recovery processes (Berger, 2004; Enarson \& Meyreles, 2004; Lewis \& Nazneen, 2009).

\section{IDPs and their Priorities: The Need for a Gender-Based Approach}

Who are IDPs? According to Deng (1998), the former representative of the UN Secretary General, IDPs are people who take flight within the boundaries of their home country, seeking safety from armed conflicts, violations of human rights, or natural- or human-made disasters. Research shows that IDPs experience extreme food, health, shelter, security, and livelihood insecurities (Cullen \& Ivers, 2010; Farmer, 2012; Joshi \& 
Mehir, 2009; IDPproject.org; IDP Global Report, 2017). In 1998, Deng called the flight of IDPs "the most pressing humanitarian challenges of our time" (Suhrke, 1999, p. 341). In 2001, the Office of the High Commissioner for Human Rights (OHCHR) called for the creation of the Guiding Principles on Internal Displacement to address the then 20.5 million IDPs. (The Office of the UN High Commission for Refugees, 2018). Of the many principles, the first four declare that IDPs should not be discriminated against, and should enjoy the full equality, rights, and freedoms under the international and domestic laws as other citizens. All authorities should observe these principles and provide protection and humanitarian assistance, mainly to the most vulnerable populations. Principles 7 through 11 invoke the legal and human rights to life, dignity, liberty, and security for IDPs. In part due to many natural disasters - hurricanes, floods, climate change displacement, and armed conflicts - little progress has been made since 1998 (Internal Displacement Monitoring Centre, 2017; InternalDisplacement.org, 2017; International Organization for Migration, 2011; UN Office for the Coordination of Humanitarian Affairs, 2018).

IDP priorities and gender-based differences. Women are widely recognized as the most vulnerable IDPs in post-disaster camp situations. They are often victims of rape, sexual assault, forced labor, and forced recruitment (in conflict laden areas; Internal Displacement Monitoring Centre, 2017). Unlike for refugees, no international humanitarian organization for IDPs exists. Hence, several organizations such as the United Nations High Commissioner for Refugees (UNHCR), the International Committee of the Red Cross (ICRC), the International Organization for Migration (IOM), and many other INGOs have stepped up their efforts to address the needs of IDPs worldwide. In 
2018, on the 20th anniversary of Deng's declaration, the Internal Displacement Monitoring Centre (IDMC) reported there were 65 million IDPs worldwide, an increase of over 20 million from the 2016 reported numbers (Internal Displacement Monitoring Centre, 2017). Worldwide, one person per second becomes an IDP (InternalDisplacement.org, 2017).

\section{IDPs and Their Participation in Disaster Recovery}

IDP participation. Researchers suggest that the process of participation may be a political one, taking on different forms and existing at various levels while serving diverse interests (Akar \& Gopalan, 2009; Apaza, 2015; Chandrasekhar, Zhang, \& Xiao, 2014; Cornwall, 2003; White, 1996; Yonder, 2007). Participation is an active process, according to Lasswell (1936) -- a political theory of who gets what, where and how. Who participates comprises people of diverse backgrounds and circumstances. Researchers suggest that participation is not a homogenous process, and that disadvantaged groups (women, the poor, the elderly, and the LGBTQ communities) need special mechanisms to participate, such as women-led meetings, designated meeting spaces, confidentiality, and security (Chandrasekhar, 2012; Cutter, 2006; Enarson \& Morrow, 1998; Fothergill \& Peek, 2015). The what entails the needs, wants, goals, and tools essential to the participation process. Sarah White (1996) found that "sharing through participation did not necessarily mean sharing in power" (p. 6). There are many instances where, despite the availability of public forums to "voice" their post-disaster long-term recovery needs and grievances, some men and many women felt those needs and grievances went unaddressed by governments, NGOs, or international agencies (Dupuy, 2010; Enarson \& Pease, 2016). 
Hirschman (1978) introduced "exit, voice, and loyalty" as a general marketing formula that has since been adapted by researchers as an explanatory formula for human behavior (Gammage, 2004). Hirschman defined "exit" as the opportunity to leave undesirable circumstances and "loyalty" as inhibiting movement or complaint. Hirschman (1978) conceptualized "voice" as an attempt to change practices or to appeal to a higher authority in order to force change. He added that the possession of voice affords an individual or group the opportunity to articulate discontent, from a "faint grumbling to violent protest" (p. 16). Gilligan (1993) explained, "to have a voice is to be human...but speaking depends on listening and being heard" (p. xvi). According to Abbott (2014) “"Voice' refers to the values, opinions, beliefs, perspectives, and cultural backgrounds as well as the degree to which those values, opinions, beliefs, and perspectives are considered, included, listened to, and acted upon when important decisions are being made" (para. 1). Women in the long-term recovery phase particularly IDP women - are often denied the opportunity to voice their priorities and be heard by governments, NGOs, and international agencies (Goldscheid, 2007; Schuller, 2010). The rare times IDP women do exercise voice, many feel the exercise does not yield tangible outcomes such as increased camp security or accessibility to healthcare and education (Concannon \& Lindstrom, 2011).

The scholarship on representative bureaucracy is based primarily on the premise that having spokespersons and officeholders in administrative and political positions is a public good and, when provided, it should reflect the interests, opinions, needs, and values of the general public (Keiser, Wilkins, Meier, \& Holland, 2002; Kingsley, 1944; Selden, 1997). In Haiti, the dominant minority consists of wealthy, educated, politically 
connected men (Fatton, 2011; Horton, 2012; Schuller, 2012, 2016). Women occupy very few government positions in local or national government agencies. Despite the dearth of representation, internally displaced women leverage various forms of social capital to actively participate in their recovery.

Ganapati (2012) argued there were many advantages of social capital for women after the earthquake in Turkey. Social capital in the forms of "civic consciousness" ( $p$. 419) and of social networks transformed women's political and socioeconomic vulnerabilities into capabilities during recovery. These capabilities became resources which enabled women to lobby policymakers for rehabilitative programs geared towards their community, family, and individual needs. Social capital capabilities afford women choices when faced with using exit, voice, or loyalty tactics.

Citizen participation in the long-term disaster recovery process means different things to different people based on their prior participatory experiences.

Factors that hinder IDP participation. Although there is not much in the literature regarding participation of women IDPs in recovery processes, the literature provides some insights on the types of barriers that could hinder women's participation in decision making processes. I categorize these barriers under three categories below: individual-level barriers that relate to the IDPs themselves, institutional barriers (formal and informal), and policymaker related barriers (within the government and agency).

Institutional barriers. The second level of barriers relates to institutions as articulated in new institutional economics theory. "Institutions" refer to "frameworks of norms, rules, and practices which structure action in social contexts" (Healey, 2007, p. 64). Institutions may be informal or formal (North, 1990). They are informal when 
constructed as socially transmitted information, and their constraints are then transmitted as part of heritage or culture ${ }^{5}$. Institutions are formal when there are written rules devised by humans. Many organizations, both private and public, have deeply embedded cultural assumptions based on gender (Emirlayer \& Johnson, 2008; Mills, 1988; Stivers, 1995). Acker (2012) wrote, "The culture usually includes definitions of gendered behaviors, both acceptable and unacceptable, and images of multiple masculinities and femininities" (p. 216). Culture is learned, not imposed, and can be unlearned and redesigned (Bullivant, 2011; Schein, 2014).

International agencies and NGOs. As with governments, these types of agencies may also reflect the institutional biases of their originating countries. Critics of humanitarian aid contend that this aid becomes a foreign aid tool whereby agencies become the agents for first-world political and economic policies (Katz, 2013; Klein, 2007, 2013; Schwartz, 2017). Klein (2005) argued that under the pretext of reconstruction, a modern version of colonialism is asserted by first-world countries and their agencies upon third-world and developing countries. She cited the following four factors as hindering citizen participation in the long-term recovery process: (a) the process of reconstruction is always slow; (b) foreign consultants are paid considerably more than are local talent, resulting in a higher cost of living; (c) local talent is excluded from jobs, training, and most importantly the decision-making process; and (d) most

${ }^{5}$ North defined culture as the way individuals process and utilize information and affect the way informal constraints are specified. 
NGOs and contractors are not transparent, even though the first-world and international agencies fund them. Lewis and Nazneen (2009) portrayed an NGO as:

... normally characterized in the literature as an independent organization that is neither run by government nor driven by the profit motive like private sector businesses. Yet there are some NGOs that receive high levels of government funding and possess some of the characteristics of bureaucracies, while others can resemble highly professionalized private organizations with strongly corporate identities. (2009, p. 2)

Governments. Many governments do not consider women as important stakeholders in the long-term socioeconomic and political post-disaster recovery (Bradshaw, 2004; 2013; Enarson \& Meyreles, 2004). They are often excluded from productivity networks such as financial systems. Governments often view IDPs as usually poor and as "the other," and as such do not afford them their rights as citizens (UN Office for the Coordination of Humanitarian Affairs, 2018). Within the broader context of process-related issues, specific factors such as corruption, lack of communication, undelivered services, and inequitable distribution of resources were also identified as consequences of government inadequacy (Fook, 2011; Luke, 2012). Stoyan et al. (2016) found the aspects of government performance and citizen engagement may differ in the developing world where economic insecurity, political instability, and state weakness are commonplace. Formal institutions (such as government or NGO bureaucracies) may hinder public participation in post-disaster events by defining which populations are included in the "public" of "public participation" or by not allowing for a meaningful incorporation of feedback received from the public (Ganapati \& Ganapati, 
2009; Ganapati \& Mukherji, 2014). According to Arnstein (1969) citizen participation allows a redistribution of power that includes marginalized groups. Arnstein (1969) warned of the dangers between the many forms of empty participatory rituals disguised as citizen participation mechanisms - powerless citizen meetings meant to placate versus mechanisms designed to empower groups- meetings with real power. She proposed real citizen participation should equate to citizen power (Arnstein, 1969),

Policymaker barriers. The third level of barriers relates to the policymakers themselves. Representative bureaucracy theory informs the understanding of these barriers. The scholarship in this domain is primarily based on the premise that representative bureaucracy — that is, having spokespersons and officeholders in administrative and political positions - is a public good and, when provided, it should reflect the interests, opinions, needs, and values of the general public (Keiser, Wilkins, Meier, \& Holland, 2002; Kingsley, 1944; Coleman-Selden, 1997). The UN (2017) reported that only $22.8 \%$ of all national parliamentarians and only $18.3 \%$ of government ministers were women; the most commonly held portfolio by women ministers were the environment, natural resources, and energy, followed by social sectors such as social affairs, education, and the family. With such low levels of representation, women stakeholders have a difficult time gaining recognition from local and national governments. Chandrasekhar (2012) noted, "the challenge for recovery managers following disasters, therefore, is to facilitate stakeholder participation in a context of changing urgency, disparate power, intentional or inadvertent exclusion of stakeholders, and persistent mistrust" (p. 627). These challenges may become insurmountable when recovery managers do not reflect the population they serve. For example, IDP camp 
committees are usually headed by men who may then foster an environment of uneven and inequitable resource distribution (Horton, 2012; L'Etang, 2012).

Individual barriers. Gilligan (1993) suggested that voice and participation for women may be perceived as selfish and as abandonment of family responsibilities given societal roles and responsibilities expected of women in a given culture. Bullivant (2011) defined "culture" regarding a group's survival device: "This consists of the public knowledge and conceptions embodied in the behavior, artifacts, or cultural forms that enable the group to adapt to three kinds of environments: the natural, the social, and the metaphysical" (p. 43). These cultural limitations often refer to women's' standing in society (i.e., subordination by men), their distrust of the government, or the hindrance posed by their faith or spirituality. Men may be considered better leaders than women if women are acknowledged at all (Acker 2012; Bendl, 2000; Cook \& Glass, 2014; Schein, 1973). White (1996) theorized that women might not participate due to their lowered expectations, perhaps believing that they are powerless and unable to effect changes in their environments.

According to Marquart-Pyatt and Retrezelker (2007), in a normal or pre- disaster environment citizen trust in government rests not only on the trustworthiness of the public officials and of the structural processes in which they operate, but also on the perception of whether those processes are fair. When individuals trust a process, they then participate more often and feel more valued as citizens. Hetherington (1998) found that if citizen support for government institutions diminishes then distrust follows, which hinders the government from providing services and solving problems effectively. This 
vicious cycle in turn breeds more distrust as citizens question the intentions and efficacy of the government.

Factors that enable IDP participation. IDP participation in the long-term disaster recovery process means different things to different people based on their prior participatory experiences. Researchers posit that several factors such as power, legitimacy, the urgency of action, and trust exist and thus drive the participation (or nonparticipation) of citizens in the long-term recovery of post-disaster communities (Agarwal, 2001; Cornwall, 2003; Ganapati \& Ganapati, 2009; Pyles, 2015). The power factor in the participatory context includes the processes and institutions created by governments, NGOs, and international agencies for stakeholders to influence the decision-making process. Legitimacy is the recognition given to stakeholder claims by agencies and governments. The time-sensitive nature of stakeholder claims of food, shelter, and security needs (especially in a post-disaster recovery context) should initiate urgency of action.

White (1996) conceded in a non-disaster context regardless of the appearance of increased participation, participation alone did not guarantee successful outcomes for women. The type of participation (nominal, representative, and transformative) was a critical factor. Nominal participation allows women to feel part of a group even with very little time spent in the process. Representative participation creates a partnership between NGOs and local beneficiaries, and supports women expressing their priorities and taking part in the planning and execution of a project's sustainability. Transformative participation presents an excellent opportunity for women to participate and empowers women, gives voice to their concerns, and grants them the space to generate options as 
well as opportunities for collective action. Public Administration scholars (eg. Guo \& Neshkova, 2012; Stivers, 1990) contended that public participation has the ability to bring about better public programs and policies, and enhance public management performance. For example Guo and Neshkova (2012) found active citizen participation worked best at the beginning and final stages ( infromation sharing and assessment) of the budget process. Ianiello, Iacuzzio, Fdele, and Brusati, (2018) concluded ongoing interactions between governments and stakeholders informed and improved citizen participation.

Social capital. Rahill et al. (2014) suggested that social capital has components which are both structural (formal networks) and attitudinal (norms, values, and understandings). Both types of components play important roles in the success or failure of individuals and communities during the post-disaster long-term recovery process. David Aldrich (2010) wrote,

Given the growing evidence that social capital serves as a core component in recovery, increasing stocks of it in vulnerable communities, such as the Gulf Coast of the United States and rural fishing villages in India may prove to be a more efficient use of private and public-sector resources. The variation in recovery is a function of the quality and quantity of multiple types of social connections. (p. 62)

Danes and colleagues (Danes et al., 2009) found that following a disaster, women entrepreneuers in the U.S. leveraged more social capital resources for maintaining family business resiliency. They called on family and friends for clean-up assistance as well as for financial support of their businesses. George (2013) researched the importance of 
social networks in the recovery and reconstruction of communities. In her research of post-Katrina recovery, she proposed that different networks such as faith-based, sporting, and workplace relationships may overlap and enhance an individual's capacity to weather the recovery process; however, these same networks may exclude others based on gender, race, or class. Ganapati (2012) argued there were many advantages of social capital for women after the October 2011 earthquake in Turkey. Social capital in the form of "civic consciousness" (p. 419) along with social networks transformed women's political and socioeconomic vulnerabilities into capabilities during recovery. These capabilities became resources that enabled women to lobby policymakers for rehabilitative programs geared towards their community, family, and individual needs.

Grassroots and community organizations. George (2013) argued that disaster recovery is more participatory, inclusive, and accurately targeted when groups undertake it closest to those who are affected. Researchers (Aldrich, 2011; David, 2008; Ganapati, 2012; Soares \& Mullings, 2009) found that local people understand the local needs in ways that government bureaucrats and NGOs often do not. The top-down disaster response efforts often utilized by state bureaucracies, NGOs, and international aid agencies in a variety of locations have failed to enlist local participation.

Luft (2008) wrote that in the post-Katrina emergent grassroots relief efforts, the Common Ground Collective (CGC) became the temporary home to an estimated 13,000 would-be relief workers who came to New Orleans to gut houses, distribute supplies, conduct bioremediation, and offer other services. Green et al. (2011) found, "In its oneyear anniversary, CGC had organized 10,000 volunteers to provide relief and assistance to hurricane survivors and had supported well over 100,000 people in seven parishes" ( $\mathrm{p}$. 
319). David (2008) discovered that the grassroots group Women of the Storm engaged in performative political practices aimed at increasing government support for Gulf Coast recovery efforts. The group also modified place-based practices related to ritual acts of mourning and remembrance, appropriated and transformed disaster-related symbol systems, and aimed to establish new forms of moral responsibility as part of its collective actions.

The feminist political ecology (FPE) framework attempts to integrate and to place gender within political and cultural ecology. In this theoretical model, gender is treated as a critical factor in shaping the livelihoods of men and women (Rocheleau, ThomasSlayter, \& Wangari, 1996). FPE recognizes that gender differences exist not only because there are biological differences between men and women, but also because gender is socially constructed and context dependent (Elmhirst, 2011; Hyndman \& Alwis, 2003; Joshi \& Mehir, 2009). According to Elmhirst (2011), FPE also dispels the myth of women as passive or dependent victims by recounting stories of women as actively engaged in individual and community development. The neglect of their inclusion in short- and long-term recovery processes is especially relevant when we insert the gender dimension into disaster recovery.

Scholars and practitioners specializing in gender within the field of disaster management (Blaikie, Cannon, Davis, \& Wisner, 2004; Bradshaw, 2013; Enarson \& Pease, 2016) assert that socio-economically and politically insecure people, regardless of gender, are the most vulnerable and resource disadvantaged. Researchers examine how disenfranchised women prior to a human-made or natural disaster (whether they live in wealthy nations such as the United States or in developing countries such as Haiti) are the 
most affected while also the least visible population in policies, and thus left even more impoverished than they were before the disaster (Bell 2012; Enarson, Fothergill, \& Peek 2007; Enarson \& Morrow 1998; Fordham, 2012; Reigner et al., 2008; Schwartz, 2012).

\section{Chapter Summary}

In this chapter, I discussed the relevant literature on disaster management and briefly reviewed the "life cycle" or phases of disaster management: preparedness, mitigation, response, and recovery (Phillips, 2009). These phases allow governments, agencies, communities, and individuals to organize specific activities and strategies for minimizing the after-effects of disasters. Second, the literature review presented Phillips' (2009) dimensions of the recovery phase of disaster management. Within the different dimensions of recovery IDPs often find themselves forgotten and voiceless (Schuller, 2016). Third, I examined the literature espousing the integration of a gender-based approach in the post-disaster long-term recovery phase of IDPs specific to women. Lastly, I explored IDP participation in their recovery with an emphasis on women, and the factors that enable or hinder their participation.

Of the four phases of disaster emergency management, the long-term recovery phase is the least explored and written about, especially in the public administration literature. Within the disaster recovery literature, the following research questions remain unanswered and are the focus of this dissertation:

Q1. What are the gendered long-term recovery priorities of the IDPs in Haiti? Why do women place priorities on some issues more than others during the recovery period? This question expands our understanding of the differences between the long- 
term recovery priorities of women compared to men IDPs and interrogates the reasons behind such differences.

Q2. What are the factors that enable or hinder the participation of women IDPs during decision-making processes from expressing their preferences regarding rebuilding needs and priorities? For instance, what are the individual-level, institution-related (formal or informal), and policymaker-related factors that affect women's participation? This central question and its sub-questions allow the study of women IDPs' voices.

Q3. How can policymakers and NGO representatives address the unique and varied needs of women while also ensuring an equitable long-term post-disaster recovery process? This question informs decision makers in the Haitian government as well as domestic and international non-governmental organizations as to how to most effectively design and implement gender-informed post-disaster recovery policies and programs. When informed decisions are made and implemented, women will have a more active voice, which will promote a more equitable recovery process. 


\section{CHAPTER III \\ METHODOLOGY}

\section{Introduction}

Understanding women IDPs' unique recovery priorities and experiences to participate in decision making processes, as sought by my research questions, required employing qualitative methods. My data collection included interviews, focus groups, field observations and the review of secondary sources. I gathered first-hand data through 43 in-depth interviews with the IDPs, community leaders and international and Haitian decision makers involved in policy making with respect to the IDPs and through field observations. Furthermore, I used interview $(n=54)$ and focus group data $(n=12$ focus groups) from the NSF study on social capital and shelter recovery that was conducted immediately after the earthquake by a group of researchers from Florida International University, the University of South Florida and the Haitian Institute of Community Health (Institut Haitien de Santé Communautaire). I conducted the analysis of qualitative data in NVivo 11 Pro.

In this chapter, I first introduce the research context of Haiti and explain why I chose three communities in Haiti for an in-depth examination. I then describe each of my data collection methods and provide details on how I coded and analyzed the collected data.

\section{Research Context: Haiti and the 2010 Earthquake}

Haiti is a country of 11.11 million people with a relatively even proportion of men $(49.6 \%)$ and women $(50.4 \%$; UNESCO, 2017). It has a very young population - half is under the age of 20. The median life expectancy for women is 63 years of age and 60 for 
men. The overall literacy rate is $60.7 \%$ however, the literacy rate for men is $64.34 \%$ while the $57.3 \%$ literacy rate for women (USAID, 2017). This disparity reflects the cultural tradition of educating men first and women last (Bell, 2001; Schuller, 2016). Among the youth (15 to 24 years), the literacy rate is $82.5 \%$ (USAID, 2017), which not only reflects a cultural shift but also the commitment and determination of Haitian families to prioritize education above other needs (Kaussen, 2011; Luzencourt \& Gulbrandson, 2010; Padgett \& Warnecke, 2011).

According to the Haitian Embassy in Washington D.C. (2017), the metro area of Port-au-Prince (Port-au-Prince, Delmas, Cite Soleil, Carrefour, Tabarre, and Pétion-Ville) has a population of over 2.6 million inhabitants with a $14 \%$ rate of unemploymentapproximately 300,000 people. This unemployment number does not reflect Haitians in the restavek system -working for room and board, or the underemployed. More than half of the population under age $14(66 \%)$ depends on the production and earning capacity of $34 \%$ of the population (age 15-64). This ratio shows the economic pressure placed on the employed minority and lack of available job/earning opportunities for the majority (World Bank, 2017).

Dr. Paul Farmer (2012) described the discriminatory economic conditions of poverty, inadequate housing, gender discrimination, and lack of collaboration between NGOs and the Haitian government as chronic events exacerbated by the 2010 earthquake. In January of 2010, $54 \%$ of the Haitian population lived on \$1 USD per day; an unregulated shanty town like Cité Soleil, originally built to house 3,000 to 5,000 became one of the largest slums in the Western Hemisphere housing 200,000 to 400,000 residents (L'Etang, 2012). Gender inequality in Haitian laws and banking/lending practices 
prevented the masses and especially women from political and entrepreneurial participation (Bell, 2001, 2010, 2012; Schuller, 2010, 2012).

On January 12, 2010, an earthquake struck Haiti. The map in Figure 2 illustrates the areas affected by the earthquake. The earthquake killed an estimated 222,570 people and left 3.7 million people affected one way or the other (World Bank, 2013). In the summer of 2010, 1.5 million internally displaced persons (IDPs) were in 1,300 predominantly makeshift camps distributed across Port-au-Prince. The weak Haitian state-often called a "failed state"6 (Bell 2012; Padgett \& Warnecke 2010; Schuller 2014; Torgman 2012) represented powerlessness of governmental authorities to perform their functions such as enforcing the rule of law, maintaining economic and structural infrastructures, and supplying health and education services. The 2010 earthquake exacerbated the failed state environment. The Haitian government suffered crippling losses both regarding infrastructure and personnel. All but one government building stood after the earthquake and hundreds of employees were killed (Bell 21012; Deuremy 2011; Horton 2012). As Haitians put it, "Tout Ayiti kraze" ("The whole country is no more") (Fatton, 2011, p.164).

\footnotetext{
${ }^{6}$ This refers to Haiti's inability to provide basic services to its citizens
} 


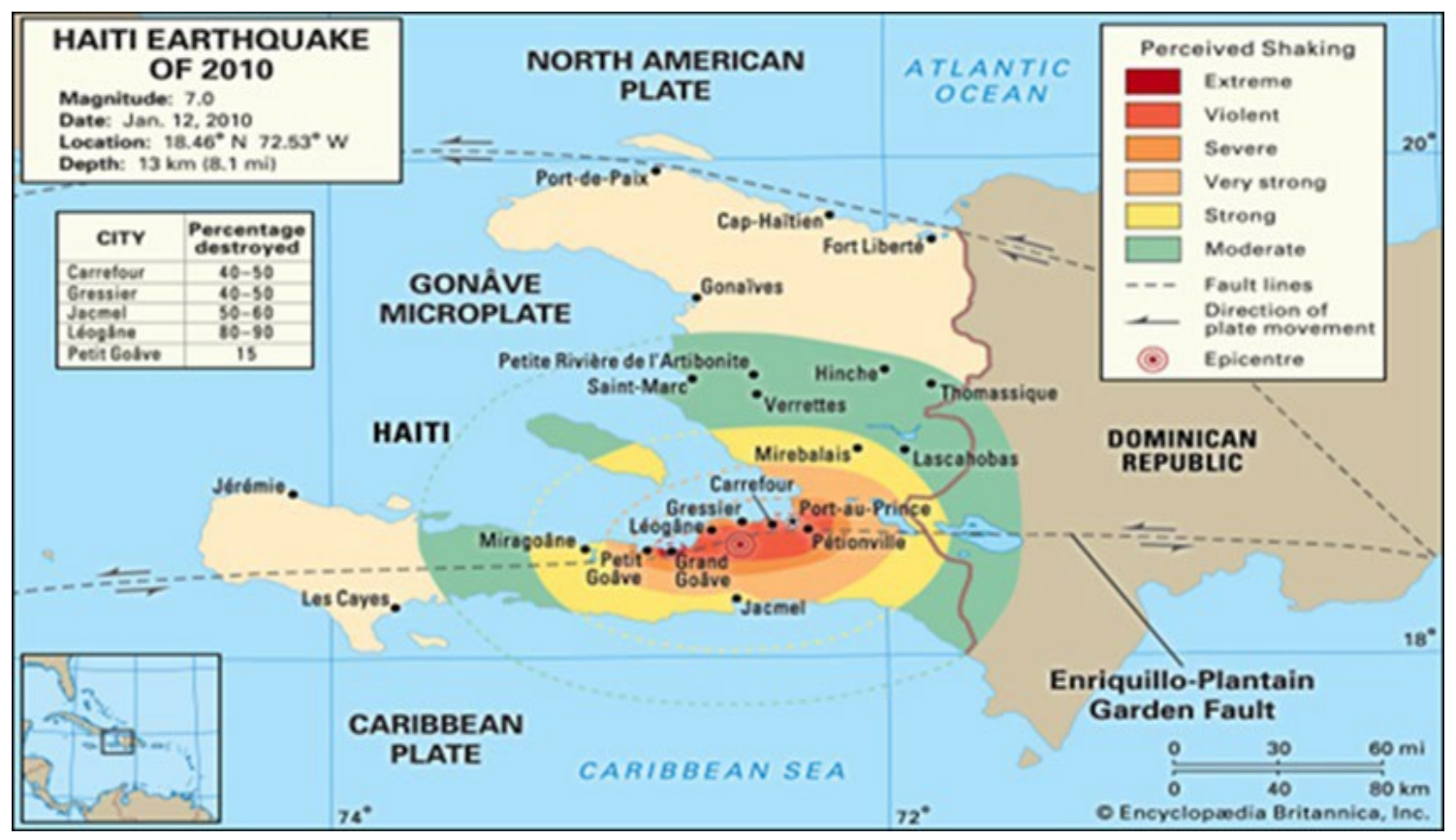

Figure 2. Map of Haiti Earthquake of 2010 (from Britannica.com).

The earthquake left 1.5 million IDPs in search of shelter in its immediate aftermath (IDPs; World Bank 2013). Although NGOs and government programs have now closed over 1,200 camps and relocated IDPs, according to the International Organization for Migration (IOM; 2017), there are still 40,000 to 60,000 post-earthquake IDP residents in 31 camps across Port-au-Prince. Despite the drop in the number of postearthquake IDPs from camps in the greater Port-au-Prince area, other factors (e.g., human-made, climate) have caused the IDP population to grow within other parts of the country (Internal Displacement Monitoring Centre, 2017; InternalDisplacement.org, 2017; USAID, 2018). For example, the government of the Dominican Republic created a human-made situation when in 2010 they denied Dominican citizenship to persons of Haitian descent and expelled them from the country, thereby creating a new wave of displaced persons. Various sources (Ariza, 2017; Haiti Libre, 2017; Newland \& Salant, 2017; UN Office for the Coordination of Humanitarian Affairs [UN OCHA], 2018) 
reported that over 100,000 Haitians now live in displacement camps along the HaitianDominican border. Newland and Salant (2017) stated: "Many returnees were born in the Dominican Republic, and without knowledge of Haitian Creole or close contacts in Haiti, end up living in squalid camps along the border" (para 2).

In addition to the increase in displacement caused by the Dominican government, Hurricanes Matthew (2016) and Irma (2017) created close to 700,000 additional displaced persons in Haiti (Country Meters, 2018). Hurricane Matthew struck on October 4, 2016, and devastated Haiti's southwest départments of Grand'Anse and Sud, destroying 200,000 homes and affecting close to 1.2 million people, over 175,000 of whom were forced into temporary shelters (Trevino \& Deinnger, 2016; World Bank, 2017). The hurricanes also destroyed crops and large swaths of agricultural land, throwing millions into food insecurity (Anthem, 2016). The picture in Figure 3 was taken in an area of Grand'Anse where residents lost $90 \%$ of their homes after Hurricane Matthew.

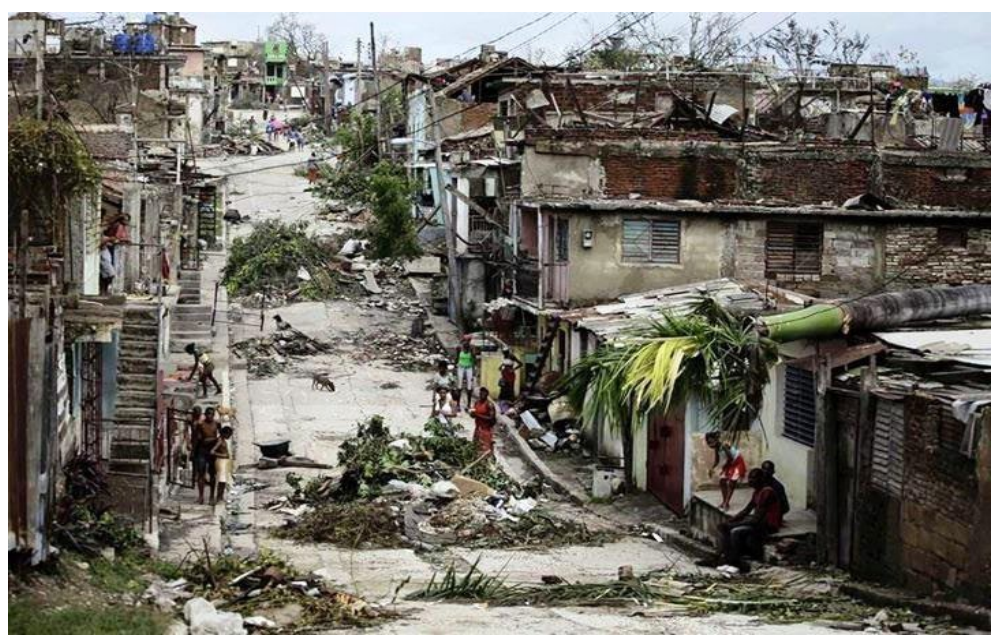

Figure 3. Grand'Anse in 2016 after Hurricane Matthew. (Photo: EU Delegation to the Republic of Haiti). 
In addition to the destruction caused by this hurricane, the winds from 2017's Hurricane Irma caused severe damage to Haiti's crops in the North. Thousands of small farmers lost their banana, plantain, avocado, and breadfruit crops - staples of the Haitian diet. According to Charles of the Miami-Herald, "The northwest, which was already one of the poorest regions of the poverty-stricken country along with the northeast, was overlooked after Matthew, with attention focused more on the harder-hit Grand'Anse and southwestern regions" (Charles, 2017) See figure 4.

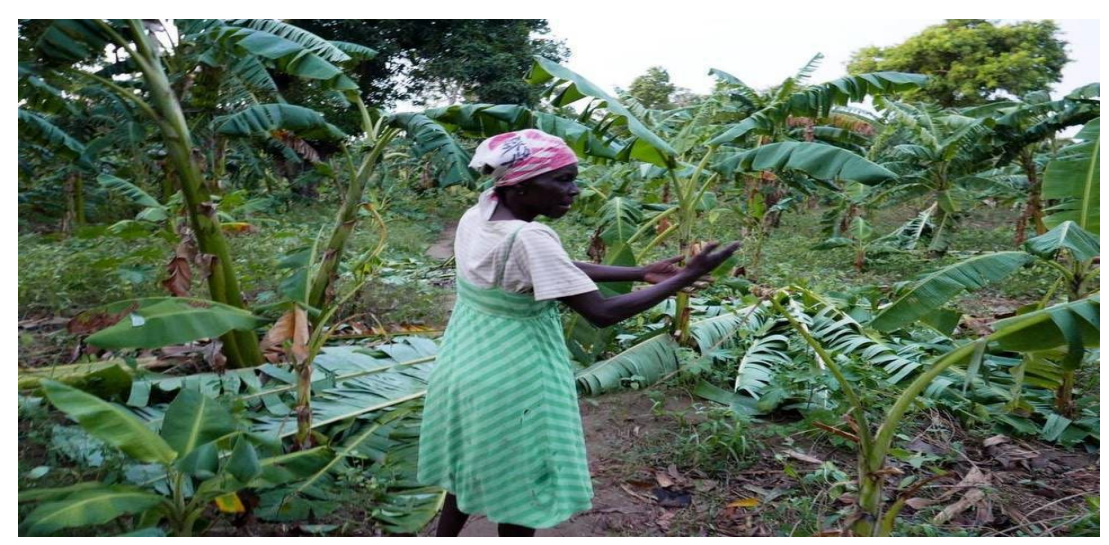

Figure 4. A Haitian farmer points to destroyed banana trees after Hurricane Irma (Source: miamiherald.com).

With Haiti exposed to the various disasters - the earthquake in 2010, Hurricanes Matthew in 2016 and Irma in 2017, and the ongoing expulsion of Dominicans of Haitian descent - the number of IDPs in 2018 ( 1 million) is now climbing to the post-earthquake level of 1.5 million.

The post-earthquake environment in Haiti was a mix of short-term and long-term recovery needs such as debris management, body removal, home repair and reconstruction, and the delivery of essential needs such as shelter, food, water, and emergency healthcare. According to Time magazine's Desvarieux (2010), after the 2010 
earthquake, Haiti had 20 million to 25 million cubic yards of debris, enough to fill the New Orleans Superdome five times - and only one approved dumping site for the entire country at the Port-au-Prince terminal Varreux. In June of 2010, the Interim Haiti Reconstruction Committee (IHRC) in partnership with the United Nations Development Program (UNDP) approved $\$ 22$ million USD for a debris removal program aimed at employing Haitians in thousands of jobs in debris recycling, removal, and processing. By June 2011, an estimated 7,000 Haitians were trained in the fields of manual and mechanical rubble removal, recycling, house repair skills, as well as electric wiring, carpentry, and masonry. Equally crucial to the debris removal process was the recovery, removal, and disposal of bodies (McEntire, Sadiq, \& Gupta, 2012).

The body recovery challenges in post-earthquake Haiti were primarily around issues of logistics, cultural and religious traditions, and the lack of volunteers, equipment, and supplies (Ghosh, 2010). Historically the capitol Port-au-Prince had sufficient but few morgues. The enormity of the number of the deceased (exact numbers ranged from 250,000 to 300,000 (McEntire, Sadiq, \& Gupta, 2012) after the January 12 earthquake overwhelmed the government of Haiti and international agencies. Due to the slow body removal process as well as the lack of coffins and mortuaries, many frustrated family members took charge of burying their loved ones. The traditional blend of Catholic and Voodoo religious and cultural burial rituals was abandoned. This relinquishment exacerbated the emotional trauma experienced by many and prolonged the psychosocial grief and healing processes (Bloem \& Miller, 2013). The Haitian government and international agencies focused their limited resources on the immediate shelter and shortterm recovery survivor needs (Ghosh, 2010; McEntire et al., 2012). 
The Interim Haitian Reconstruction Committee (IHRC) pointed out equally vital in IDP post-disaster needs was the government and NGO assessment and reconstruction of damaged homes (Desvarieux, 2010). The World Bank (WB; 2010) estimated that in post-earthquake Haiti, 180,000 or more homes were damaged or destroyed, and 1.5 million people were displaced. In a 2010 World Bank report, by December 2010, the World Bank committed an estimated $\$ 65$ million USD to the Port-au-Prince Neighborhood Housing Reconstruction Project. The overall project objective was to assist over 10,000 households in rebuilding their homes and livelihoods using cash grants and to improving waste sanitation, roads, and social facilities.

The following section explains why I chose the areas of Delmas, Canapé Vert, and Pétion-Ville as case study sites.

\section{Case Study Sites}

Before the earthquake, Haiti's largest metropolitan area and capital Port-au-Prince lacked an estimated 500,000 housing units (The Haiti Equality Collective, 2010). Approximately $95 \%$ of Haitians (55\% of whom lived on $\$ 1.25$ USD per day) relied on privately funded, poorly constructed buildings with unregulated rents in crowded slums known as "bidonvilles" (Pamuk, 2006). These informal settlements often lacked access to essential services and were in high-risk flood zones (USAID, 2018). These slums or settlements are a phenomenon in many parts of the developed and developing countries of the world. In the United States they are "shanty towns" or "tent cities," in Brazil they are "favelas," and in Tunisia and the Philippines, they are "shanty towns" (Pamuk, 2006). The inhabitants of bidonvilles in Haiti (See Figure 5), as those in the different iterations 
mentioned, lack land tenure security and access to infrastructures such as water and electricity.

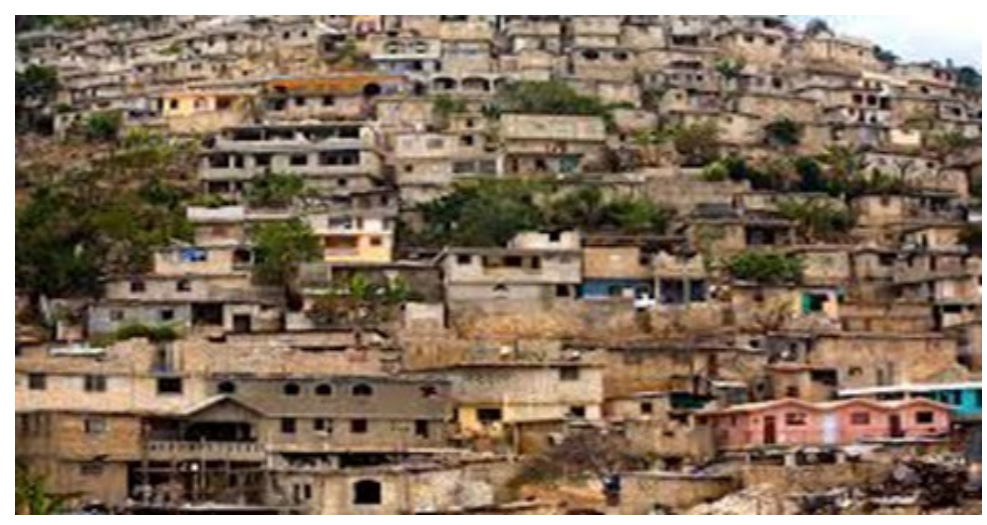

Figure 5. Pétion-Ville bidonville before the earthquake.

(Source : https://www.flickr.com/photos/dangerding/)

This dissertation research focused on three socioeconomically different communes (districts) in or near the Port-au-Prince arrondissement (an administrative division within a city): Delmas, Pétion-Ville and the neighborhood of Canapé Vert within the arrondissement of Port- au- Prince. These communes were originally selected as the focus of the previously-cited NSF study as they were adjacent yet socio-economically diverse communities in Port-au-Prince. Each of them, though, had lower-income areas devastated by the earthquakes and housed the IDPs. The USAID map in Figure 6 displays the Pétion-Ville, Delmas, and Canapé Vert communes immediately after the 2010 earthquake. 


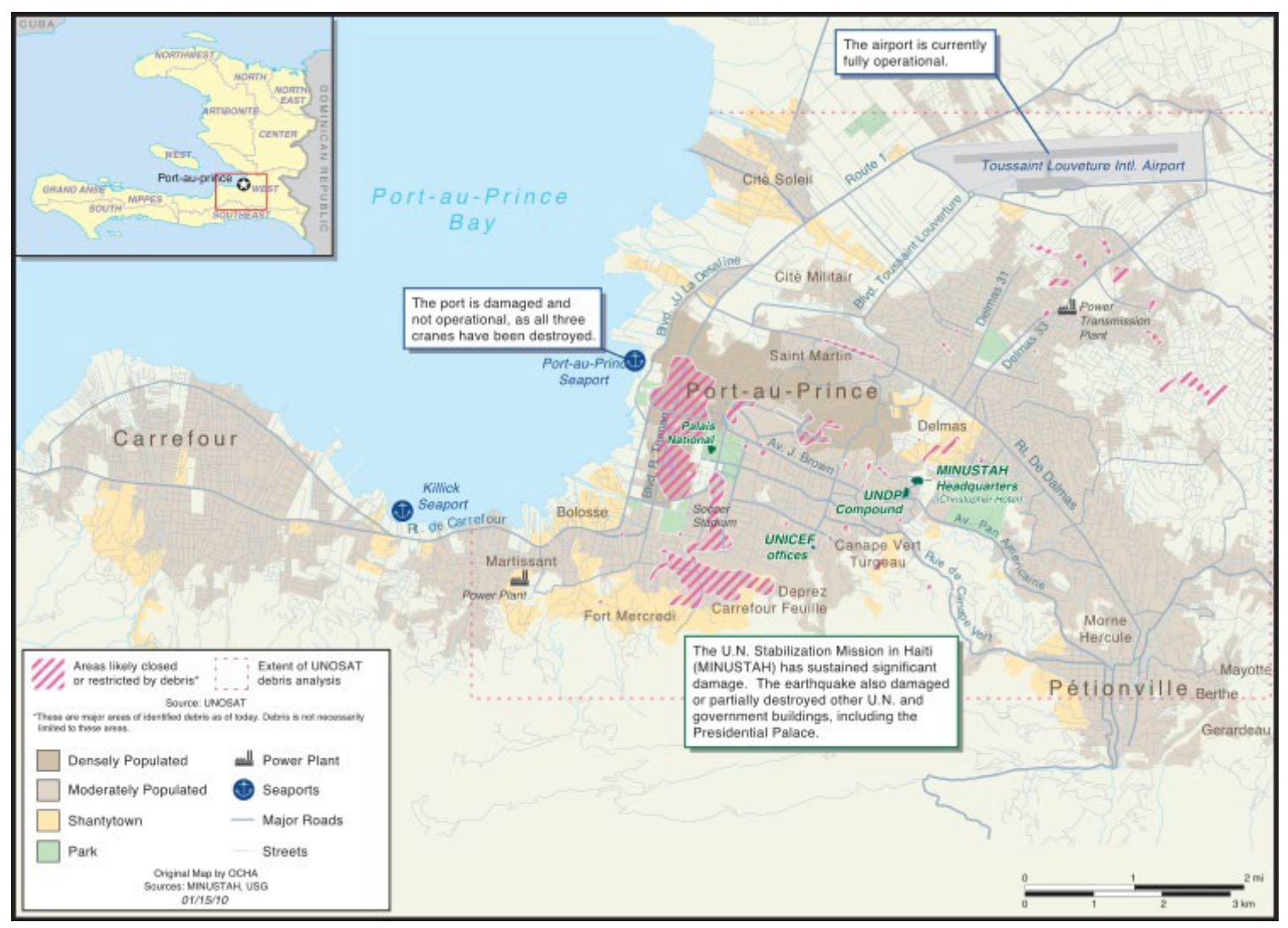

Figure 6. Areas in Haiti affected by the 2010 earthquake. https://reliefweb.int/sites/reliefweb.int/files/resources/DC40C4474B767BFB852576B500 77C2B3-map.pdf

The commune of Delmas is located three kilometers from downtown Port-auPrince and contains one of the city's main roads. Delmas has a population of 284,079 ( (Rahill \& Ganapati, 2017) and is a middle-income, mixed-use (commercial/industrial and residential) area. The Delmas 32 neighborhood was the most affected area after the earthquake with a loss of approximately 7,000 lives (Malbranche, 2015). Figure 7 is a map of the Delmas area and surrounding neighborhoods. 


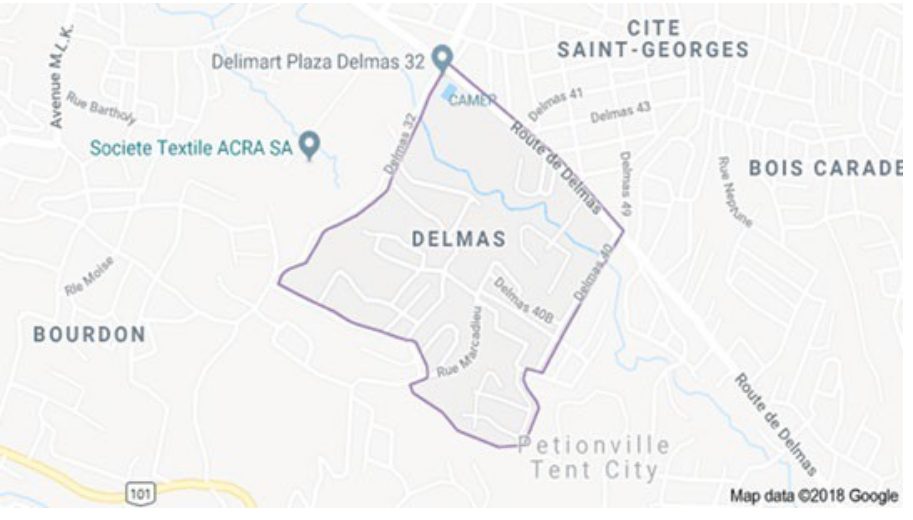

Figure 7. Boundaries of Delmas. (Google Maps, 2018)

Pétion-Ville has a population of just over 283 million (World Population Review, 2018) and is primarily a high-income area. It is a suburban town located four kilometers from downtown Port-au-Prince and is where in 2010, between 4,000 and 5,000 displaced people set up camps around two of its town squares, at Place Boyer and Place Saint Pierre. Central business districts and wealthy homes surrounded these neighborhoods (L'Etang, 2012). The map in Figure 8 shows Pétion-Ville and surrounding areas.

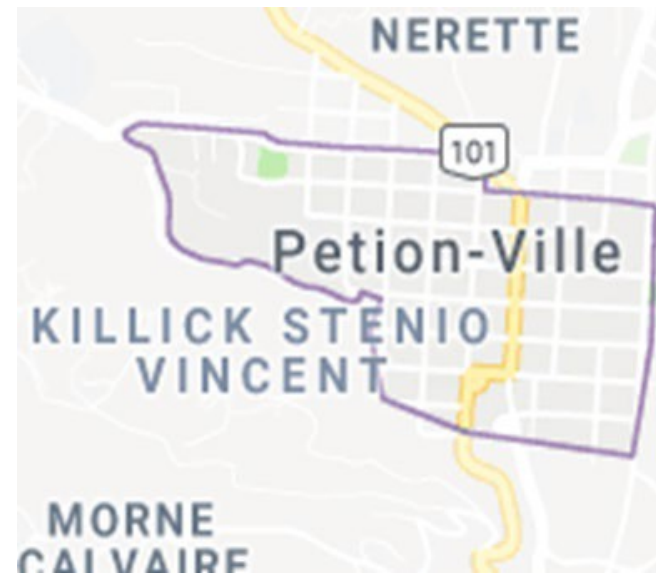

Figure 8. Boundaries of Pétion-Ville

One of the most populated camps in Port-au-Prince is $\mathrm{J} / \mathrm{P}$ HRO, found on the Pétion-Ville Country Club golf course, which housed about 60,000 displaced persons (J/P Haitian Relief Organization, 2018). As a research assistant, I visited this camp in 2011 
and spoke to several camp inhabitants who were waiting for medical care as well as for water from a public water storage unit. According to the J/P HRO website (2018), this camp closed in 2014, and through a protection/transition program all 60,000 IDPs were successfully relocated to the Delmas 32 neighborhood. Figure 9 is an aerial photograph of the J/P HRO camp, which I visited.

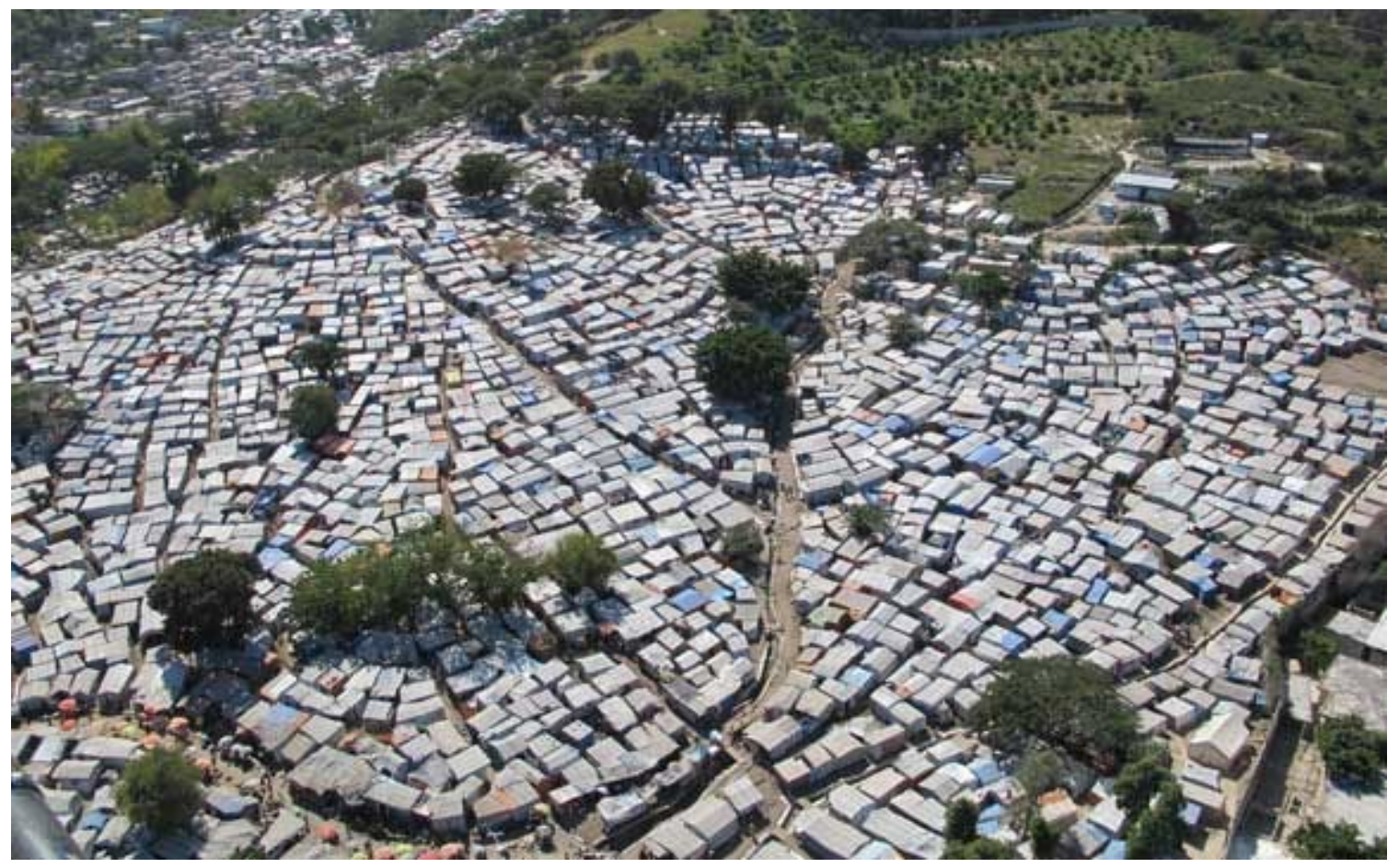

Figure 9. The J/P HRO camp in 2011. (J/P HRO, 2018)

Canapé Vert (Figure 10) is an area located approximately 1.5 kilometers from the center of Port-au-Prince. Historically, it was primarily a high-income area with some low-income neighborhoods. In the 1990s, as farmers from the surrounding rural areas faced food and economic insecurity, they migrated to a section of Canapé Vert of mainly low-income housing and slums (bidonvilles). 


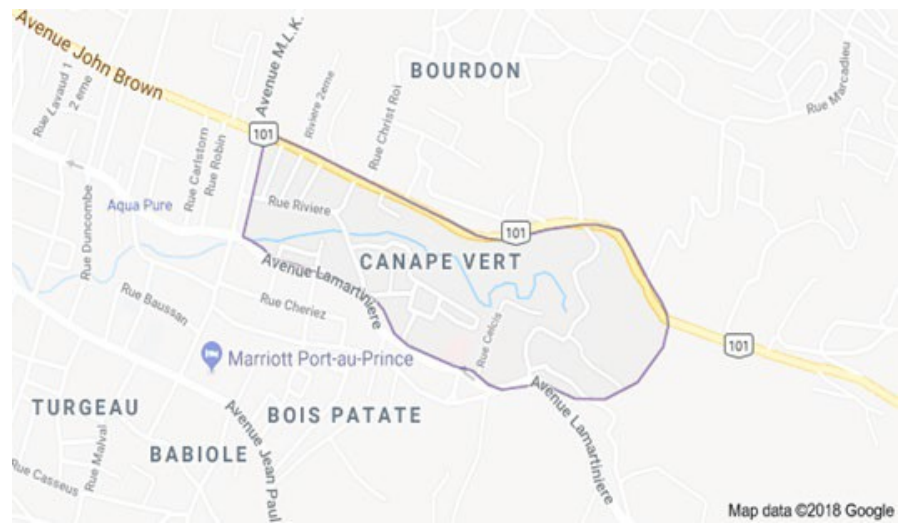

Figure 10. Canapé Vert boundaries.

As of January 2018, there are 15-17,000 IDPs living in Delmas, 3-5,000 in Pétion-Ville and 3-4,000 in Canapé Vert (ACAPS, 2018). These communities were models for the 16/6 relocation program, which - under the auspices of the Haiti Reconstruction Fund's (HRF) ${ }^{7}$ - was designed to help Haiti rebuild its housing capital and relocate IDPs from 6 camps to 16 neighborhoods (Haiti Reconstruction Fund, 2012). The six priority camps chosen for relocation in Port-au-Prince were Place Saint-Pierre and Place Boyer (in Pétion-Ville); Stade Sylvio Cator, Primature, and Maïs Gâté (in Delmas), and Place Canapé Vert. The camp inhabitants were recipients of either family rental grants or existing home rehabilitation or rebuilding. The 16/6 project facilitated the restoration of 16 return neighborhoods. The initiatives within the $16 / 6$ project proposed improved housing reconstruction, increased access to essential services identified by communities, and the creation of income-generating opportunities (Haiti Libre, 2011).

In 2018 , the largest resettlement community called Canaan is located three miles outside of Delmas (Kushner, 2017). The Canaan development began after the 2010

\footnotetext{
${ }^{7} 16 / 6$ was supported by the Haitian Ministry of Public Works, World Bank (WB), the InternationalAmerican Development Bank (IDB) The International Finance Corporation (IFC and, 17 countries (including The U.S., Canada, and France).
} 
earthquake as a displacement camp on about 7,500 acres of dry, arid land designated by then-President Préval (Zidor, 2012). Canaan then evolved into an informal displacement camp into separate communities of 200,000 displaced and resettled Haitians. Residents (with the help of the Haitian diaspora) invested more than $\$ 100$ million USD and created their city, Canaan (Ott, 2016). Canaan has football pitches, barber shops, restaurants, lottery booths, pharmacies, beauty salons, and grocery stores. There are now 204 schools and 111 churches, as well as a hospital and a health center. Figure 11 shows Canaan in 2010 when it was designated as a displacement camp and stands in stark contrast to the more recent image of Canaan as of 2016, which is now an unofficial city (Figure 12).

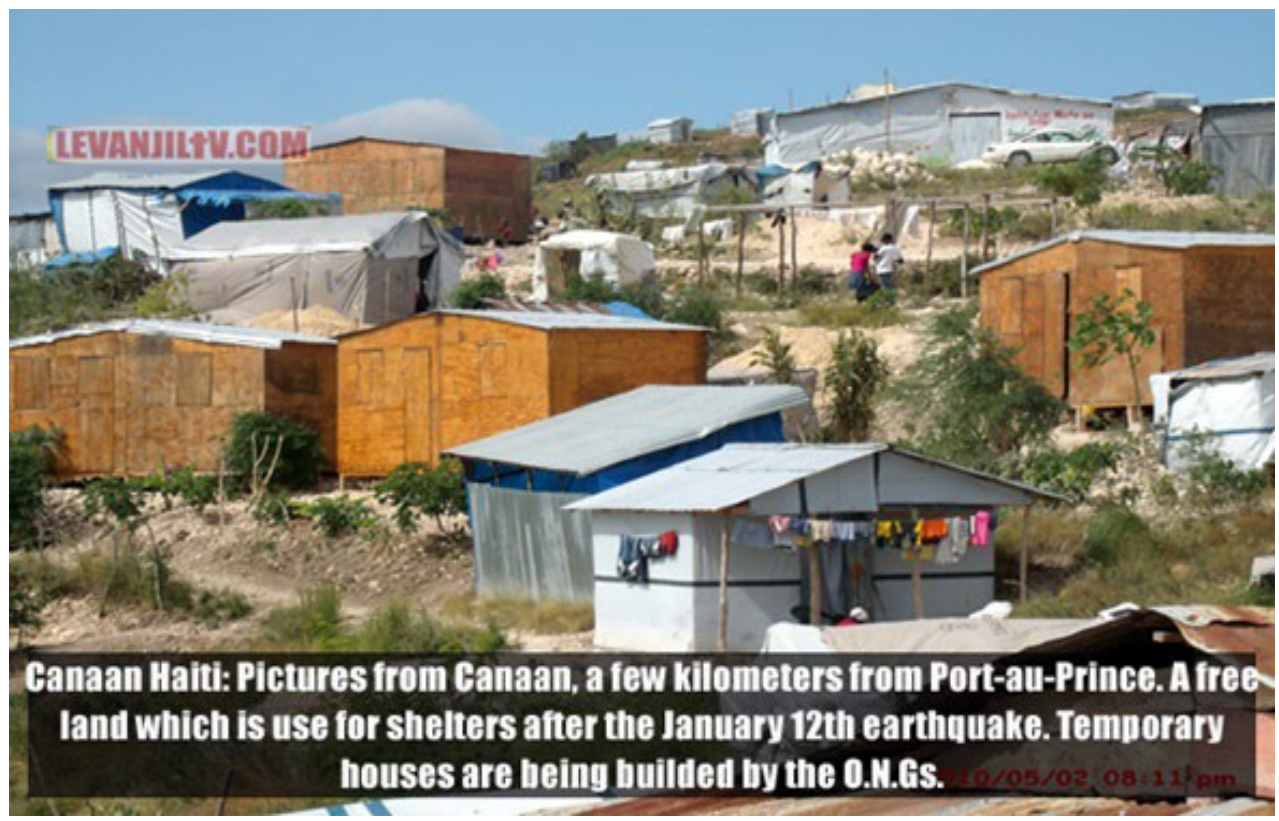

Figure 11. Canaan in 2010. (www.pinsdaddy.com) 


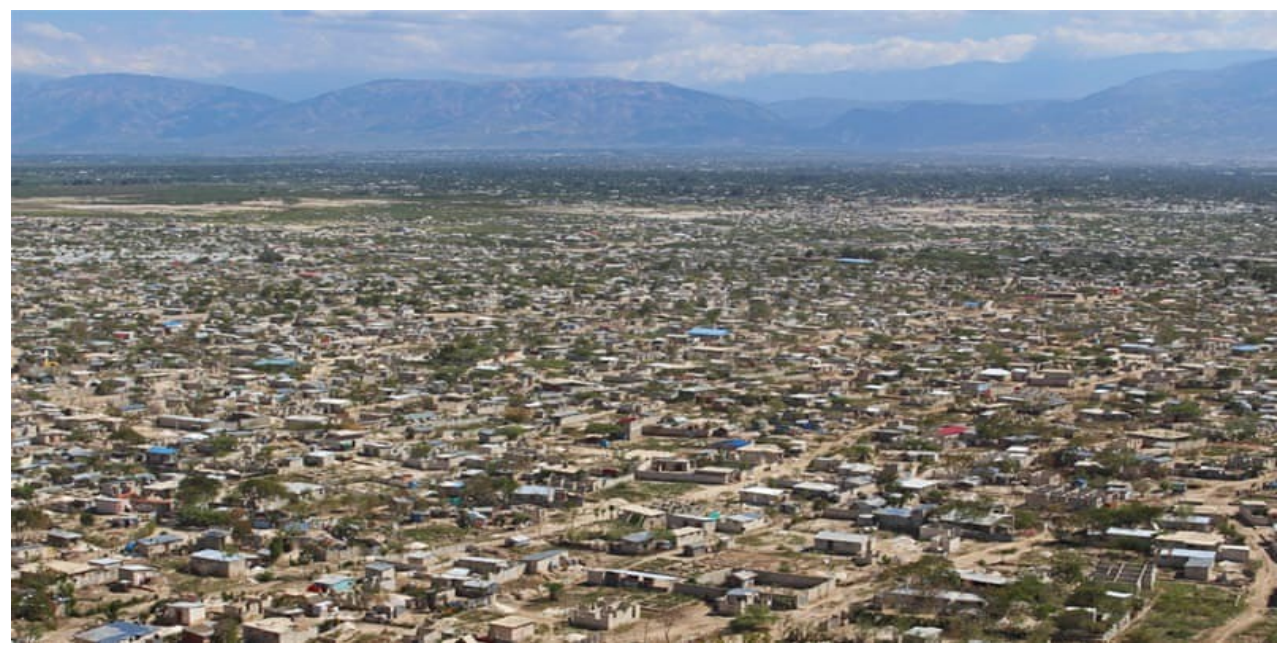

Figure 12. Canaan in 2016. (www.Aljazeera.com)

\section{Data Collection Methods}

The analysis in this study draws on data from interviews, focus groups, field observations and a review of secondary sources, I discuss each source below.

In-depth interviews. To understand the gendered long-term recovery priorities of IDPs, the reasons behind such priorities, and factors that affect women IDPs' participation in decision-making processes, I conducted semi-structured interviews with the following groups: (a) women and men IDPs from diverse groups (with respect to age, marital status, and levels of education); (b) community leaders (e.g., IDP camp committee officials); and (c) Haitian and international policymakers (e.g., from international NGOs). Although the perspectives and viewpoints of the IDP women and men were critical to this dissertation's research, equally important were the perceptions and experiences of Haitian policymakers, NGO directors and international aid agency program directors.

From 2017 to 2018, I completed 43 semi-structured interviews, at which point the analysis reached saturation (Bowen, 2008; Morse, 1995). According to McNabb (2012), 
the use of semi-structured interviews allows the interviewer to create an informal and open interview atmosphere, yet adhere to a guided line of inquiry. The open-ended questions in the interview guide allowed a natural conversation style while still ensuring the inclusion of critical research themes: participation, priorities, voice, gender, and organizational interventions in the recovery process.

I conducted the interviews primarily via phone in the preferred language of the interviewees and according to the socially acceptable norms in Haiti (e.g., speaking in French with government officials or Haitian Creole with IDPs). The interviews lasted on average 1.5 hours, but if the informant wished to continue, I did not stop them. I documented the interviews with written notes or made audio recordings with the informed consent of the participants. At times, cell phone service was spotty regardless of the system I used (regular cell service or internet-enabled WhatsApp). The quality of the call reception determined whether I recorded the phone interview or took notes. The scanned notes and audio files were saved to an external drive. I transcribed the audiorecorded interviews verbatim and analyzed the data using the qualitative analysis software NVivo 11 Pro. As themes emerged - through word searches, word clouds, and word trees - I coded and analyzed the transcripts (see the Data Analysis section, below).

I used two different versions of a semi-structured interview guide (see Appendix A) approved by the Institutional Review Board at Florida International University. The first guide was in Creole for women and men IDP informants and community leaders. It focused on the women IDP's current priorities and levels of participation. The second guide was in a French and English version for the Haitian and internal NGO officials, respectively (see Appendix B). It delved into these decision makers' organizations' 
processes and post-earthquake programs. It began by gathering information on each informant's job responsibilities, the agency or government department where they were employed, and their time spent working in Haiti. It then probed about how Haitian government agencies and NGOs addressed women's and men's IDP priorities in the preand post-earthquke context. Next, the interview guide asked study participants to describe gender priority differences, participation, and voice of both women and men. The final sections of the interview guide explored policy actions for the Haitian government and the NGOs.

In the interview guides, I included several questions to address my overall research questions. For instance, to understand the gendered recovery priorities of the IDPs and why women or men prioritize issues differently during the recovery period (Specific Aim 1), I asked four questions about the informant's top recovery priorities within the first year of the earthquake (2010) and the informant's current priorities (2017-2018) and if and how they informed the authorities about those short- and longterm priorities.

(1) What was your top recovery priority?

(2) Please explain why this was important to you at the time.

(3) In what ways did the Haitian government address your top recovery priority at that time?

(4) In what ways did the international agencies address your top recovery priority at that time?

Then, I examined the similarities and differences between the priorities of displaced women and men in the interview guide by asking the following: 
(1) Do you think women and men have different or similar recovery priorities?

(2) Why do you think women and men have different or similar recovery priorities? Please explain why you think this way.

I probed about whether the priorities were related to the individual's household, community, or to the Haitian government and international aid agencies.

To examine the processes that enable or hinder the participation of women IDPs in decision-making processes or expressing their preferences regarding rebuilding needs and priorities (Specific Aim 2), I used the following questions about who the informants spoke to, where the information was shared, and the informant's perceived outcomes in the short- and long-term.

(1) Did you inform the Haitian government or the international agencies about your top recovery priority at that time?

(2) Who did you inform about your top recovery priority (e.g., the international agency or the Haitian government)?

(3) Please tell me why you wanted to inform them about your top recovery priority (e.g., the international agency as opposed to the Haitian government).

(4) How did you inform them about your top recovery priority (e.g., by writing a letter, attending a meeting, arranging a meeting or through a community-based organization)?

(5) Please tell me why you decided not to inform them about your top recovery priority.

(6) When you spoke, did anyone listen within the first year of the earthquake? 
To gather insights on how policymakers and representatives of NGOs should address the unique and varied needs of women and ensure an equitable long-term postdisaster recovery process (Specific Aim 3), I asked the informants what they believed the Haitian government and NGOs needed to do.

(1) What do you think the Haitian government needs to do to better understand your top recovery priorities?

(2) What do you think the Haitian government needs to do to better address your top recovery priorities?

(3) What do you think the Haitian government needs to do to better understand Haitian women's (or men's) top recovery priorities in general?

(4) What do you think the Haitian government needs to do to better address Haitian women's (or men's) top recovery priorities in general?

I found the IDP informants and community leaders for my dissertation first by contacting the participants of the NSF study (see Rahill et al. 2014 for details on the NSF study sample). I had access to the contact information of NSF study participants, including their physical addresses, phone numbers (of themselves and two of their references), and email addresses. As for the Haitian government and international NGO officials, I identified the initial sample through an extensive search and analysis of secondary sources including newspapers, government and NGO websites, reports, LinkedIn, and Facebook. In LinkedIn, I searched through 1,000 contacts for current or former NGO directors and members of the Haitian government. I focused on their work histories, the timeframes (from 2010 to present), and the organizations for whom the 
contacts worked (for example the UN, IOM, Doctors without Borders, and the different ministries within the Haitian government). I then emailed 50 professionals who fit my criteria from the Haitian government and the NGOs. The emails yielded five replies (a $10 \%$ response rate). I connected with the five professionals who responded and sent them my proposal abstract, the confidentiality form, and the questionnaire to review. From a search of my LinkedIn network of over 400 connections, I found an NGO director who accepted the interview invitation. Within Facebook, I searched through over 4,000 contacts and reached out to 25 people via messenger, 3 of whom replied (a $12 \%$ response rate) and accepted the interview. I expanded my initial IDP, community leader and policymaker sample utilizing snowball sampling (Padgett, 2016).

The 43 total informants who participated in this study fell into one of the following categories: current or former residents of displacement camps in Delmas, Pétion-Ville, and Canapé Vert $(n=34)$; community leaders such as those who established local non-profits $(n=2)$; and Haitian government policymakers $(n=2)$ or representatives of international aid agencies $(n=5)$ who were very familiar with gender and participation policies, the focus of this study.

As shown in Table 1 below, the IDP participants of the study were either new informants I identified through snowball sampling (Group $1 ; n=25$ ) or those recruited from the NSF study who had participated in the focus groups in 2010 and 2011 (Group 2; $n=8)$ 
Table 1

IDP Interview Participants by Location and Gender

\begin{tabular}{lcccc}
\hline & \multicolumn{2}{c}{ GROUP 1 } & \multicolumn{2}{c}{ GROUP 2 } \\
\hline & Female & Male & Female & Male \\
\hline Pétion- & 9 & 2 & 2 & 2 \\
Ville & 6 & 2 & 1 & 1 \\
Delmas & 4 & 2 & 1 & 1 \\
Canapé & 19 & 6 & 4 & 4 \\
Vert & & & & \\
\hline TOTAL & & & &
\end{tabular}

Of the 23 IDP women who participated in the interviews of my dissertation, $29 \%$ reported that they were born in Port-au-Prince and $71 \%$ outside of Port-au-Prince (in other parts of Haiti). Conversely, $70 \%$ of the participating IDP men were born in Port-auPrince, and 29\% from outside the city. Most of the women (66\%) and 50\% of the men were under the age of 50 . Regarding family structure, $62.5 \%$ of the women reported that they were single, separated, divorced, or widowed, and $37.5 \%$ were married or living in konkibinaj - a system in Haiti where one man supports multiple households. Of the male participants, $60 \%$ were single or divorced, and $40 \%$ were married or in konkibinaj.

When asked about work, there was no distinction made between formal (working 40 hours or more weekly for an employer) or informal work (self-employed selling goods or services). Within the study sample, $33 \%$ of the women engaged in some sort of work compared to $40 \%$ of the men, and $45 \%$ of non-working women depend on a spouse/partner or child to support the family. Regarding education levels, $66 \%$ of women are illiterate ${ }^{8}$ or have only a primary school education, $12.5 \%$ have a secondary

\footnotetext{
${ }^{8}$ UNESCO 2007 defined illiterate as the inability to read and write
} 
education. In contrast, $40 \%$ of the men have only a primary school education, and $60 \%$ have a baccalaureate or some university education.

When questioned about religious affiliation, $50 \%$ of the women and $30 \%$ of the men reported their religion as Catholic, the remaining as Protestant. When asked, "Do/did you belong to an organization?" - a key factor in this dissertation's research $-25 \%$ of the women reported that they belonged to a church organization and $20 \%$ of the men belonged to a community organization. In 2010 , the participation rate in the camp committees for women was $50 \%$ and for men $75 \%$.

In addition to the new interviews I conducted with Groups 1 and 2 for my dissertation, I used data from the 54 interviews (Group 3) conducted as part of the NSF study. These interviews were also conducted with community leaders and Haitian and international aid agency representatives. Of the 54 interviews, 9 were with female participants while 45 were with male participants (see Rahill et al., 2014 for further details on these interviews).

Focus Groups. In addition to data collected through interviews conducted for my dissertation and for the NSF study, I used data collected through the focus groups of the NSF study. A total of 12 focus groups of were conducted for the NSF study, six with only women, and the other six with only men. In each community, four focus groups were facilitated: two baseline focus groups divided by gender at the beginning of the study (May 2010), and another two divided by gender six months later (November 2010). Focus group participants for the NSF study were mainly recruited through the Haitian Institute of Community Health (Institut Haïtien_de Santé Communautaire) and snowball sampling (referrals). 
The study's focus group participants ( $n=63 ; 29$ women, 34 men) were residents of the three communities mentioned earlier (Delmas, Pétion-Ville, and Canapé Vert). The distribution of these participants by gender is provided in Table 2 (Rahill et al. 2014). About two-thirds (62\%) of the focus group participants from the baseline focus groups participated in the follow-up focus groups. Therefore, the actual number of people who participated in the focus groups were 47 . Within the baseline sample, $83 \%$ had high school education or less, and 75\% were under age 35 .

Table 2

IDP Focus Group Participants by Location and Gender

\begin{tabular}{|l|c|c|}
\hline & Female & Male \\
\hline Pétion-Ville & 10 & 12 \\
\cline { 2 - 3 } Delmas & 6 & 9 \\
\cline { 2 - 3 } Canapé Vert & 13 & 13 \\
\hline GROUP 4 TOTAL & 29 & 34 \\
\hline
\end{tabular}

Several questions discussed in NSF study's focus groups were relevant to the participatory aspects of my dissertation, such as:

- To what extent do you think the government of Haiti has involved the residents of___ [name of community] while preparing their plans for rebuilding the community?

- To what extent do you think the government of Haiti has involved those affected by the earthquake while preparing their plans for rebuilding Port-auPrince and the entire country?

- To what extent do you think the government of Haiti has involved those in other parts of the country while preparing their plans for rebuilding the entire country? 
Participant observation. This study used earlier participant observations conducted by this researcher and by the researchers of the NSF study. I traveled to Haiti in 2011 as part of another research study on the emotional labor of disaster response and recovery workers funded by the National Institutes of Health and had a chance to gather insights on the living conditions of the IDP camps located in the areas of Delmas, PétionVille, and Canapé Vert. As a member of the field research team in Haiti, I visited one of the largest camps in Haiti at that time, the Jenkins/Penn Haitian Relief Organization (J/P HRO) camp in Pétion-Ville.

For the NSF study, the researchers conducted participant observation in a variety of settings, including the IDP camps, church gatherings, street protests, voodoo ceremonies, and meetings organized by international aid agencies for inter-agency coordination (what are called UN Cluster Meetings). I had access to their recorded observations and field notes.

Review of secondary sources. The period from post-earthquake 2010 until 2018 served as my time frame for my analysis of the secondary sources. One such source was the letters written by the IDPs as part of a project undertaken by the International Organization for Migration (IOM), which is now a United Nations agency between 2010 and 2011. The project was called the Tanbou (Drum) project; and it involved placing of suggestion boxes by the IOM in IDP camps in Port au Prince and inviting the displaced to voice their concerns, hopes, and dreams. The goal of the project was to allow IDPs the opportunity to reach out to local and International organizations voicing their needs and concerns. In other words, it gave a voice to Haiti's IDPs. The IOM received and catalogued 5,000 letters (International Organization for Migration, 2011). When possible, 
the IOM sent text messages to camp dwellers acknowledging their letters. These letters are found on various websites (McVeigh, 2011) and YouTube videos (International Organization for Migration, 2011) in which the letter writers are recorded reading their own letters. The analysis of these IDP written letters added a unique dimension to my research by allowing immediate post-earthquake first-person priorities into the research stream. The analysis of these publicly available IDP-written letters consisted of 11 letters ( 5 from women and 5 from men, and 1 general communique from the camp committee) written by IDPs in camps Canaan and Corail-Cesselesse between August and September of 2010. Of those who contributed letters during this project, two IDP women and two men lived in Caanan, and three women and three men lived in camp Corail-Cesselesse. I examined the priorities of the women and men letter writers and studied what they wrote for similarities and differences.

In addition to the IDP letters accessed through IOM's Tanbou project, I examined post-disaster recovery related regulations, policies, and programs in Haiti. For this, I first conducted an in-depth analysis of the post-disaster needs assessment (PDNA) outlining Haiti's post-earthquake opportunities and challenges (Eves, 2011; Lauterbach, 2012). I then identified international aid agencies that were actively involved in Haiti's recovery and evaluated the content of their websites, documents and reports. These agencies included, for instance, Doctors Without Borders, Grameen International, Institute for Justice and Democracy in Haiti, IOM, J/P HRO, MADRE, Partners in Health, IFRC, United Nations Educational Scientific and Cultural Organization (UNESCO), United States Agency for International Development (USAID), United Nations High Commission for Refugees (UNHCR), United Nations Development Program (UNDP), 
and financial institutions such as the International Monetary Fund (IMF) and the World Bank. I also collected information on recovery programs undertaken by the Haitian government and these agencies, looking for the integration of IDP needs in the short- and long-term recovery programs and initiatives. Some of these programs I studied, for instance, included: (a) the Inter-American Development Bank’s “Learning by Doing” project (HA-M1032) which was designed to train families in Haiti to rebuild; (b) the IDB's Emergency Shelter Provision project (HA-G1004) which was designed to provide emergency shelter in Haiti's most vulnerable areas; and (c) the World Bank's Port-auPrince Neighborhood Reconstruction Program; and (d) the Haitian government's voucher relocation program for IDPs (16/6). Furthermore, as part of my analysis of secondary sources, I examined international articles from newspapers such as Le Noveliste, The Haitian Times (published by the diaspora in the United States), The Miami Herald, and The New York Times. Haitian and Haitian-American videos and diaspora blogs such as Bien-AimePost.com also informed this research.

Review of secondary sources helped me identify and understand IDPs priorities particularly those of internally displaced women - and how program and policy instruments enable or hinder women IDPs' participation in their long-term recovery processes.

\section{Data Management}

Confidentiality. As a part of the informed consent, all interviewees (dissertation and previous NSF participants), and focus group participants were briefed on the purpose of the study by email, phone, or in person as well as their rights as participants and the confidentiality of their responses. For the in-person interviews, participants indicated 
their willingness to participate by verbally consenting prior to the interview. The informants were offered a copy of the informed consent form which included contact information for myself, the Principal Investigator of the study and the Institutional Review Board (IRB).

Ensuring confidentiality was an essential step for gaining the trust of participants and increasing the likelihood that their responses were straightforward and genuine, especially in the cases of Haitian government officials and NGO directors. Hence, I used pseudonyms in the study. For the IDP interviewees, confidentiality was critical for allay fears of retaliation from the government or NGOs. A file holding a reference list of names and contact information was stored in a separate, secured account.

\section{Data Analysis}

I transferred all project data from the interviews, focus groups, observation and secondary sources to the NVivo 11 Pro software, a data management system that allows organization, transcription, and analysis of various media (audio and written). I coded and analyzed interviews and media according to frequency and context in NVivo, which identifies emergent themes in the data. This coding allowed me to generate themes according to the questions asked, as well as to assess the relevance of those interview questions to the relevant research question.

I analyzed the findings (preserved in Haitian Kreyol) from the follow-up interviews with repeat and new participants as well as from interviews and focus groups conducted during the original NSF study. Although data from the earlier study had been coded and analyzed, that coding scheme was not focused on the specific needs of women IDPs (even though focus groups were conducted with women). Hence, I re-coded that 
data for this study. While analyzing the data, I utilized both directed and summative approaches to content analysis (Hsieh \& Shannon, 2005).

Directed approach. The directed approach to content analysis starts with a theory or relevant research findings as guidance for developing interview questions. Initial codes emerged from the informants' answers. Five theories within the directed approach informed my research: (a) feminist political ecology, (b) disaster gender studies, (c) representative bureaucracy, (d) social capital, and (e) exit, voice and loyalty.

Summative approach. For the purposes of this study, the summative approach involved counting and comparing (e.g., of keywords) as well as interpreting the underlying context of the texts (interviews and letters) and of emerging themes such as: sekirtite and insekirite (security and insecurity, a constant theme woman voiced) and partisipasyon (participation). For this purpose, I used the NVivo coding methods of word clouds. A word cloud is an analysis tool that represents the frequency that words and phrases occur using font size (i.e., higher-frequency words are written in larger font size). I used this tool to understand the words and phrases surrounding essential words in this research. Words such as "women," "priorities," and "people" were found in participant responses to my research questionnaires as well as probes in all my questions. Figure 13 is a word cloud sample of the 10 most frequently mentioned words mentioned in the 2010 Canapé Vert women's focus group interview (Rahill et al., 2014). The 10 most frequent words in the NSF study’s Canapé Vert women’s focus group interview (Rahill et al., 2014). 


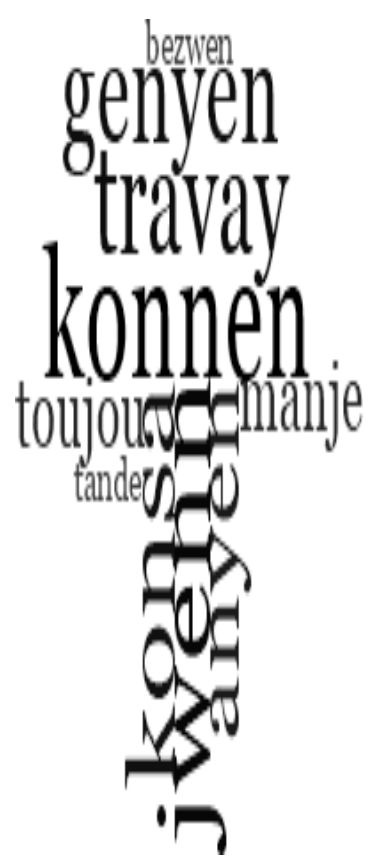

Figure 13. World cloud of most frequently mentioned terms (translations below).

\begin{tabular}{|l|l|l|l|}
\hline bezwen & need or needs & toujou & always \\
\hline genyen & have & manje & food \\
\hline travay & work & jwenn & find \\
\hline konnen & know & anyen & nothing \\
\hline konsa & what & tander & listen \\
\hline
\end{tabular}

\section{Ensuring Quality in Qualitative Research}

There are various techniques to ensure the quality of one's research. These recommended techniques are credibility, transferability, dependability, and confirmability (Lincoln \& Guba, 1985; Whitemore, Chase, \& Mandle, 2001). The following are brief descriptions of how I used each of these techniques for this study.

Credibility. I established that my findings were believable from the perspective of the study participants by restating and clarifying their statements back to them (i.e., member checking). For example, the word bezwen found in the Figure 13 word cloud has 
many meanings. A Creole speaker may mean "I need" or "my needs" are... I also used triangulation (employing multiple data collection methods - interviews, focus groups and secondary sources) to ensure believability. The interviews gave voice to IDPs, especially to women, who as of 2018 still reside in displacement camps.

Transferability. My dissertation focuses on IDPs in the Port-au-Prince communities of Delmas, Pétion-Ville, and Canapé Vert, the findings (explained in the following chapter). To ensure transferability of my findings to other displacement camps in Haiti and elsewhere in the world, I provided rich descriptions in the dissertation.

Dependability. I enlisted three other researchers familiar with Haiti's IDP environment to review and critique my findings.

Confirmability. Audio recordings were transcribed verbatim in Haitian Creole to ensure that the intended meanings were preserved in the original language used.

\section{Chapter Summary: Methodological Strengths and Limitations}

Women made up half of the 1.5 million internally displaced persons (IDPs) who stayed in the 1,300 makeshift tent camps in post-earthquake Haiti in 2010 (Internal Displacement Monitoring Centre, 2017). This earthquake highlighted the unique vulnerabilities IDP women faced, and that thousands continue to endure (Anthem, 2016; Bradshaw, 2013; Farmer, 2012; Horton, 2012; UN Office for the Coordination of Humanitarian Affairs, 2018). IDP women were vulnerable to situations such as rape, sexual assault, forced labor, food insecurity, and unsanitary conditions - many of which were circumstances created by inadequate short- and long-term recovery shelters in the aftermath of the disaster (Arend \& Vitale, 2013; Bell, 2012; Duremy, 2011; Rahill, Ganapati, \& Mukerji, 2014; Rahill \& Ganapati, 2017). 
As of 2018, over 50,000 IDPs in Haiti continue to suffer from discrimination (CEPR, 2013; Reini, 2010) and economic barriers to rebuilding (Corbet, 2014). They experience predatory lending practices (Gender Action Network, 2013), lack access to affordable housing options and political representation in local governments (Fatton, 2011; Haiti Libre, 2017; Kushner, 2017). Thus, the IDPs believe that living in camps creates additional challenges to their long-term economic, sociological, and political recovery, and many of these issues are reflected in the study's findings. Immediately following the 2010 earthquake, the bourgeoisie and elite of Pétion-Ville were initially tolerant of the displacement camps; however, 14 months later they were pressuring public officials to clear the camps and their poor inhabitants from the area (Reini, 2010). In cooperation with the Haitian government, the council of Pétion-Ville devised a voucher program $(16 / 6)^{9}$ to entice or pressure camp dwellers to leave the area (CEPR, 2013; IJDH, 2012; Schuller, 2012). The program offered \$500 USD to each family to leave their tents and camps. Many inhabitants were reluctant to go since the amount offered would barely cover one year's rent.

The qualitative methods I used in this dissertation research helped me understand the unique beliefs, experiences, and perceptions of internally displaced women and men in post-earthquake Haiti as well as of community leaders, and Haitian and international policymakers. I would not have been able to capture these without relying on interviews, focus groups, field observations and review of secondary sources. Yet, the study has some methodological limitations.

\footnotetext{
${ }^{9}$ This program 16 neighborhoods and 6 camps (16/6) was framed as an opportunity for IDPs to leave the camps.
} 
First, the analysis relies on a small sample of IDPs in just three neighborhoods of Port-au-Prince, Haiti. However, it has the potential to contribute to the scholarship on the priorities, needs, and participation of internally displaced women in similar cultures and environments.

Second, the displacement of 2010 study participants and changes in phone numbers posed additional challenges and limitations as I could not include them in the dissertation study.

Third, those living in IDP camps during the 2017-2018 period may not accurately recall what their priorities and needs were in the immediate aftermath of the earthquake, seven or eight years after the event.

Fourth, as in other studies on participation, there is a mismatch between policymakers referred to by the IDPs and those whom I interviewed for the study. I did, however, make every effort to conduct interviews with the specific policymakers that IDPs in the three communities referred to; however, due to a new government, many of the former officials were no longer in office. Similarly, there were challenges of reaching the specific policymakers from the international agencies study participants referred to since there is typically a high turnover in these agencies.

Fifth, although the study touches upon men's perspectives on disaster recovery and participation for comparison purposes, its focus is on IDP women rather than IDP men. Sixth, I acknowledge that I possessed some preconceived ideas of IDPs in Haiti that might have affected how I designed, conducted and interpreted the study. I tried to make every effort, however, to revisit and question my assumptions at each step of the study. To make sure that I am not misinterpreting what they told me, I also checked my 
understanding (or lack thereof) of issues with the informants. In that process, I realized that the IDP men may not be as forthcoming with a female outsider such as myself. Although I was born in Haiti and speak Creole, I am considered an outsider (Diaspora or Blanc). This distinction may have caused some reticence on the part of some of the study informants to share their insights on IDP priorities and participation in decision making processes.

As mentioned previously, however, this study builds upon and extends previous research including interview, focus group, and observation data (Rahill et al., 2014), thus a unique and powerful strength is the longitudinal data collected across the two studies (from 2010 to 2018). 


\section{CHAPTER IV}

\section{FINDINGS}

\section{Overview}

The word goudougoudou (the Creole word for "earthquake") onomatopoetically describes the frightening roaring sound the tremors made during the 2010 earthquake. To the millions of earthquake survivors, the word goudougoudou brings back images concrete tumbling, sensations of falling and being covered in white concrete dust, and people yelling for assistance - into their consciousness and dreams (Schuller, 2016). In 2018, my research informants described life in Haiti as "avant goudougoudou et après goudougoudou" (before the earthquake and after the earthquake). For millions of Haitians, the goudougoudou transformed their lives from citizen to often invisible internally displaced person (moun invisibles; Kaussen, 2011; L'Etang, 2012; Richard, 2012).

This chapter presents the key findings of the study based on interviews, focus groups, field observations and the review of secondary sources conducted for this dissertation study and for the NSF study to understand the perspectives of these invisible persons: the IDPs. In line with the three specific aims and their related research questions, the chapter first talks about the similarities and differences in priorities of women and men IDPs, with further details on why there are such similarities or differences. It then presents the factors that either hindered or enabled participation of women IDPs in decision making processes during post-disaster recovery. Specifically, it looks at how women IDPs' participation was affected by the diverse range of organizations involved in recovery, formal institutions (e.g., rules and regulations) on participation, policymaker 
related factors (e.g., stigma towards the IDPs), IDP related factors (e.g., lack of trust in policymakers), place-related factors (e.g., lack of access to transportation), and civic network related factors (e.g., women's groups).

\section{Priorities of Women and Men IDPs: Similarities and Differences}

My first specific aim in this dissertation was to understand the long-term rebuilding priorities of the IDPs and the reasons behind such priorities through a gendered lens. To analyze these priorities from the informants and community leaders who participated in the earlier study (Rahill et al., 2014), I created several node searches exploring the following themes: "bezwen" (need), "manjé" (food), "ensekirite lasante" (healthcare insecurity), "lojman ensekirite" (shelter insecurity), "pèdi finansye" (lost financial help), "pèdi rezo sosyal" or "lacou" (lost social capital).

The word cloud and list in Figure 14 represents the top 25 words from all informants (both women and men) when asked about their 2010 needs.

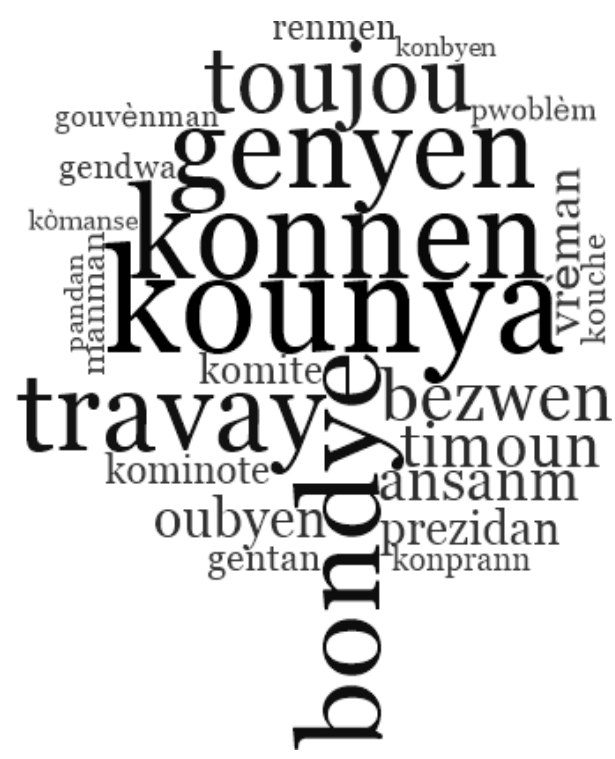

Figure 14. Word cloud of top 25 Creole words in 2010 (translations below). 


\begin{tabular}{|l|l|l|l|l|l|l|l|}
\hline \multicolumn{2}{|l|}{ Middle top-bottom } & \multicolumn{2}{l|}{ Top-clockwise } & \multicolumn{2}{l|}{ Clockwise cont. } & \multicolumn{2}{l|}{ Clockwise cont. } \\
\hline Creole & English & Creole & English & Creole & English & Creole & English \\
\hline toujou & always & remen & Like & ansamn & together & komite & commit-tee \\
\hline genyen & have & konbyen & $\begin{array}{l}\text { how } \\
\text { much }\end{array}$ & prezidan & president & manmam & mother \\
\hline konnen & know & problem & problems & koprann & $\begin{array}{l}\text { under- } \\
\text { stand }\end{array}$ & pandan & during \\
\hline kounya & today & vreman & really & getan & $\begin{array}{l}\text { have } \\
\text { time }\end{array}$ & komanse & started \\
\hline bondye & God & kouche & sleep & oubyen & either & gendwan & the right \\
\hline & & bezwen & need & $\begin{array}{l}\text { komi- } \\
\text { note }\end{array}$ & $\begin{array}{l}\text { com- } \\
\text { munity }\end{array}$ & $\begin{array}{l}\text { gouven- } \\
\text { man }\end{array}$ & $\begin{array}{l}\text { govern- } \\
\text { ment }\end{array}$ \\
\hline
\end{tabular}

I also conducted a cluster analysis, which offers a visual representation that highlights differences in the data by grouping nodes that share similar words or values. Figure 15 is a cluster diagram of the top eight words that cluster around the Creole words “mwen” (I or me), “manjé” (food /eat), "vie” (live), “mandé” (ask), and “bezwen” (need). 

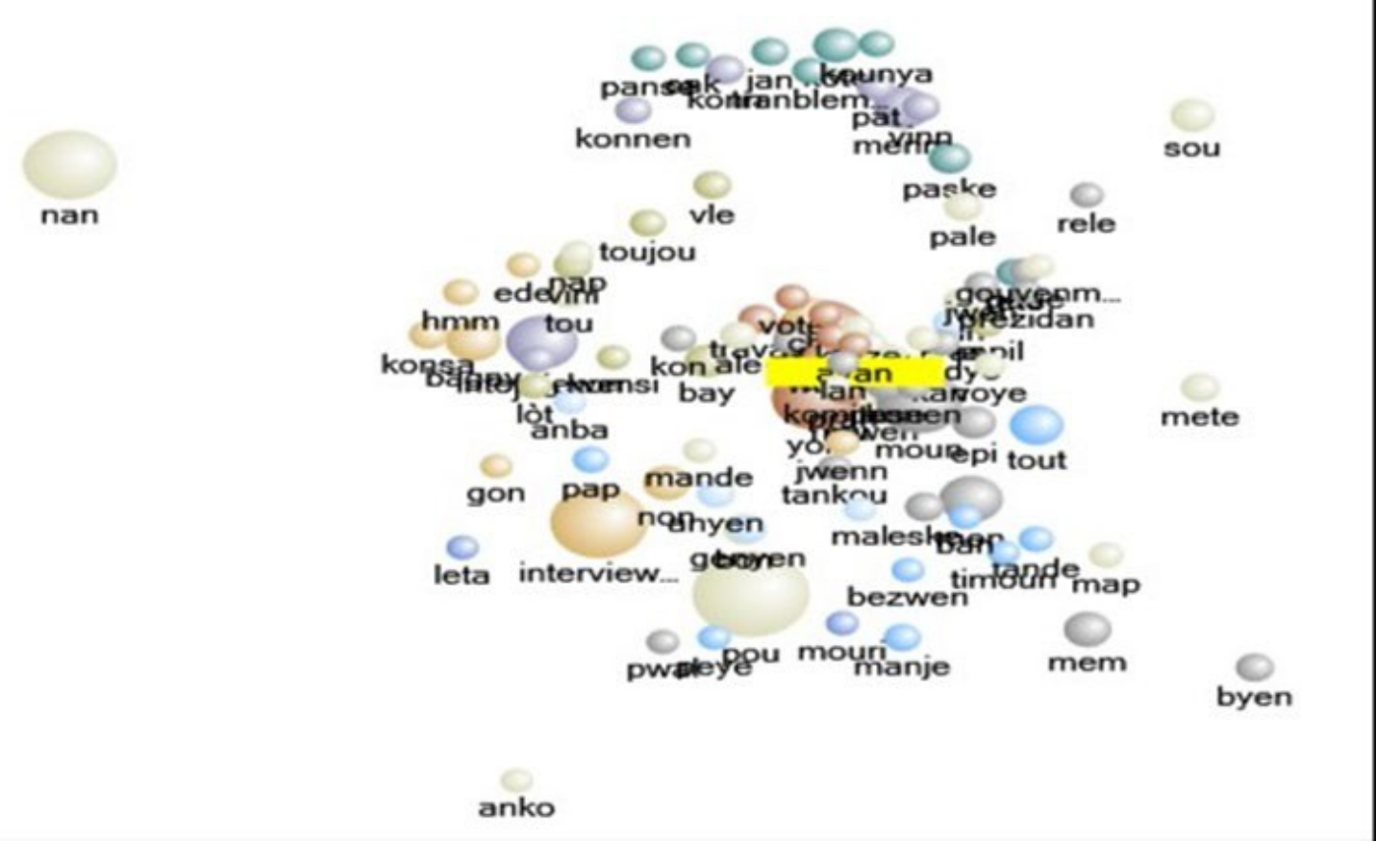

Figure 15. Cluster analysis illustrating words clustered around "mwen" ("I" or "me").

The analysis of the data revealed that despite some similarites between the recovery priories of women and men IDPs in the short- (food security, sanitation/cleanliness, returning home and to pre-disaster community) and long-term (access to secure shelter), women had several additional priorities due to: (1) the traditional roles they play in the household (a reproductive role as a mother and nurturer and productive role as a caregaver and income generator); (2) their perception inside and outside the household as passive "victims" that needed help; and, (3) the location (away from the city center) and conditions of IDP camps (e.g., increased risks of sexual assaults and violence in IDP camps, cholera outbreak) within which they lived. I explain the common priorities of the genders as well as gender-specific priorities below. 
1.a. Common Priorities. As shown in Figure 19 women and men IDP informants had more shared rebuilding priorities in the immediate aftermath of the disaster, compared to their shared long-term rebuilding priorities. In the long-term, however, their priorities diverged more, becoming more gender-specific. Their short-term priorities were related to food security, sanitation/cleanliness, returning home, returning to their pre-disaster communities and secure temporary shelter while long-term ones emphasized such things as access to long-term permanent housing, secure temporary shelter and sanitation.

Women and men, IDP informants' mutual emphasis on food security in the shortterm is understandable given that they were all affected by the earthquake and had to think about their families' immediate basic needs first. The emphasis on sanitation/cleanliness had more to do with the poor sanitary conditions of the camps. The emphasis on returning home and to their pre-disaster communities highlighted the importance of the loss of their social networks (e.g., being away from their pre-disaster neighbors and living next to strangers in the camps that they do not necessarily trust) and attachment to their pre-disaster homes and communities, irrespetive of gender.

Overall, $58 \%$ of the women stated that returning to their homes with family was a priority in 2010. Similarly, half (50\%) of the men stated that going home and rebuilding was a top priority the first-year post-earthquake. The following are example interview statements with IDPs, with their pseudonyms (used to protect informant identities) followed by "M" (man) or "W" (woman): Jackie and Carlo (men) shared their 2010 priority to return home. Jackie (M): My wife and I had a priority to return home with family. 
In this study, the general IDP sentiment of going back home refutes the view of many international and national observers: that IDPs were comfortable in the camps and preferred to stay in them. Schuller (2010) wrote, "In post-earthquake Haiti, this narrative carried weight, cited by members of the U.S. Congress as justification for delay sending the $\$ 1.15$ billion USD in pledged aid" (Schuller, 2010). Various narratives (Kaussen, 2011; Richard, 2012) framed IDPs as free riders, and as people who took advantage of camp services, available water, education opportunities, some health services, and free shelter. According to the Internal Displacement Organization (2017), people moved between camps to access livelihood opportunities or following forced evictions.

\section{1.b. Common priorities that require a more nuanced, gender-based understanding.}

Although some priorities of women and men IDPs seemed to be similar both in the shortand long-term, they required a more nuanced and deeper understanding from policymakers in terms of the dimension of the problem each group wanted to be addressed and the solutions that they wanted to see. These priorities related to protection and income generation as detailed below.

Protection. While women IDPs had genuine concerns about their bodily integrity in the face of sexual assault and violence threats in IDP camps, men were more concerned about the protection of their private property against robbery, even avoiding to use the words often mentioned by women (e.g., rape) in the context of protection.

In my research, women referred to their security (or lack thereof) regarding gender-based violence, specifically rape (kajok); in contrast, male informants never used the term "rape" (Gabriel et al., 2016; Hoeffler, Honore, \& Gage, 2017). Camp conditions were generally overcrowded, poorly lit, and with latrines and bathing facilities far from 
most IDP tents. The tents were easily flooded and torn, exposing IDPs - especially women - to violence and rape (Kaussen, 2011; Schuller, 2014). Although the women IDPs in this study were grateful for the tents or prélas (tarps) in the camps immediately after the earthquake in 2010, their lack of security and violence were key issues, especially for those with children.

In $2010,55 \%$ of women informants stated that violence against women was a top priority for IDP women. Of the women interviewed, 16\% confided in me they were raped and needed medical care. According to the IJDH (2011), due to the stigma attached to the victim, many women and girls were discouraged from reporting rape or sexual assaults. Women who did report such assaults to the police were often told that the police could do nothing and that it was the government's problem. My informants were especially concerned for the safety of younger women and girls. The following quote from Betti (W) echoes this fear: We needed security, especially for the girls. They (men) raped young girls. The increase of intimate partner violence was also a concern of women informants. Intimate partner violence is a culturally embedded aspect of life in Haiti; for example, it is an accepted practice for men to beat their wives and daughters (MADRE, n.d.).

As verified by my informants, many women are afraid to report incidents of rape for fear of retribution from the perpetrator or scorn from government officials. According to the Institute for Justice and Democracy in Haiti (IJDH; 2010), rapes in the camps were dramatically underreported. In the first two months after the earthquake, Komisyon Fanm Viktim pou Viktim (KOFAVIV; Commission of Women for Women, a grassroots women's advocacy group in Haiti) tracked 230 incidents of rape in just 15 camps in Port- 
au-Prince. Médecins Sans Frontières (Doctors Without Borders) reported 68 cases of rape in April 2010 at one of their clinics in Port-au-Prince.

In contrast, the men in my study - if they spoke of security at all (as protection against robbery, or fights) - used the word sekirite, a general term for safety. One IDP, Paul (M), said: The government should put in place more security, roads, water, and construction. When I probed further what he meant by "security," he suggested more police or army presence, so people were not robbed or beaten. Again, the men informants in this study never spoke of violence or rape towards women and girls as a security concern.

Income generation. Although both women and men informants prioritized income generation, they defined the experience differently. In terms of income generation, women IDPs preferred to have self-employment, in part due to their reproductive role as a mother and nurturer and their productive role as a caregiver and income generator inside the household. The ti machanns are the center of Haitian market life, which in turn links the agricultural and urban centers. This intricate informal economy is designed with market rotation days, which enables the seller to attend and sell to different areas on alternating days. The average distance traveled to get to market is 4 to 8 miles, although a trek of 40 miles is not uncommon (Torro, 2009). According to the World Bank (2018), the average market woman earns \$2-5 USD per day. These meager earnings are at times barely enough to feed their families, yet some revenue is better than nothing. Still, this grower-to-vendor market network provides a sense of camaraderie, resilience, and support for Haitian women in their quest for survival, both in economic and social terms (Beasley, 2012; Began \& Schuller, 2009; Torro, 2009). 
In $2017 / 18$ IDP women informant interviews, I found that $60 \%$ of the women felt that money for their own business was a current priority. Women wanted to earn money to finish school or to send their children to school. Sandra (W): I was abandoned by my 10-year old's father, and it is my responsibility to feed, clothe, and send my child to school.

Women informants shared, although they listed themselves as heads of household, many of the women informants stated they entered into a kokibinaj living arrangement to have supplemental financial assistance from a man. The concept of a livelihood system, and not necessarily a job per se, was important to women in IDP camps. Livelihood systems encompass the necessary capital and resources that people employ when making a living. Women-headed households are the norm in Haitian communities, which is a pattern that is recreated in IDP camps either from abandonment, the death of a spouse, or as mentioned above, the accepted practice of kokibinaj (Dubois, 2012; Duramy, 2011; Schuller, 2016). Regardless of circumstance, single-earner households are rare in Haiti due to the high rate of poverty (Affairs, 2018; Charles, 2017; Padgett \& Warnecke, 2011). Women young and old must work to support their families, their communities, and the Haitian economy (see Figure 16). In Haiti, women are called "Poto Mitan" (middle post or pillar), holding families, communities, and businesses together (Began \& Schuller, 2009). These women eke out a living and support their families while constrained by dire economic conditions and are viewed by many as the "pillars of Haitian society." 


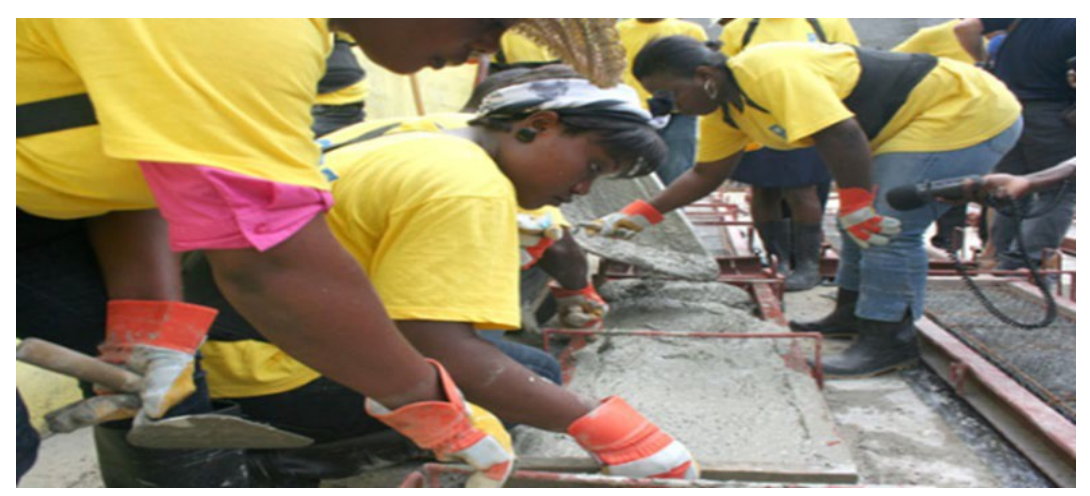

Figure 16. Haitian women in the Rebuilding Haiti training program (United Nations Development Program, 2014)

In 2018, Haiti was ranked the poorest country in the Western Hemisphere (UN

Office for the Coordination of Humanitarian Affairs, 2018). More than 54\% of Haiti's population lives on less than $\$ 1$ USD per day. Women's work and small enterprises have historically played a significant role in Haiti's economic development and stability. Before Haiti's independence in 1804, women worked alongside men in the sugar, coffee, and sisal plantations (Dubois, 2012). Women created informal businesses (très petites entreprises, very small enterprises), setting themselves up as tailors, cooks, and babysitters within their slave communities to support both male and female workers (Hossein, 2012). The ti machanns (small market sellers) of today are descendants of this group.

Women in Haiti "manage" poverty and care for their families through these informal small businesses (USAID, 2017). Seager (2009) defined the concept of "managing poverty" as the ability women have as caretakers and providers, and who through personal austerity and labor are able to compensate for diminished family resources. Haitian women work outside the home utilizing a myriad of self-taught and naturally acquired work skills (Began \& Schuller, 2009; Bell, 2012; Haiti Libre, 2017; 
Padgett \& Warnecke, 2011). Many pre-disaster businesses continued after the 2010 earthquake through the sheer ingenuity and resilience of these women. On the day after the quake, a reporter noted, "There were women cooking and selling food in the middle of the street and selling anything they could" (Beasley, 2012; Bell, 2012). Women in Haiti run their businesses regardless of the environment to provide for their families, working long hours to do so. These women - Poto Mitan - actively manage their economic livelihoods with scant resources. In Haiti, the more impoverished the household, the more dependent the family is on female revenue streams (Padgett \& Warnecke, 2011).

When women have an income, substantial evidence indicates that this money is more likely to be spent on food and children's needs. In Haiti, women are generally responsible for food selection and preparation as well as for the care and feeding of children (Finch, 2010; Global Food Security, 2013; Seager, 2005).

Sadie (NGO director). It seems women have a greater sense of urgency to work because they are responsible for their kids. I don't want to generalize too much, but men don't generally have to worry about their kids going to school. Gender roles in Haiti are very pronounced.

Women provide for their children's educational needs, tuition, books and uniforms very often by running a small business (très petite entreprises) which may consist of buying and selling produce or clothes, and cooking meals to sell. Although women are the primary economic drivers of the Haitian economy (Gender Action Network, 2013; Haiti Libre, 2017; Rhodes, 2001), they are the last to eat and the last to reap the benefits of many global interventions. 
Unlike women IDPs who preferred flexible jobs closer to home, men IDPs, who considered themselves as the primary bread winner of the household, desired jobs outside their household. This study's men informants reported feeling that men needed jobs more than women because men bore more financial responsibilities than women. Jean (M): Men in Haiti have more responsibility than women, they can't just wait and see - yo paka rete ak gade. (In Haiti, the phrase yo paka rete ak gade means a person is waiting for someone to help). In Haiti under the culturally accepted practice of konkibinaj (men having more than one family), many men have and are responsible for several families (Bell, 2012; Schwartz, 2016). Although culturally women are expected to take care of the home and family; if the man refuses to support the household, then the woman becomes the primary economic provider. In Haiti, women's and men's roles are social and historical constructs (Bell, 2001, 2010, 2012). Both women and men may carry the burdens of societal expectations - men as the breadwinner and women as the keeper of the home - and suffer because of them. Due to many patriarchal societal demands, men may tend to engage in risk-taking behaviors and place themselves in danger (Enarson \& Pease, 2016). For example, men may not heed disaster warnings or may believe they are safe from impending disasters (Ikeda, 1995; Luke, 2012).

Enarson and Meyreles (2004), theorized that in most patriarcal societies, women have the triple burden of their (inside) reproductive role, (outside) productive role, and (wider outside) community role. This theory manifests itself in Haiti. The reproductive role is that of mother and nurturer; the productive role entails being a family caregiver and income generator; and as community citizens, women are caregivers of the extended family and the more vulnerable (the disabled or sick) in the community (Gender Action 
Network, 2013). These various roles also produce additional burdens on women, particularly when they are heads of households. As more women become educated and employed, their roles in society shift and they take on more responsibilities (Gabriel et al., 2016; Hossein, 2012). Most men in Haiti tend to identify with the productive family role more so than any other role (Dubois, 2012; Schwartz, 2016).

Of the men informants in 2017/18,60\% reported having a job as a critical need. Most men have more than one household due to kokibinaj (historically embedded polygyny in Haiti since slavery and the plantation era pre-1804 independence), which then forces women to become the primary caregiver as well as economic head of household. Schwartz (2016) paints a different picture of konkibinaj in Haiti. From his research, he disaggregates the concept from rural and urban points of view and posits that although kokibinaj in rural Haiti is not legal, it is different than the traditionally viewed “extramarital affair." Schwartz argues that all Haitians regardless of where they reside recognize the institution, and all women in the unions are recognized as wives. He also challenges feminist researchers (Began \& Schuller, 2009; Bell, 2001, 2010; Schuller, 2016) who decry the evils of kokibinaj and points out that this arrangement may bolster women's independence by providing women with more socioeconomic power than was previously believed. "The man provides a home and the capital necessary for his wife to engage in marketing activities and to invest in productive, labor-intensive activities centered around the household (working for wages, planting gardens and tending livestock)" (Schwartz, 2016, p. 2). Schwartz goes on to add that having a family and children then becomes a socially accepted option for some women. "The household is the mechanism of survival in rural Haiti, and it is children, that makes the household 
productive" (Schwartz, 2016, p. 10). Schwartz's counternarratives provide alternative insights into the socioeconomic arrangement of kokibinaj in Haitian society.

Female-only prorities. Regarding priorities, $75 \%$ of the women and $60 \%$ of men IDP informants felt that women and men had in 2010 post-earthquake and currently-2018 have different priorities. As shown in Figure 19 Female IDPs' unique priorities, not necessarily prioritized by men, were related to the education of their children (especially young, child bearing women), healthcare (both in terms of physical and mental health), transportation and changing the perception of passive, helpless women IDPs. Their gender-specific emphasis on education was understandable given their reproductive role in the household. Of the informants interviewed immediately after the 2010 earthquake, more women than men reported placing a high priority on the basic needs of their children (e.g., food and schooling). Most women's letters to the International Organization for Migration and camp committee meetings centered on food, shelter, and education for their children. In the following statement, Yannik (W) spoke of creating a better life for her kids as her priority: What I went through in this country Haiti, I don't want my children to go through the same thing.

Education. Haitian women are staunch proponents of the education of their children and sacrifice their personal needs to provide a better future for them (Schuller, 2016). Most schools in Haiti are private schools whose fees are paid by the student's family. Currently, in Haiti, \$175 USD can supply a child with one year's tuition, uniform, shoes, books, pens, and pencils (The Mission Haiti, 2018). However, in a country where the average wage is $\$ 1-2$ USD per day, this fee is a huge financial burden and out of reach for many Haitian families. 
According to the U.N. Human Rights Council (2009), when family education funds are limited, girls are excluded and stay home or work. In Haiti, this work is typical as that of a ti machann (market vendor) or as a restavek (live-in servant). The restavek system in Haiti is a culturally embedded practice of placing poor children either with more financially stable relatives or with rich families, with the promise of education as part of this living arrangement (Pierre, Glen, \& Tardieu, 2009). According to the Pan American Development Foundation (2009), the number of restaveks in Haiti is between 300,000 and 400,000 (59\% of whom are girls). After the 2010 earthquake, many organizations reported that the number of restaveks increased (Bell, 2012; The Lost Children of Haiti, 2010; Restavek Foundation, 2011).

Before the earthquake, Haiti's government allocated very little financial support to the education sector (Luzencourt \& Gulbrandson, 2010; World Bank, 2011). The Haitian government (2007) reported that of the 123,000 students admitted to Haitian secondary schools in 2004, only $82,000(67 \%)$ received secondary schooling, and most of those who completed their secondary education did not enroll in universities. With the state's lack of institutional strength and capacity to provide essential services to the Haitian citizens, $92 \%$ of the education sector was privatized and unaffordable for most families (World Bank, 2011). This lack of funding left many schools without supplies, management, and qualified teachers. Thus, the education sector experienced high dropout rates and low enrollment rates due to economic hardships sustained by families. The lack of general economic opportunities causes high repetition rates because once again, school fees are the responsibility of the individual families, and most often the women of the family pay them (USAID, 2017). 
The earthquake occurred midway through the 2009-2010 school year. For the remainder of that school year, the Haitian government and the World Bank designed an emergency fund that paid for teacher salaries to ensure that schools remained open. In the following school year (2010-2011), the funding concentrated on paying tuition for poor students and on school feeding programs (World Bank, 2011). Franz (2010) documented the various educational challenges that schools, and teachers faced and continued to face in Port-au-Prince. Top educators felt that long-term recovery was unsustainable without education. One educator said "The earthquake did not kill Haitians; the lack of information and education did. They didn't know what to do when the event occurred" (Franz, 2010). According to a former Minister of Education, there are about 65,000 teachers in Haiti, of whom 30,000-40,000 are poorly trained (Franz, 2010).

Discriminatory linguistic barriers add yet another layer of complication to the efficacy and equity of education in Haiti, where there is a long-protracted battle over whether to teach in French or Creole. Both are official languages, but the socioeconomically disadvantaged masses speak only Creole (Luzencourt \& Gulbrandson, 2010). Even though almost all Haitian children speak Creole, textbooks are in French and teachers are required to instruct in French. Haitian government officials continue to advocate for French as the official educational language, thereby propagating the narrative of "the poor majority" as outsiders in their own country (USAID, 2017) ${ }^{10}$. This narrative is further compounded by significant rates of illiteracy across the lifespan, as discussed in Chapter III (USAID, 2017). In my study, younger IDP women informants -

\footnotetext{
${ }^{10}$ Estimates show that between $5-40 \%$ of Haitians speak French, depending on the school level they finished.
} 
those under the age of 30 - prioritized their education. They believed an advanced education would provide more economic opportunities for themselves and for their children, not only in Haiti but especially in other countries.

Healthcare. IDP women's priority in healthcare was closely related to the unique threats their children, and they faced in the aftermath of the earthquake (e.g., cholera, sexual assault, PTSD). Although men IDPs also suffered from some of the same illnesses their children and women suffered (e.g., cholera), they may not have mentioned it as one of their top priorities since they culturally considered illness as a weakness, reserved for "weak" women. In 2010 and in 2018 the women informants felt the camps in this study provided insufficient healthcare. The following statement from Marlene (W) illustrates her frustration with her circumstances in the camp: I needed the help of the government and the hospital and did not receive any help.

Several women informants also mentioned cholera as a health concern both now (2018) and immediately following the earthquake in 2010. According to the United Nations Development Program (2016), since the outbreak of cholera in Haiti in 2010, an estimated 780,000 people have been affected by the disease, and more than 9,000 people have died as a result (United Nations Development Group, 2017). In one instance, experts determined that a U.N. peacekeeping camp was the source of the disease (Domonoske, 2016). In 2016, the United Nations admitted that it played some role in the deadly outbreak. One participant, Martha stated that she desperately needed financial help because she had family members stricken with cholera. Cholera - an infectious disease that causes severe, watery diarrhea - spreads through contaminated water and causes dehydration, and if left untreated can lead to death within a few hours (Domonoske, 
2016). The women were outraged that improved sanitation and water attainment were still issues in the camps in 2018. One informant shared that she spoke with many sources in attempts to change health and security conditions in the camp by visiting press and aid representatives, yet nothing changed. In 2010 post-earthquake and in 2017/18 the lack of transportation from the camps in Delmas, Pétion-Ville, or Canapé-Vert to other parts of Port-au-Prince presented severe health, business and educational challenges for the IDP women.

IDP women informants felt the camps were unsafe. The tents were made of cloth and easily cut and ripped. The women informants talked about how bathing and toilet facilities were usually far away and poorly lit at night. Women were put at further risk because these temporary facilities were not permanent structures and easily accessed. Women and girls were assaulted and very often raped in their tents or on the way to bathroom facilities. They formed protection groups among themselves to avoid these assaults. Gina (W) stated as women we have to take care of ourselves and our children, women are in greater danger than men. The women in this study believed assaults or rapes were not perpetrated on men, so the men were not as concerned as the women were. Gina -Koté yo pap fe violans sou gasón yo pap ezite fel sou famn yo. (assaults don’t happen on men, but those who commit the assaults don't hesitate to do it to women).

Women spoke of the loss of friends and the loss of community support that they had before the earthquake. A women informant from Canapé Vert stated before the earthquake in their small community "we lived like a family, we used to help each other with our children and sometimes took turns cooking for each other". Francoise (W) declared Nous te genyen solidarité- We were together. Many IDP informants lost family 
members who were never identified because people were buried in mass graves. The survivors had many questions and felt no one assisted them.

Women IDPs in this study believed their mental stress or depression was due to restricted personal space in the camps. Women informants felt they needed time and space to mourn for lost family members and friends. One agency director spoke of the cultural practices and rituals associated with the mourning process- the individual or family in mourning is usually surrounded by friends and other family members. People visit, bring food and console each other, unfortunately those in camps never had the opportunity to mourn properly.

Transportation. The women informants shared they often lacked money for transportation and hospital fees. Overall, $8 \%$ of my informants were women who were unable to work and said they needed financial assistance, not jobs. Another $8 \%$ of this study's informants were injured women, now handicapped, who stated that health was a priority. Overall, $75 \%$ of the women informants were also concerned with a lack of affordable and secure transportation for themselves and their family. Transportation is essential for running businesses, bringing goods to market, taking children to school, and visiting the few available medical centers (Farmer, 2012; Gender Action Network, 2013; Haiti Libre, 2017).

Women informants' emphasis on transportation had to do with two factors: their productive role as an income generator (many needed transportation for purchasing and selling goods in the market) and the distant location of IDP camps following evictions from more central areas. Women often rely on small businesses to have the flexibility 
necessary to fulfill both home and family responsibilities. Men IDPs may not have mentioned transportation as a priority because they had more transportation options.

Men in Haiti have more transportation choices than women do; besides the small buses (tap-taps; see Figure 17), private cars (camionettes), and taxis which women use when they have the funds, men are also free to choose motorcycles and scooters as alternative modes of transportation.

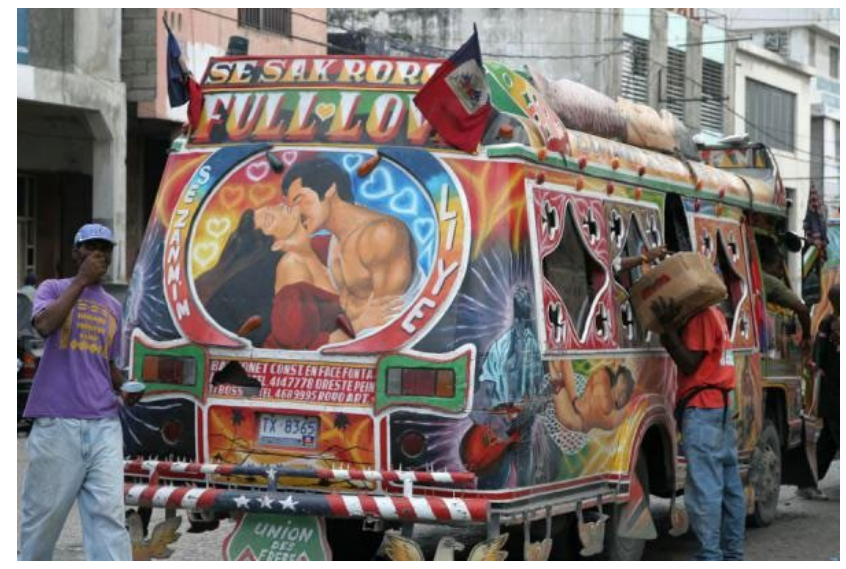

Figure 17. Image of a tap-tap in Haiti. Source:

http://www.traveladventures.org/continents/americas/tap-tap.html

Motorcycles can be a dangerous option in a metropolitan city like Port-au-Prince without traffic lights, marked road lanes, or speed limits, and many unlicensed drivers (Haiti Observer, 2017). McLaughlin and Rogers (2013) reported on the proliferation of motorcycles used by many young men as an inexpensive and fast mode of transportation. However, they noted that the popularity of these motorcycles led to an increase in minor as well as severe injuries.

Passive victims versus strong survivors. In addition to these three women-specific priorities- the education of their children, healthcare (both in terms of physical and mental health) and transportation, women were also genuinely concerned how the media, 
NGOs and international agencies framed IDP women as passive victims who needed help as opposed to the image of men as strong survivors. Irma (W) felt it was important after the event (the earthquake) that women in the camps were not viewed as victims but as valued people. Data does not always capture the essential activities of both men and women, thus leading to assumptions discounting women's roles and needs within financial livelihood systems. Haitian women micro-entrepreneurs navigate their livelihoods, sometimes despite $\mathrm{NGO}$ and government strategies and policies that continue to treat them as beneficiaries of largesse or as victims rather than as principal actors driving the national economy (Beasley, 2012; Brun, 2012; Farmer, 2012). In a postearthquake survey conducted by Oxfam, Haitian women "emphasized the need to restore livelihoods rather than receive relief. They felt that outsiders were not listening" (UNDP, 2011). One of my director informants believed the Haitian government facilitated and disseminated the narrative of women as victims to drive funding. Several directors in this study found after the earthquake many organizations drove the disaster narrative in Haitito say that things were not improving to keep funds flowing.

Male-only priorities. As shown in Figure 19, men IDP's only unique priority, not necessarily prioritized by women in this study, was related to their desire to be politically active. In this study the IDP men were more inclined to be politically active postearthquake more so than women IDPs. Unless they had children, lost a spouse and became the family's primary caretaker, men IDPs were less constrained by familial responsibilities. Many IDP informants experienced unequal distribution of food, tents and prélas. They viewed these disparities as power grabs from those IDP committees with more power and influence than others. An informant in a Delmas camp believed because 
the Pétion-Ville camp was in a more affluent area the IDPs had more supplies and resources because "They knew people". The IDP men informants believed being politically active would provide additional resources in the camps or access to livelihood opportunities such as jobs in reconstruction and entrée to permanent shelter before others who were not politically involved. In 2010, according to an IDP informant aid, food kits, tents and other items that the government received for the relief of the masses were stocked away for use to gain votes during the elections.

The Haitian populace- especially men have long held the belief that politics could provide wealth and power. Their mistrust of the elite and government officials came from years of watching those in power prosper by exploiting the country's resources (Fan, 2013). A community leader in the Delmas camp stated They (the government) think that the masses have nothing good to offer. They call on the big Chiefs of state who are like them ... They think that only big heads have something to offer. Researchers (Dubois, 2012; Dupuy, 2010; Fan, 2013; Fatton, 2010, 2011) contended politics in Haiti has been historically viewed by the elite or those in power as a private opportunity to enrich themselves not as an opportunity to serve the Haitian public. State resources used for private gain by the $5 \%$ elite left $95 \%$ of the citizenry fighting for the resources left over. The men IDP informants saw the presidential election as an opportunity for remuneration. After all, if a candidate and their party wanted to win, votes could be purchased.

Due to the January 2010 earthquake, national elections scheduled for that February were postponed until November. Following opposition charges of fraud, the government upheld an Organization of American States (OAS) recommendation 
concerning the run-off election and replaced the government candidate, who had come in second by a narrow margin, with Michel Martelly, a popular musician and businessperson (Taft-Morales, 2011). Martelly won the March 2011 run-off and faced hostile opposition in a fragmented legislature. Overall, state weakness, international interference and instability characterized Haitian politics (Schuller 2016). To Haitians, the intervention of external forces signaled a lack of trust in Haitian capabilities. Once again, the Haitian population regarded the election process with distrust. Figures 18 and 19 recap this study's findings on IDP priorities.

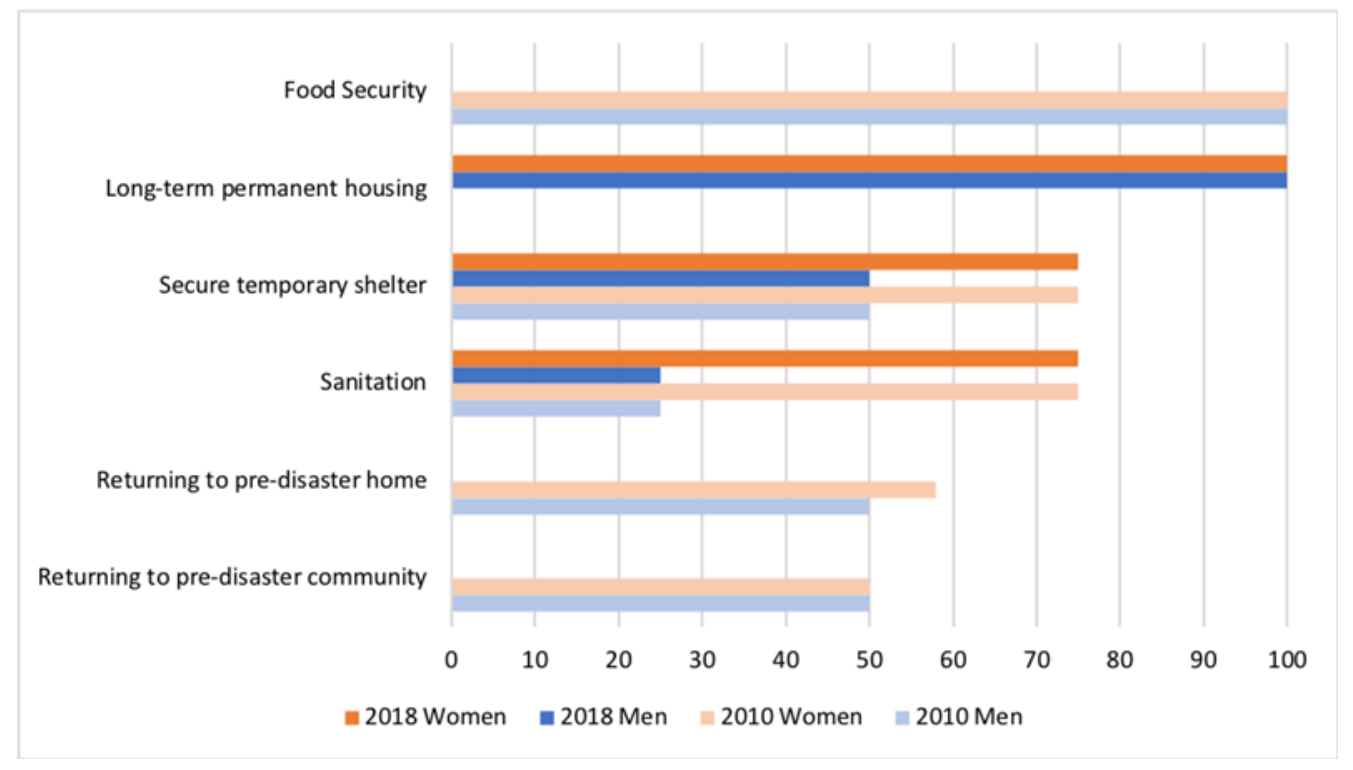

Figure 18. IDP Priorities: Similarities 


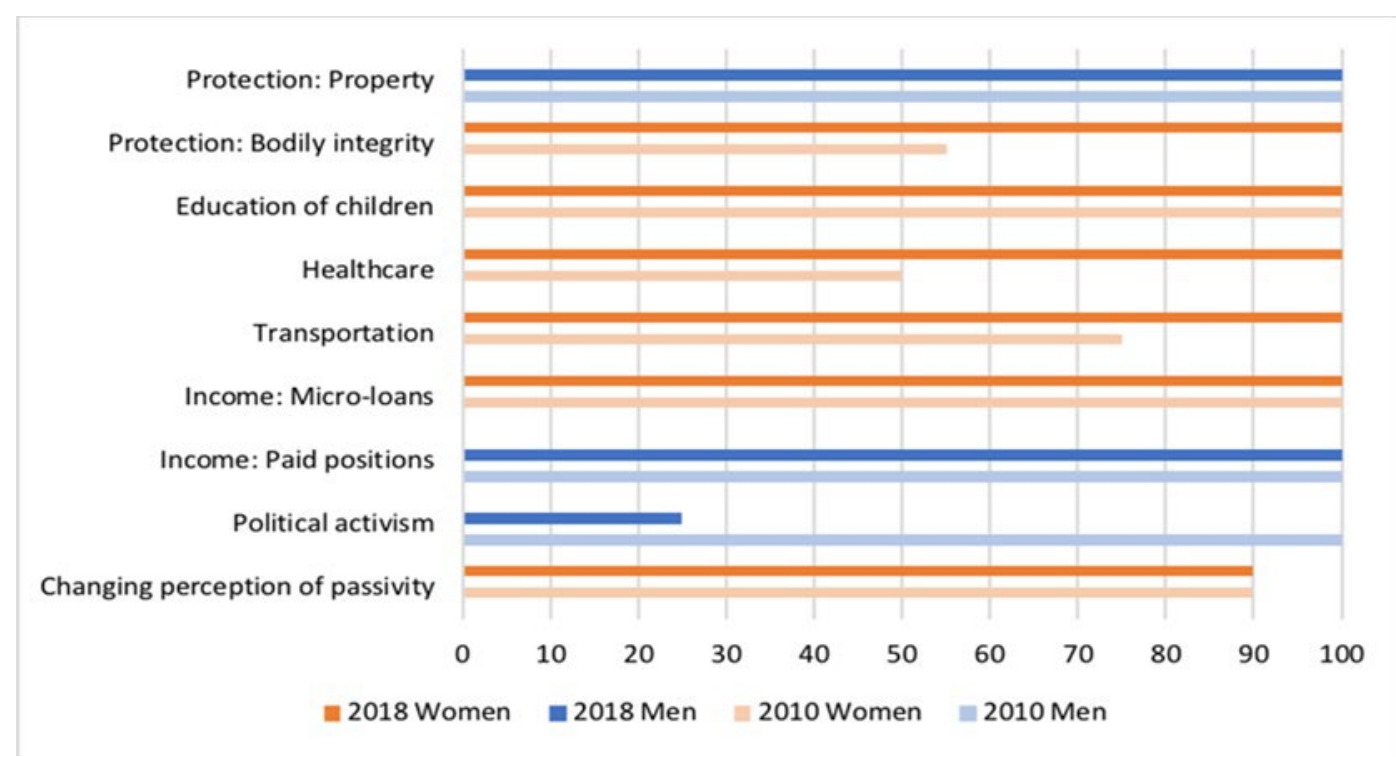

Figure 19. IDP Priorities: Differences

\section{Recap of Priorities Summary}

The IDP priorities similarities (Figure 18) illustrates the most frequently reported priorities reported by this study's IDP informants in Haiti, both immediately following the 2010 earthquake as well as eight years (and two hurricanes) later, in 2018. Immediately following the earthquake in 2010 , the top reported priorities of both women and men IDP informants were (a) ascertaining the safety of their family members, (b) returning home with their families, (c) shelter security and stability - camp conditions were generally overcrowded and poorly lit; the tents were easily flooded and torn, exposing IDPs - especially women - to violence and rape, (d) access to food, and (e) sanitation-latrines and bathing facilities were far from most IDP tents.

Income generation (e.g., financial aid, microcredit) was mentioned as a shared priority only in 2018. That said, the types of employment sought by the IDPs varied by gender: men sought paid positions while women focused on self-employment. Women 
often rely on small businesses to have the flexibility necessary to fulfill both home and family responsibilities.

Although, both men and women IDP informants expressed that security within the camp was a priority in 2010 and in 2018; men focused on the safety of their property while women feared for their personal safety. Only women IDPs reported education, healthcare-especially cholera, and transportation as a top priority - both in 2010 and 2018. The camps in this study provided insufficient healthcare, and the women IDPs lacked money for transportation and hospital fees.

Political activism was a priority reported only by men IDPs in 2010 which, when studied along with factors hindering IDP participation (see Figure 20), is a difference due in large part to women being excluded from camp committees. Perhaps related to this finding, only women expressed changing the perception that they were passive victims as a priority.

\section{Priorities from the Perspectives of Policymakers}

Policymakers' perspectives of IDP priorities were similar to that of the perspectives of the IDPs. They mentioned sanitation, security, and income producing activities as the top three priorities. Some international policymakers thought that the Haitian government was exaggerating instances of rape and assaults on women in IDP camps to ask for more funding from the international NGOs.

Haiti is a country where there are always problems, and it all became worse after the earthquake (Mark, director of a Haitian nonprofit specifically working in IDP camps).

I asked policymakers and international officials what they observed to be Haitian IDP priorities in 2010 post-earthquake and found that all agreed on three priorities that 
were common to women and men: the lack of (a) sanitation, (b) security, and (c) incomeproducing activities. In the words of two of my study informants (using pseudonyms to preserve anonymity):

Charles (NGO director): I believe the top three priorities for women were sanitation, lack of security and lack of income generation. The top priority I saw men needed was a job. One of the main programs used to help IDPs earn money was debris and garbage removal. The Haitian government resisted the offer of help from other agencies so that IDPs could earn money.

Sally (NGO director): I came to Haiti after the earthquake and what I was hearing from people was I don't need water or food I need a job. And that was sort of the inspiration behind creating the for-profit side of our non-profit. Nobody ever thinks about job creation, especially for women.

Security, especially for women. According to my informants - officials, as well as IDPs - IDP camps were constructed and designed without taking into consideration diverse security needs, such as lighting and placement of latrines and showers, which resulted in women being put at even greater risks of violence. Miriam (manager) believed women IDPs worried about and experienced more violence than men. IDP women and grassroots women's organizations decried the increase of gender-based violence to the Haitian government and all entities working in Haiti (Cullen \& Ivers, 2010; Eves, 2011). NGOs, international agencies, and the Haitian government could not agree on the importance of camp security, the number of incidences of rape reported, how perpetrators should be held accountable, and which entities should provide security in the camps 
(Amnesty International, 2017; Institute for Justice and Democracy in Haiti \& Bureau des Avocats Internationaux, 2010). The same issues of lack of adequate reporting systems and security forces as well as dangerous camp environments persisted in 2018 (Amnesty International, 2017; Doctors Without Borders, 2017; Haiti Libre, 2017).

Sam (NGO lawyer): NGOs were downplaying those reports of violence. I'm trying to be fair to everyone but realizing that I won't be fair. The NGOs felt that the numbers of rapes weren't supported and that the news was playing along with the demonization of Haitians and the women were saying this is what is happening to us and we need this added in the meeting, grassroots groups wanted to control the narrative which they previously could not do.

This perspective is not without dissent. Schwartz (2017) argued that NGO reports of gender-based violence were inflated to induce donor assistance. In 2011, Schwartz attempted to quantify the amount of money donated for rape causes and was unsuccessful. However, in 2010 he noted that donations to MADRE (an international women's rights organization) - the international arm of KOFAVIV in Haiti saw their donations increase from $\$ 800,000$ USD in 2009 to $\$ 2.9$ million USD (Schwartz, 2017). Schwartz continues his radical stance on the "business of the humanitarian aid industry" stating there are many international NGO and Haitian NGO financial abuses in Haiti. He also accuses various Haitian government administrators of manipulating human rights abuses as a political propaganda tool (p. 203). Schwartz (2017) urged humanitarian aid agencies working in Haiti to confront recipient deceit and plow through the dishonesty to help as many needy beneficiaries as possible. He asserted that the structural processes of 
many aid agencies created victims of the poor, to receive aid, they had to fit a certain profile - usually that of viktim (victim).

Food insecurity. Charles (director) observed that some men, due to multiple families, were more selfish than women. He said:

If the food was given to a man, the woman he is with may not see the food. When food aid is given to a woman, the family is fed. Some men food and voucher recipients also sold the food and vouchers to earn money.

Research shows that after a disaster in cultures in which polygyny is a culturally accepted practice, when male heads of household are designated recipients, they distribute rations to the various families under their care. Unequal food distribution can lead to increased malnutrition and food insecurity for women and children (Gender Action Network, 2013; Inter-Agency Standing Committee, 2017). Failed gender-based policies such as food aid coupons designed by the United Nations, which were originally designed to give women independence from men, instead created additional challenges to women IDPs' security in the camps (Fatton, 2011; Kaussen, 2011), very often putting women at risk of additional violence (Dodd \& Espinosa, 2010).

Charles (director) shared that when his organization delivered food to many camps, the men were quite aggressive: We weren't sure if women and children received food. We then devised a system to give to women; the men then shoved the women. Food distribution was an imperfect system. According to many of my informants, NGOs and international organizations would not provide aid to camps unless committees were formed. NGO-directed clusters aimed to provide services to the diverse camp populations: women, men, families, seniors, and the disabled (ACAPS, 2018; CEPR, 
2013; World Bank, 2011). Self-selection resulted in few women on the committees; either by bullying towards women IDPs or the tendency for women not to voice their concerns publicly, IDP men became the aid power brokers. This unequal distribution of representation inhibited many women from voicing their concerns and needs. Maddie (a nonprofit director) offered a unique perspective on the held belief of timidity by IDP women:

Women were preoccupied post-earthquake in 2010 and to some extent today in 2018 with providing food and shelter for their families. Survival comes first. Committee meetings were not important; many women who attended felt nothing (results) came out of those meetings.

This perception of government and NGO inaction supports the same views that IDP women informants shared during their interviews with me.

Sanitation challenges and the cholera epidemic. Many IDP camps did not have water or sanitation facilities to overcome the cholera outbreak following the 2010 earthquake (Bloem \& Miller, 2013; Farmer, 2012). According to the United Nations Development Program (2016) since the outbreak of cholera in Haiti in 2010, an estimated 780,000 people have been affected by the disease, and more than 9,000 people have died as a result (United Nations Development Group, 2017). In one instance, experts determined that a U.N. peacekeeping camp was the source of the disease (Domonoske, 2016). In 2016, the United Nations admitted it played some role in the deadly outbreak. The Haitian government and international health organizations implemented programs that highlighted improved sanitation including the WASH program (water, sanitation, and 
hygiene). Recent cholera epidemics after Hurricane Matthew highlighted the ongoing vulnerability of the population to the disease (Center for Disease Control, 2018).

Gender differences in IDP priorities. Charles (agency director) stated that the Haitian government disseminated the disaster narrative, specifically the plight of IDPs, so that funds and donations would continue flowing into the country. Some benefits that emerged from this manipulation were the creation of free medical service programs for women (Schwartz, 2017). Other organizations, however, felt that this narrative was not helpful. For example, grassroots women's organizations Komisyon Fanm Viktim Pou Viktim (KOFAVIV) - the Haitian arm of the international women's rights organization MADRE - had women advocates working with rape survivors in IDP camps, and Haitian women of Miami (FANM) challenged the stereotypical images presented by the media and by many NGOs of poor Haitian women as passive victims in the disorganized and chaotic environments of IDP camps or communities.

They drew on the Haitian tradition of lacou ("one helping the other"), coumbite (collective work groups such as adaptive cooperation in farming and housework in the community), and tontines (savings groups through community lending systems; Beasley 2012; Hossein, 2012; Rahill, Ganapati, \& Mukerji, 2014). Haitian women circumvented barriers to formal microloans lending by practicing sabotaj ${ }^{11}$ - seeking grant credit, bartering, or negotiating businesses with members of these unofficial lending groups. This quasi-secret community of lenders and borrowers (untaxed and unrecognized by governments) enabled women to sustain their families and small businesses.

\footnotetext{
${ }^{11}$ Sabotaj is the Creole word for the French word "sabotage," meaning subversion.
} 
The following table recaps the IDP Priorities according to this study's policymaker informants.

Table 3

IDP Priorities According to Study Policymaker Informants

2010

2018

Similar Priorities
Food security
Sanitation/Cleanliness
Human rights as Haitian citizens
Pifferent Priorities
domestic violence
Education of children
$\begin{aligned} & \text { Incolthcare (both physical healthcare, especially for cholera } \\ & \text { victims; and mental healthcare, especially for victims of sexual } \\ & \text { assault and domestic violence) }\end{aligned}$

A comparison of this table (Table 3) with the IDP priorities (Figures 18 and 19) shows that the policymakers' perceptions of shared priorities (by both women and men) were similar to that of the IDP's shared priorities, especially with respect to food security, security, sanitation/cleanliness and income generating activities. What they failed to see 
was the IDP's shared desires to return to their pre-disaster homes and communities, perhaps in part because of their perception that the IDPs.

Different priorities. There seems to be a broad agreement in terms of genderspecific priorities between the policymakers and the IDPs as well. However, policymakers were not informed about IDP men's emphasis on protection of private property or on political activism. Neither were they informed about women IDPs' needs with respect to transportation and changing their perception as passive victims.

\section{Factors That Enabled or Hinder Women IDPs' Participation in Recovery}

The second aim of the study was to determine factors that enable or hinder IDP women's participation in decision-making during recovery processes. This aim dealt with factors that either give women opportunities or that hinder them from expressing their unique needs and priorities in the rebuilding process.

Some researchers posit that Haitian women hesitate to exert their voices during recovery processes in part due to their standing within their society (i.e., subordination by men, some of whom have multiple partners; acceptability of violence against women and girls), and in part because they feel impeded by a lack of trust in their government or by traditions of their faith and spirituality (Cullen \& Ivers, 2010; Cunningham, 2012). Other researchers assert that women, especially IDP women, are vocal defenders of their rights as citizens to have shelter, education for their children, and livelihood opportunities despite the socio-cultural and political forces conspiring against them (Bell, 2010; Concannon \& Lindstrom, 2011; Schuller, 2012, 2016).

Women IDP infromants-50\% in this study voiced their priorities to decision makers less than men IDPs $-60 \%$ both in short- and long-term recovery. Still, however, 
women IDPs who lived in formal camps made efforts to participate in decision-making processes in recovery. However, their participation was not in formal participatory settings (e.g., U.N. Cluster meetings). Rather, it was limited to participation in informal settings (e.g., camp committee meetings, church meetings) at the neighborhood level, which was closer to them.

There were six broad factors that affected women IDP's participation in decision making processes in the post-earthquake context to inform authorities about their priorities (see Figure 20): (1) organizational factors (e.g., diverse range of organizations with diverse organizational cultures); (2) formal institutional factors (e.g., lack of participatory mechanisms customized for IDPs); (3) policymaker-related factors (e.g., stigma towards the IDPs); (4) IDP related factors (e.g., lack of trust); (5) place-related factors (e.g., lack of access to transportation); and, (6) civic networks or grassroots organizations-related factors (e.g., women's groups). Each of these is explained below.

Organizational factors (barriers). Haiti is a failed state which cannot even provide its citizens with basic services. Hence, besides the Haitian government, there were a number of international and national NGOs attending to the needs of IDPs during the recovery period. The diversity of recovery actors itself made it difficult for the IDP women to participate, especially those who lived in informal camps (e.g., those that were not managed by the Haitian government or the international NGOs), as they did not know who to turn to for their specific problems. 


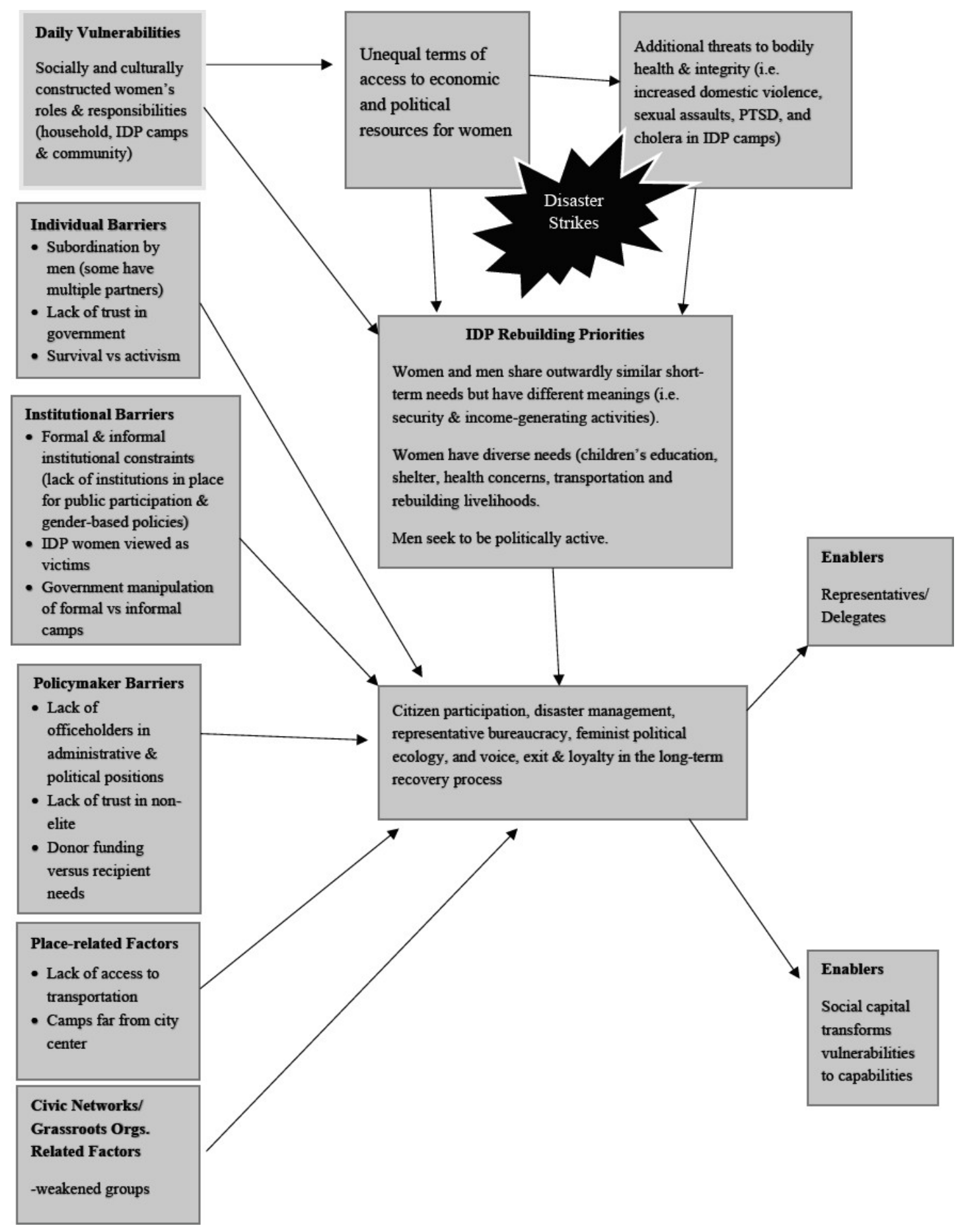

Figure 20. Factors affecting IDP participation. 
In their responses to queries about whether the government had helped in recovery, informants rarely used the word gouvenmen but instead used yo ("they") and moun ("people"). The cultural uses of the words yo and moun in Haiti denote the people in power. One woman from Canapé Vert exclaimed, moun pa aide ("no one is helping"). Another woman interviewed in Delmas said, yo pas ede ("no one helps"). A male participant from Pétion-Ville stated, moun qui responsab nan peyi a pa fé anya sa ("people responsible in the country do nothing").

When I asked interviewees the difference between how the government acted before and after the earthquake, they made statements such as "What government?" "We have no government." "We feel as though we are not in any government." A 2015 report by the World Bank concluded that a social contract ${ }^{12}$ was missing between the government of Haiti and its citizens. Since the overthrow of dictator Jean-Claude Duvalier's government in 1986, Haiti has had 18 changes in leadership. These oftenvolatile political upsets paved the way for weak governments sponsored by an elite group in favor of few government regulations and unfettered import policies. Despite years of NGO and foreign aid, Haiti (also known as "the Republic of NGOs") is constantly short of both cash and professional civil servants (Lendman, 2010). Researchers argued the disenfranchisement of the Haitian government by NGOs contributed to the state's failure (Hallward, 2010; Torgman, 2012; Wilentz, 2013). After the 2010 earthquake, the failed Haitian state could not provide infrastructure, the rule of law, or services such as health and education to its citizens. The Haitian populace trusted that the government would

\footnotetext{
${ }^{12}$ Jean Jacques Rousseau (1762) defined a social contract as an agreement between a government and its citizens whereby rights were granted and protected.
} 
assist with critical needs such as shelter, food, medical care, and water; however, the Haitian government could not assist its citizens. Although the government suffered crippling losses both around infrastructure and personnel, the lack of acknowledgement that IDPs were suffering was inexcusable (Bell, 2012; Duremy, 2011; Farmer, 2012; Horton, 2012; Schuller, 2014).

As a failed state, the Haitian government did not have any formal mechanisms in place to be in contact with or involve the IDPs in decision making processes. It did not guarantee rights to the IDPs either. Of the study's IDP informants, $90 \%$ felt abandoned by the Haitian government and by the international agencies that left the country. Lawrence vented his frustration at the government's inaction: It is the government's responsibility to help us and give us what was promised in the elections. The IDPs in this study mistrusted the Haitian government and refused to acknowledge that the government after the 2010 earthquake, suffered crippling losses. Daniel was the only informant from this study to sympathize with the Haitian government: The government wanted to help us but did not have the means. All but one government building still stood, and hundreds of government employees were killed. The earthquake demolished the already fragile government, law enforcement, judicial, and health systems. The government's ineffectiveness further eroded citizen trust (Bell, 2012; Duramy, 2011; Horton, 2012; Schuller, 2014). On a similar note, a woman community leader in 2010 stated: The confidence we had in the state (government) has gotten worse.

The IDP informants felt that in the quake's immediate aftermath (2010 to 2011), the burden to help the public was solely the responsibility of NGOs or international agencies, and that the Haitian government was absent. A man community leader from 
Delmas stated, Nou pas gen konfyans na gouvenman ("We do not trust the government"). Another man community leader reported: Since the earthquake, the government has ridiculed the people. The government has fooled us because they have no plans, no goal to help the people who are suffering. After the earthquake, many of the respondents felt the government and the aid agency procedures hindered rather than helped the public's recovery. Expressed by many as: leta pa ge plan ofisyel pou komunote ("the state has no official plan for the community"). Another Canapé Vert informant stated leta menmen li pou mete moun deyo sou terre ("The state itself was putting people off the land").

It is also important to note that the international recovery process by NGOs, international aid organizations, and the Haitian government was often chaotic. After the earthquake, the international community continued to undermine the Haitian government, governance, and its people, as witnessed by the creation of the Interim Haiti Reconstruction Committee (IHRC; Dubois, 2012). To the Haitian people fighting for an independent government and the right to create its unique version of governance, the reconstruction pronouncements by international organizations constituted a total disregard for Haiti's capabilities. Sam, an NGO lawyer, explained this as follows: I was critical of the Haitian government, I felt they could have exercised more leadership. On the other hand, there were constraints around that from the international community - the international agencies, $N G O s$, and member countries of the Interim-Haiti Reconstruction Committee (IHRC) were not willing to listen to anyone, particularly Haitian voices.

And thus, on April 1, 2011, 40 popular Haitian organizations called for the dissolution of the IHRC committee. These organizations went on to bluntly state: 
Our analysis and evidence leads us to conclude that Haitian society continues to be locked into the same traps of exclusion, dependency, and ignorance of our strengths, our resources, our identity. The structures of domination and dependence are reproduced and reinforced by the constellation of agencies, including MINUSTAH (the United Nations), the IHRC, and large international NGOs. (Edmonds, 2012, p. 342)

In 2017, the Haitian government expelled 300 NGOs operating in the country (Maxime, 2017). According to the newspaper, Haiti Sentinel "Minister Fleurant said that the 257 organizations had violated a September 14, 1989 decree regarding their functioning. Fleurant, the Minister of Planning and External Cooperation at the time, said that these institutions must finance what the Haitian people needed and not what they, themselves, considered to be necessary. "And the interventions must be carried out, in front, by the leadership of the government" (Maxime, 2017, para. 3). Although as of 2018 the Haitian government was creating additional regulations for NGOs operating in the country, there remained a grave lack of coordination between the government and those NGOs (Patterson, 2018).

Formal institutional factors (both barriers and enablers). Institutional factors were both barriers and enablers with respect to women IDPs' participation in decision making processes in recovery. Institutions that were developed for recovery were not reflective of women IDP's unique needs and strengths (e.g., Haiti's PDNA vs Nepal's PDNA which emphasized the need for a gendered approach to recovery). The international NGOs, on the other hand, made efforts to establish formal mechanims to allow for IDPs to voice their concerns. The most notable of such mechanisms were the 
U.N. Cluster Meetings and the IDP camp committees. After the 2010 earthquake in Haiti, a Post-Disaster Needs Assessment (PDNA) was developed by the World Bank, the Haitian government, the Inter-American Development Bank, the United Nations system, the European Commission, and the Economic Commission for Latin America and the Caribbean, which enlisted 200 various national and international experts (The Government of Haiti and the World Bank, 2010). This PDNA assessed Haiti's postearthquake economic damages, losses, and needs. The experts separated into eight teams covering the following domains: governance, environment and risk and disaster management, social sectors, infrastructures, production, cross-cutting themes (youth, gender, vulnerable persons, employment), regional development, and macroeconomic analysis. These PDNA teams examined the earthquake's impact on financial performance, employment, and poverty. The outcome of these efforts was an assessment of damages at $\$ 7.8$ billion USD. The PDNA's recovery needs section took into account the activities of rehabilitation and reconstruction, but failed to formulate specific plans for women and other marginalized communities.

My analysis suggests that most of the programs and assessments mentioned did not address women's priorities, especially IDP women (Bell, 2010; Cullen \& Ivers, 2010; Duremy, 2011; Gender Action Network, 2013; The Haiti Equality Collective, 2010). In 2010, The Haiti Gender Shadow report (The Haiti Equality Collective, 2010), a collaborative report produced by grassroots and international women's groups, challenged the PDNA's lack of integration of women's priorities, views, or voices in its evaluations. According to this report: 
Women, youth, disabled persons and a host of other identified "vulnerable populations" in Haiti often play key, yet "invisible" roles in post-disaster recovery and reconstruction. The Haitian government, foreign governments, international donors and INGOs have difficulty in formally recognizing, analyzing, quantifying, differentiating or implementing the valuable contributions of such groups. Hence, key cross-cutting issues such as gender-based violence, gender inequality, age inequality and socio-economic disaggregated data are often placed on the back burner, without formal financial or planning support. (p. 38)

Once again in 2013, the Gender Action Network provided an in-depth analysis of the WB- and IDB-funded reconstruction and long-term recovery projects across Haiti's public sectors entitled "Building Back by Half." This report tackled the financial opportunities and challenges associated with reconstruction and recovery programs in post-earthquake Haiti. In this iteration - like its 2010 critique of the PDNA - this report found that women's issues of livelihood funding, educational opportunities, healthcare, and housing needs were still overlooked (Gender Action Network, 2013). For example, the IDP relocation program $16 / 6$, which gave families in six camps $\$ 500$ USD each to move into housing across 16 rehabilitated neighborhoods, was hardly sufficient to rent a bare room for one year. However, despite the lack of electricity or sanitation, women reported that they felt safer in these dwellings than in tents or tarpaulins (prélas) in the camps (Gender Action Network, 2013).

In his assessment of the Post Disaster Needs Assessment (PDNA), Haiti's Prime Minister Bellerive (2010) contended that the analysis of Haiti's short-term rehabilitation needs, and reconstruction led to the development of the eight essential themed sectors 
listed above. These sectors were led by multi-national directors who then developed cluster teams. These cluster teams were tasked with creating a multi-sector review of damage and losses as well as an action plan for the identification, recovery, and rebuilding needs from 6 months to 10 years (The Government of Haiti and the World Bank, 2010).

There were two critical issues with these cluster meetings. First, many cluster meetings involving the various sectors such as infrastructure, housing, and healthcare took place in the United States or Canada, effectively excluding Haitian government officials. Second, local sector cluster meetings in Haiti were conducted in English or French, effectively excluding IDPs and grassroots organizations. One U.S. informant very familiar with Haiti labled this practice of limiting the Haitian participation as blandization ("whitening the process"). Local cluster meetings were initially designed as collaborative opportunities to adress short- and long-term recovery needs such as shelter, food, sanitation, and water with the Haitian government ministries, IDP camp committees, and grassroots organizations.

The Cluster Meetings were open to the public. Yet, they were not very inclusive of the IDPs in general, in part because they were mostly held in English or French (that are not spoken by the masses) and in part because they were held in places that were difficult to access and even intimidating (e.g., heavily guarded UN Base). Hence, most U.N. Cluster meetings were attended by representatives from the Haitian government and the international or national NGOs, without a single IDP or a community leader.The cluster meetings originally designed as collaborative opportunities did not fulfill their 
mission. The IDPs in this study-especially women reported feeling that collaborative activities did not exist.

According to many of my informants, NGOs and international organizations would not provide aid to camps unless committees were formed. My women IDP informants reported that most committees consisted mainly of men. When women spoke up, they were often discouraged at the lack of progress. NGOs and international agencies designated most camp committees as the unofficial "voice" of IDPs residents in those camps. According to the Global Justice Clinic (Louvri, 2012), some camp committees such as the J/P Haitian Relieve Organization (J/P HRO) in Pétion-Ville morphed into complaint mechanisms used by camp dwellers. In the J/P HRO camp, both MINUSTAH and the PNH (Haitian national police) had offices inside the camp and conducted some patrols. These security patrols were deemed to be ineffective by camp dwellers since rapes and other violent attacks took place regardless of MINUSTAH or PNH proximity. Denise (W), one of my informants, reported that the camp also had some informal resident-run security patrols: The state was useless; the victims had to help each other and defend themselves.

As reported by the women informants, most IDP camp committee members were men. A Haitian government informant interviewed in 2017 noted that some camp committee members - especially in the quake's immediate aftermath - used food supplies as a means of rewarding those close to them as well as bribing or coercing camp dwellers (usually women and girls) willing to provide services, including sexual "services," to the committee members. Horton (2012) reported that inconsistent access 
to food and economic opportunities in many IDP camps increased sexual exploitation of women and girls. Horton (2012) noted:

In some camps, where male dominated committees control aid distribution, women have been forced to negotiate sexual favors to meet basic needs and obtain access to supplies. More broadly, women leaders link post-earthquake economic hardship to a rise in the number of women and girls engaging in sex work. (p. 302)

Still, however, women IDPs who lived in formal camps were able to voice their concerns in rather camp committee meetings (although they thought nothing came out of their participation). Women IDPs who lived in informal camps did not even have much of that opportunity. They were mainly limited to participating in church meetings.

The actual results the IDPs in this study sought were camp security, improved sanitation, healthcare access, education, and rebuilding aid for existing or new housing. I asked the informants whether they communicated with Haitian officials or NGOs regarding their priorities post-earthquake 2010 and if those priorities were addressed. Of the women informants, $42 \%$ said they told officials via camp committee meetings, and that although the NGOs provided food, water, and tents, the women did not see an improvement in the camp environment or feel that their long-term needs of returning home were being supported. In 2010, 58\% of women informants did not speak to officials, and said they felt nothing would come of speaking up. These women observed that when others spoke up nothing changed, as did $40 \%$ of men who reported that they did not inform officials because they felt nothing would happen if they did. Of the $60 \%$ of men informants who spoke out, most were disappointed by government ineptitude. 
Daniel's (M) statement is an example of their disappointment: Officials came by for information about what we needed and then nothing. I thought they had the means to help.

In 2018, the absence of public sector goods such as lighting, bathrooms, and bathing facilities, and the lack of police presence still contributes to insecurity in Haiti's IDP camps (Cohen, 2017; Hoeffler, Honore, \& Gage, 2017; International Organization for Migration, 2018). IDPs did not experience or "see" (wè, frequently used in IDP answers) real outcomes.

IDPs wanted to participate and reported feeling that Haitian laws should strengthen their access to participation, so they can better voice their priorities. Most of the men said that they did not need the Haitian government to be involved and preferred neighborhood committees designed by international agencies, which would assess their needs and create jobs. While my informants viewed the government's 2010 and 2018 recovery efforts as ineffective, some IDPs remained hopeful that the government would intercede on their behalf. Overall, in $2017 / 18,42 \%$ of women and $70 \%$ of men informants felt the Haitian government should have committees investigate their living conditions as well as allow IDPs a voice in recovery.

Policymaker-related factors (barriers), There were several policymaker related barriers. First, Haitian policymakers, who are mostly wealthy, educated (mostly outside Haiti) and politically connected men, treated the IDPs, both women and men, as invisibles. There was a consensus across all the study's informants that the government (including the officials) did not recognize the existence of the Haitian populace (moun invisibles). 
The IDPs endure a great deal of sociological stigma around living in a camp, and describe their existence as being moun invisibles (invisible people). According to my findings, many women IDPs interviewed for this study still feel they are invisible actors moun invisibles - and thus often voiceless in the long-term recovery process. When asked why the use of the word "invisible," many informants reported feeling that the Haitian government and international aid agencies treated them not as active participants in their recovery but solely as numbers or program recipients. Delving deeper into this perception, I found that many informants responded to NGO or outside agency surveys probing their needs yet experienced no positive changes within the camps because of their participation. The moun invisibles sentiment is difficult to refute when the Haitian government and international agencies could not provide a valid estimate of the number of IDPs after the 2010 earthquake. IDP estimates after the quake ranged from 1.5 million to 2 million, depending on the organization reporting and the date of the report (IJDH, 2012; CEPR, 2013; Happel \& Yaffe, 2017; Internal Displacement Organization, 2017; International Organization for Migration, 2018).

When asked whether NGOs and the Haitian government assisted the IDPs with recovery priorities, a woman IDP informant Michele described the camp in Delmas where she resided as more disadvantaged than a camp in Canapé Vert. Michele stated she was told that Canapé Vert was a wealthier neighborhood. In her Delmas camp, "Only the poor lived here. We are invisible" (c'est moun invisibles nou ye). The following 2010 committee letter (see Figure 21) from Block 7 in Camp Corail sums up the IDP moun invisibles sentiment (International Organization for Migration, 2011). 

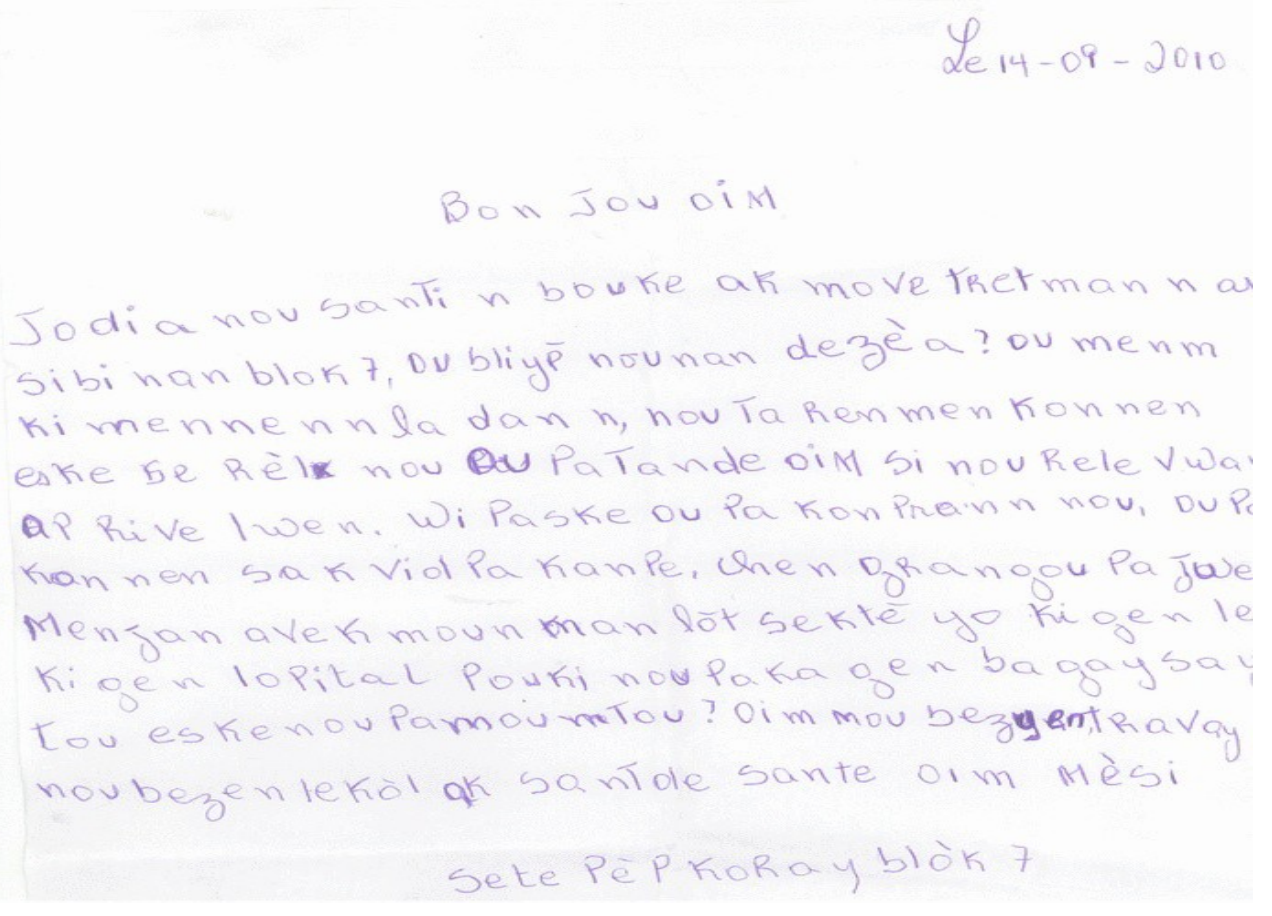

Figure 21. 2010 camp committee letter. (International Organization for Migration, 2011) This letter reads:

There wasn't enough assistance from the IOM. We feel horrible because of the treatment we have received in Block 7. You (government) forgot all the IDPs and abandoned them in this desert. If we yell loud enough, will that help? We have no food or medical care others have a hospital, and we don't. Aren't we people too? We need to work and a school for our children.

This letter in Figure 21 illustrated the frustration and despair felt by IDP women and men after the 2010 earthquake (goudougoudou in Creole). In the quake's aftermath, they believed the Haitian government would come to their aid. 
The interviewees believed that, according to the government, the only Haitians who mattered were the elite. In 2010, a man who was a community leader shared: They don't see us, the masses, but take care of themselves. Overall, $90 \%$ of this study's IDP informants held the belief Haitian officials and the elite seemed to be more concerned with two things getting funding from donors than serving the Haitian people, and looking good in the eyes of donors by showing that they were doing something with the IDPs.

The IDPs who lived in informal camps not managed by international NGOs or the government especially felt invisible in the eyes of policymakers. Some researchers argued that the Haitian government as well as some NGOs trampled on the rights of IDPs by relocating them to other camps or by evicting them from camps with no place to go (CEPR, 2013; Concannon \& Lindstrom, 2011; Corbet, 2014). The Haitian government and several NGOs created distinctions between official IDP camps such as Camp Corail and unofficial camps such as Canaan. These distinctions were designed to decrease the official number of IDPs and to justify camp closures (Kushner, 2017; Richard, 2012). NGOs officially managed the formal area known as Camp Corail just north of Port-auPrince, allowing little participation from the IDPs living within its boundaries. Several officials in this study affirmed the infrequently investigated use of the label formal versus informal camp (labels used by the Haitian government, NGOs and international agencies).

As of 2018, the percentage of women who voiced their current priorities has changed. When interviewed again 2018, informant Helene (who participated in 2010) had still not given up and continued to speak to government officials. When women IDP informants were asked whether they currently informed officials of their 2017/18 
priorities and if they felt heard, $75 \%$ reported that they saw no action taken. Helene's statement is a sentiment held by many women informants: I believed I informed the Haitian government via the camp committee after the earthquake in 2010. Although I felt listened to, nothing changed. In 2018, regardless of their previous experiences, $84 \%$ of the women continue to speak up in camp committee meetings. Of all the women IDP informants in $2018,25 \%$ of those who spoke out reported that they believed that officials dictated what they needed rather than listening to IDPs. This perception was confirmed when for example women would ask for financial assistance and were instead given a token gift. Marlene's (W) statement reflects the lack of action taken by officials: When I spoke, there were many people who listened, but I was not satisfied with them. Another IDP, Marie, told me she was tired of speaking to officials and visitors to the camps both in 2010 and in 2018. When I asked her why she was tired of speaking, she said we are still in the same unsafe place.

Second, there were few women in positions of power in the Haitian government who could voice the concerns of women IDPs. Representative Bureaucracy theory informs the understanding of these barriers. The scholarship on representative bureaucracy is primarily based on the premise that representative bureaucracy-that is having spokespersons and officeholders in administrative and political positions-is a public good and, when provided, it should reflect the interests, opinions, needs, and values of the general public (Kingsley 1944; Keiser, Wilkins, Meier, \& Holland, 2002; Selden, 1997). In Haiti women occupy very few government positions in local and national government agencies. In 2016, before President Martelly left office, there were three female ministers out of twenty-seven ministers and ambassadors. Despite the 
Haitian constitution's proviso for women to represent thirty percent of elected officials, as of January 2017, (under President Jovenel Moïse) there is one woman senator (of 30) and three women chamber deputies (of 119; Haiti Libre, 2017).

Third, there was stigma attached to the IDPs in general and to women IDPs in specific. Both Haitian and international policymakers believed that IDPs, irrespective of gender, preferred to stay in the camps to take advantage of the aid provided to them through donors even though returning to their pre-disaster home and community was one of IDPs' top priorities as shown earlier. Some even depicted the IDPs as deplorables, which mainly consisted of prostitutes and criminals. Hence, they focused more on evicting them rather than trying to involve them to solve their problems. As for women IDPs, the policymakers viewed them more as passive victims who needed help, rather than as survivors. Officials in my study supported the view of the women and men informants: IDPs in Haiti are viewed as "the other" - or in IDP words moun invisibles and not afforded their rights as citizens, specifically, their rights as outlined by the Haitian Constitution. Chapter II Sections A-J declare citizens the right to liberty, freedom of expression, and conscience, and the right to food security, work education, property, information, and security (The Haitian Government, 1987). In other words, the government does not utilize the "human rights-based approach" (Concannon \& Lindstrom, 2011). This study's finding confirming the lack of IDP rights is consistent with the various findings from other researchers (Arend \& Vitale, 2013; Duramy, 2011; Eves, 2011; The Haiti Equality Collective, 2010), which is that the Haitian justice system does not guarantee the rights of IDPs. 
Some researchers argued the Haitian government as well as some NGOs trampled on the rights of IDPs by relocating them to other camps or evicting them from camps with no place to go (CEPR, 2013; Concannon \& Lindstrom, 2011; Corbet, 2014). In 2011, the Delmas mayor and city council declared that the displacement camps were replete with prostitution and crime and used those announcements as opportunities to send police to oust residents, destroy their possessions, and abolish three camps. The initiative in Delmas prompted a humanitarian response from NGOs and human rights organizations. Despite condemnation of expulsion practices, officials in other parts of the country also used eviction tactics in other camps (L'Etang, 2012).

By the end of 2011, the expulsion of IDPs in Port-au-Prince reached over 200,000, leaving people homeless and vulnerable (L'Etang, 2012; Richard, 2012; Soumana, 2012). The Haitian government and several NGOs created distinctions between official IDP camps such as Camp Corail and unofficial camps such as Canaan. These distinctions were designed to decrease the official number of IDPs and to justify camp closures (Kushner, 2017; Richard, 2012). The formal area known as Camp Corail just north of Port-au-Prince was officially managed by NGOs with little participation from the IDPs living within its boundaries. Corbet (2014) argued that the hierarchical structure in Camp Corail prohibited the formation of community (lacou). For example, one day Robert (a consultant) observed the relocation of IDPs from one camp to another to make Haitian administrators look good. This relocation incident happened on a day the American ambassador visited Haiti. Corroborating this story, Sam (NGO lawyer) stated that an international agency put IDPs on buses and drove them around Port-au-Prince, finally leaving them in an empty field. 
One IDP, David, said: The government should give everyone the chance to live better with security. When I probed further and asked David what type of security he meant, he stated security means knowing one is safe from physical violence.

Fourth, many Haitian and international policymakers did not believe that IDPs had much to offer for their programs due to their "strange" beliefs and customs (e.g., vodoo). Hence, they did not bother to involve them in decision making processes.

Charles, a country director to Haiti, recounted a time when he attended a cluster meeting with international aid workers (blancs) about housing, which turned into a discussion on how the participants should get rid of voodoo by building churches because the participants heard that Haitians believed the earthquake was caused by voodoo. Charles said: This story was an example of how many NGOs never bothered to speak to the IDPS to find out what they needed or involve them in projects.

Fifth, the policymakers in general seemed to be more interested in dictating what IDPs should want, as opposed to making a genuine effort to listen to them. My findings suggest that women - primarily IDP women - are not regarded as essential stakeholders in the long-term socio-economic and political reconstruction of Haiti. This finding confirms earlier findings from Concannon and Lindstrom (2011), Haiti Libre (2017), Gender Action Network (2013), and Schuller (2012, 2016). My research demonstrates that in Haiti, women IDPs have sometimes participated on a local level (e.g., withincamp committees) but have not regularly participated in the broader political arena due to the lack of formal institutions in place. One of my informants, Gina, acted as an interpreter for the IOM and was dismayed when each time she attended cluster and camp committee meetings to find that she was the only Creole speaker and only woman $99 \%$ of 
the time. Gina said, I went to so many meetings, and I'm not lying, sometimes I was the only Black Haitian in those meetings.

IDP-related factors (barriers). There were also IDP related factors that hindered all IDP participation but specifically women's participation. First, the IDPs in this study did not trust the Haitian policymakers in part since they had genuine concerns about what they did with the money donated to Haiti after the earthquake. It was mostly "us vs. them." The Haitian populace has a history of mistrust in their government and views those in power as corrupt (Cynn, 2008; Dubois, 2012; Fatton, 2011). The lack of aid transparency further propagated the corrupt government viewpoint held by those who were displaced. The IDPs heard from various news sources - Haitian radio, family members abroad, social media, and Haitian newspapers - of the billions of dollars donated to Haiti for recovery and rebuilding (Connor, Rapplage, \& Angulo, 2015; Ramachandran \& Walz, 2013). Unfortunately, due to the lack of transparency by the government, NGOs and international agenciesabout these funds, the Haitian populace was not aware of how they were being disbursed. According to various reports, by 2018 Haiti had received only $1 \%$ of the \$13-13.5 USD billion in pledged aid (Johnston, 2018; Quigley \& Ramanauskas, 2016; Simmons, 2016). Understandably, IDP informants were angry the funds did not filter down to assist them in the camps and blamed the Haitian government. When asked whether the government in 2018 assisted IDPs in camps, most men informants responded derisively. Lawrence responded: Those crooks (the government) never do anything for people. Financial aid was nonexistent at the community level. One 2011 informant stated, Lajan pa antre nan me nou ditou ("Money 
hasn't come into our hands at all'). An example of the government's ineffectiveness in the eyes of IDP informants is the failure of aid sponsored housing projects.

In April 2012, Lauterbach assessed 12 Haitian government housing projects ${ }^{13}$ with critical financial ${ }^{14}$ and technical support from donors such as the World Bank (WB) and the Inter-American Development Bank (IDB). In this assessment, Lauterbach found that while the Haitian government's National Housing and Urban Development policy provided a framework for housing reconstruction, it did not assess gender integration or any gender-related issues. The policy positioned the government as a facilitator for promoting private investment in housing, and as a bidding process coordinator for the reconstruction of the housing, water, and electricity sectors (Haiti Equality Collective 2010; Lauterbach 2012). Lauterbach (2012) posited that the Haitian government's dependency on private housing options would "further marginalize the poor and women who are less likely to control family finances or predominantly responsible for unpaid time-consuming housework or are discriminated against in land tenure issues" (p. 3).

Second, this study's informants had more trust in the international NGOs that were providing for their needs. They also thought, however, nothing changed even after they voiced their concerns to these agencies. In addition, they felt abondoned by those agencies that left the country soon after the earthquake. The low percentage of women willing to participate in committees reflects the continued reluctance women have to participation. However, in 2018, my study did find a few vocal women like Marlene. Marlene (W), stated: I think the Haitian government should create a committee for us, the

\footnotetext{
${ }^{13}$ In April of 2012 the WB dispersed $\$ 0$ of the $\$ 65$ million USD committed.

${ }^{14}$ By September 2012, Lauterbach found only \$13 million plus of the \$159 million USD committed were dispersed.
} 
poor, so that they can hear our cries. She wanted the current Haitian government (under President Jovenel Moïse) to conduct assessments of their financial needs, especially the lack of jobs and borrowing opportunities for small businesses. In 2011, she participated in a job project, but the funds dried up after a year. I asked which organization funded the program and she was not sure.

It is interesting to note that $75 \%$ of IDP women informants currently hold international agencies or NGOs in higher esteem than they do the Haitian government. One hundred percent (100\%) of women IDP informants in this study agreed that the international agencies should form neighborhood committees to better incorporate the camp inhabitants' priorities, especially for transitioning out of camps and into permanent housing. Of all the study's IDP informants (both women and men), 58\% believed the international agencies should bypass the Haitian government and send aid (in the form of money and jobs) directly to the IDPs. Valerie (W) expressed a common sentiment:

International organizations should send a committee once a month to see what our needs are. like working and a place to sleep.

Of the men informants, $60 \%$ did not want the international agencies or NGOs to return. They felt they were not treated as active partners with the NGOs; rather, they were told what to do as though they were children. The men held this viewpoint due to the inaction of many organizations after their representatives came to the camps and held fact-finding meetings. Fifty percent (50\%) of this study's men informants reported speaking to camp officials of their 2017/18 priorities and felt heard but felt that nothing had changed. Daniel's statement demonstrates his perception of government officials: I don't see any officials anymore in the country. They don't do anything. The other half of 
the men informants who did not speak up felt the exercise was useless; they had participated in many NGO focus groups and found nothing improved in the camps.

Third, women's reproductive, productive and community roles did not leave them much time for participation. They had to attend to their families' basic needs. Many women informants shared because they took care of their children's food, healthcare and eduction needs they did not have the time to go to camp committee meetings. As single earner head of household women informants found ways to run their small businesses (très petites entreprises) or if they were fortunate enough they worked in factories . Women informants relied on each other to care for each other's children and to lend each other money when needed. Maurice (agency director) stated women IDPs are focused on survival and not on attending meetings.

Fourth, Some women informants felt threatened when they spoke up. They even faced risks of violence when they voiced their concerns. Sam (NGO lawyer) spoke to me about two women human rights activists who worked in the camps and specialized in advocating for victimes of rape. These two women fled Haiti because of death threats to their family and themselves. According to a UN brief (2018) women experienced violence when they attempted to vote during the 2016 presidential election. During that election only $9 \%$ of eligible women voted (UN Women, 2018). On December 13, 2017, Amnesty International sent out an urgent communique stating Women's rights defender Sanièce Petit Phat (who works in the Canaan camp) was attacked and her family was in danger of furter attacks. They moved from various safe houses to avoid futher attacks (Amnesty International, 2017). 
Fifth, women IDP informants thought more value were given to men than women in the society. Despite Haiti's independence in 1804, women were not granted the right to vote until 1950. Even then, women were classified as wards of the state until 1975. The opportunities for Haitian women to participate politically, socially, or economically were scarce in post-earthquake Haiti, which continued in 2018 (ACAPS, 2018; Amnesty International, 2017; Brubaker, 2010; Institute for Justice and Democracy in Haiti \& Bureau des Avocats Internationaux, 2010). The Gender Action Network (2013) reported only about $58 \%$ of international financial institution funded projects "discussed gender inequalities and gender roles in the project rationale and background. Forty-two percent ignored gender dimensions, and $83 \%$ did not mention gender roles in consultations (Gender Action Network, 2013). Women were not allowed to become active agents in the reconstruction process. Women informants felt they were viewed as beneficiaries of programs (as numbers) and not as active participants or change agents in Haiti's longterm recovery. Marginalized groups such as women need the opportunity to participate in the decision- making process. As actively engaged citizens, they can advocate for policies relevant to them and their families.

Place-related factors (barriers). Another barrier that affected women IDPs' participation was their lack of access to affordable transportation, especially those that were evicted from more central areas and were forced to live in the outskirts of Port au Prince. Women informants sought financial assistance to defray transportation costs but were unsuccessful. Often when they travelled they paid transportation not only for themselves but also for their children. A tap tap ride can cost anywhere from 10 to 30 Haitian gourdes (14 to 43 U.S. cents). Given that some women struggle to earn 138 
gourdes daily (\$1-2 USD) - the average Haitian wage although market vendors earn slightly more - a tap tap ride for 2-4 people becomes very expensive (Dieu-Nalu, 2018).

Social capital-related factors (enablers): One of the factors that enabled women IDP's participation was civic networks designed exclusively for women (e.g., those that provided small loans to women). Haitian women's groups were excluded from the UN's International Donors Conference in March 2010, which raised billions of dollars for Haiti's reconstruction. Despite this glaring exclusion on the world stage, researchers found that the post-earthquake period in Haiti saw a new surge in grassroots - often ad hoc - networks of women (Bell 2012; Ganapati, 2012; Horton, 2010; Hossein, 2012; Padgett \& Warnecke, 2011). According to Bell (2010) “Haitian grassroots organizations are constructing the country as opposed to reconstructing" (p. 29). Women-led organizations were changing the historically embedded political and socioeconomic discriminatory narratives against women (Fatton, 2011; Gammage, 2004; Haiti Equality Collective, 2010; Torro, 2009). According to one of my informants, Barry (lawyer), many women's groups fell apart once international funding dried up; unfortunately, many women leaders - because of their involvement in rape victims' cases - went into hiding or fled Haiti due to threats to themselves and their families. Overall, IDP informants found few mechanisms for participating in their own recovery process. IDP women and men informants encountered both informal and formal institutional barriers to participation. Those formal institutions who did have control - NGOs and international agencies - very often made decisions without consulting those who were displaced.

IDP men and women reported many common concerns: discrimination by the Haitian government, the Haitian elite and NGOs of those living in tent camps, financial 
instability, little to no control over where they lived (IDP informants were relocated to unsafe areas or given insufficient rent vouchers to leave IDP camps), and a profound loss of their guaranteed human rights. The IDPs in this study mistrusted the Haitian government. Due to lack of fund and donation usage transparency, IDP informants were angry the funds did not filter down to assist them in the camps and blamed the Haitian government. Table 4 reflects this study's participation findings.

Table 4

Study Participant Priorities

\begin{tabular}{|l|l|}
\hline \multicolumn{1}{|c|}{ All IDPs } & \multicolumn{1}{c|}{ Women IDPs only } \\
\hline Discrimination of all camp dwellers & $\begin{array}{l}\text { Non-participation in recovery process } \\
\text { (structural, environmental, historical familial) }\end{array}$ \\
\hline Loss of guaranteed human rights & Women community activists risk violence \\
\hline $\begin{array}{l}\text { Government /NGO designation of } \\
\text { official versus unofficial camps }\end{array}$ & $\begin{array}{l}\text { Government official /and camp committee } \\
\text { prejudices }\end{array}$ \\
\hline $\begin{array}{l}\text { Forced camp expulsions by the } \\
\text { Haitian government }\end{array}$ & $\begin{array}{l}\text { Government exclusionary policies (e.g. rape } \\
\text { cases were difficult to prosecute) }\end{array}$ \\
\hline $\begin{array}{l}\text { Forced relocation to dangerous } \\
\text { neighborhoods }\end{array}$ & Lack of women in government \\
\hline $\begin{array}{l}\text { Insecure housing } \\
\text { Loss of financial support (rent } \\
\text { subsidies or short-term jobs) }\end{array}$ & $\begin{array}{l}\text { Camp committee members were } \\
\text { predominantly men }\end{array}$ \\
\hline $\begin{array}{l}\text { No citizen confidence in the Haitian } \\
\text { government }\end{array}$ & $\begin{array}{l}\text { Kokibinaj (men with multiple families)- } \\
\text { women as the head of household and the } \\
\text { extended family caregivers }\end{array}$ \\
\hline & Healthcare concerns (cholera) \\
\hline & Lack of transportation \\
\hline
\end{tabular}

Women IDP informants shared additional concerns that were not mentioned by their male counterparts including lack of representation, women IDP informants reported that most committees consisted mainly of men. Women IDPs in this study who 
participated on a local level (e.g., within-camp committees) did not regularly participate in the broader political arena due to the lack of formal institutions in place (e.g., camp meetings were held in English, which excluded the Creole-speaking IDPs from participation). Voice-when women spoke up, they were often discouraged at the lack of progress.

\section{Chapter Summary}

In this chapter, I revealed that, despite some similarites between the recovery priories of women and men IDPs in the short- (food security, sanitation/cleanliness, returning home and to pre-disaster community) and long-term (access to secure shelter), women had several additional priorities. These priorities in part had to do with the traditional roles they play in the household (a reproductive role as a mother and nurturer and productive role as a caregaver and income generator). They also had to with their perception inside and outside the household as passive "victims" that needed help. The location (away from the center) and conditions of IDP camps (e.g., increased risks of sexual assaults and violence in IDP camps, cholera outbreak) within which they lived mattered for their priorities as well.

Women IDPs voiced their priorities to decision makers less than men IDPs both in short- and long-term recovery. Still, however, women IDPs who lived in formal camps made efforts to participate in decision-making processes in recovery. However, their participation was not in formal participatory settings (e.g., U.N. Cluster meetings). Rather, it was limited to participation in informal settings (e.g., camp committee meetings) at the neighborhood level, which was closer to them. There were six broad factors that affected women IDP's participation in decision making processes in the post- 
earthquake context to inform authorities about their priorities: (1) organizational factors (e.g., diverse range of organizations with diverse organizational cultures); (2) formal institutional factors (e.g., lack of participatory mechanisms customized for IDPs); (3) policymaker-related factors (e.g., stigma towards the IDPs); (4) IDP-related factors (e.g., lack of trust); (5) place-related factors (e.g., lack of access to transportation); and, (6) civic networks-related factors (e.g., women's groups). 


\section{CHAPTER V}

\section{CONCLUSIONS}

\section{Overview}

The field of disaster management is rich in research covering the phases of preparedness, response, mitigation, and short-term recovery. However, researchers often under-study the critical phase of long-term recovery. Most disaster researchers and practitioners, however, "view recovery as a process defined by two stages: short- and long-term; steps and sequences that people, organizations, and communities move through at varying rates" (Phillips, 2009, p. 22). The short-term recovery phase transitions a community from response activities to recovery efforts such as managing donations and volunteers, building temporary shelter, and clearing debris (Horton, 2012; McEntire, 2012; Phillips, 2009). The long-term recovery phase encompasses multiple dimensions of disaster recovery including debris management as well as recovery efforts around environmental, historical and cultural, housing, business, infrastructure and lifelines, social psychological, and public-sector resources (Phillips, 2009). During the long-term recovery process, all stakeholders should actively engage in community planning activities and have access to rebuilding and economic opportunities. Unfortunately, the internally displaced, the focus of this dissertation, are typically left out of these rebuilding prospects.

\section{The Importance of IDP Participation in the Recovery Process}

Internally displaced persons (IDPs) are people who - like refugees - flee their homes seeking safety from armed conflicts, violations of human rights or natural or human-made disasters, but - unlike refugees - do so within the boundaries of their home 
country. In 2018, the Internal Displacement Monitoring Centre (IDMC) reported 65 million IDPs worldwide, an increase of over 20 million from the 2016 estimates (IDMC, 2017).

Worldwide, the rate of internal displacement is one person per second (InternalDisplacement.org, 2017). Principle 1(1) of the UN Refugee Agency's Guiding Principles on Internal Displacement declares:

Internally displaced persons shall enjoy, in full equality, the same rights and freedoms under international and domestic law as do other persons in their country. They shall not be discriminated against in the enjoyment of any rights and freedoms on the ground that they are internally displaced. (OCHA, 2004, p. 2)

However, research has demonstrated that IDPs experience extreme insecurities around food, health, shelter, security, and livelihood (Cullen \& Ivers, 2010; Farmer, 2012; Joshi \& Mehir, 2009; IDP Global Report 2017; IDPproject.org). Women - widely recognized as the most vulnerable IDPs in post-disaster camp situations - are often victims of rape, sexual assault, forced labor, and forced recruitment, especially in conflict-ridden areas (IDMC, 2017). Unlike refugees, who have an the Office of the United Nations High Commissioner for Refugees (UNHCR), an international body protecting their rights no international organization for IDPs exists. Several organizations such as the Office of the United Nations High Commissioner for Refugees (UNHCR), the International Committee of the Red Cross (ICRC), the International Organization for Migration (IOM), and many international NGOs have stepped up their efforts to address the needs of IDPs worldwide. Long-term recovery for IDPs - especially women - often 
depends on the distribution of resources as well as their visibility, their access to political power, and their active participation in the recovery process (Brun, 2003; Cullen \& Ivers, 2010; InternalDisplacement.org, 2017; Schuller, 2016).

\section{Why Haiti was the Ideal Context for Exploring These Issues}

According to the International Organization for Migration (2017), there were still between 40,000 and 60,000 post-earthquake IDP residents in 31 camps across Port-auPrince as of 2017- a tremendous decrease from the 2010 high of 1.5 million. However, other factors (e.g., human-made, climate) have caused a resurgence in the IDP population within various parts of the country (IDMC, 2017; InternalDisplacement.org, 2017; USAID, 2018). For example, the government of the Dominican Republic created a human-made situation when in 2010 they denied Dominican citizenship to persons of Haitian descent, expelled them (and continue to do so), thereby generating a new wave of displaced persons. Various sources (Ariza, 2017; Haiti Libre, 2017) reported that over 100,000 Haitians now live in displacement camps along the Haitian-Dominican border. In addition to the increase in IDPs caused by the Dominican government policies, Hurricanes Matthew (2016) and Irma (2017) created close to 700,000 additional displaced persons in Haiti (Country Meters, 2018). Hurricane Matthew struck on October 4, 2016, and devastated Haiti's southwestern Départments of Grand'Anse and Sud, destroyed 200,000 homes and affected close to 1.2 million people, over 175,000 of whom were forced into temporary shelters (Trevino \& Deinnger, 2016; World Bank, 2017). With Haiti exposed to these recent disasters, the number of IDPs in 2017 (1 million) is now returning to the post-earthquake level of 1.5 million (InternalDisplacement.org, 
2017). Regrettably, the research into the long-term recovery priorities of IDPs is as relevant in 2018 as it was in 2010.

\section{Public Administration and Citizens as Internally Displaced Persons}

This study provides useful information to public administration scholars working to support individuals living in post-disaster displacement camps as they rebuild their communities and livelihoods. It may also expand policy debates and policymaking opportunities from governments in Haiti and non-governmental organizations working in these areas. After a disaster, the affected citizens look to their government for support to survive and begin the long road to recovery. Our research respondents in Haiti sought a strong government, not one which cedes its power to international agencies and donors. I recommend the Haitian government does its utmost to allow its people - particularly women - voice in the economic, political, and social rebuilding of their communities. Acknowledging the affected populations will engender trust in government. A disaster may present an opportunity for a community to build back stronger, but only if the community's citizens can participate in the process. It is important for Haiti's public administration and for NGOs to apply the findings from this study to Haiti's everincreasing IDP population. The need for IDP inclusion in Haiti's long-term recovery is as crucial as ever. After a 2010 visit to Haiti's many IDP camps, Eves (2011) observed, Camp residents question the validity and legitimacy of the presidential elections conducted while they live under tents and tarps in the center of the capital. They also implicitly indict the regimes of global capital that come in many guises, usurping, they say, their dignity daily. (para. 15) 
Unfortunately, according to my 2018 findings, not much has changed for the 40,000 to 60,000 IDPs who live in camps since 2010.

\section{Methodology Review}

To understand the beliefs, experiences, and perceptions of IDP women and men in Haiti, I conducted a qualitative research study including interviews, focus groups, and field observations. An analysis of participants' responses allowed me to identify their unique opinions and viewpoints about the IDP experience in Haiti. This research built upon and extended a previous National Science Foundation (NSF)-funded research study on social capital and shelter recovery in post-earthquake Haiti conducted by Dr. Emel Ganapati and colleagues (Rahill et al., 2014). It analyzed the findings from semistructured interviews $(n=97)$ and focus group participants $(n=63)$, at which point the analyses reached saturation.

This research focused on three socioeconomically different communes (districts) in or near the Port-au-Prince arrondissement (administrative division within a city): Pétion-Ville, Delmas, and the neighborhood of Canapé Vert. These communes were selected as these sites were the focus of the previously-cited NSF study (Rahill et al., 2014). Rahill and colleagues selected those neighboring yet socioeconomically diverse communities in Port-au-Prince because each included lower-income areas devastated by the earthquakes, and all three areas housed displaced residents. My goals for this study were to address the following three research questions:

(1) What are the gendered long-term recovery priorities of the IDPs in Haiti? Why do women place priorities on some issues more than others during the long-term recovery period? 
(2) What are the factors related to institutions and public administration (i.e., policymakers) which affect IDP women's participation in Haiti's long-term recovery process?

(3) How can policymakers and representatives of NGOs address the unique and varied needs of women while also ensuring an equitable long-term post-disaster recovery process?

\section{Gendered Long-term Recovery Priorities of the IDPs in Haiti}

The first section of this question queried women and men IDPs in Haiti on the most critical recovery priorities within the first year of the earthquake and whether they informed the authorities about those priorities.

Similar IDP priorities. According to my informants, IDPs - men as well as women - experienced similar priorities in 2010 immediately following the earthquake in Haiti. Their highest priorities were food, shelter (returning home to rebuild or repair), making sure family members were safe, and earning money to support themselves and their households. In my study, the consensus of women and men informants to return home refutes the view of many international and national observers that IDPs were either comfortable in the camps or were living in them to access services such as water, food, and healthcare.

The differences between IDP women's and men's priorities in 2010.

Displaced women had different priorities than men. For example, they cited the lack of mobility due to child and elder care as well as the lack of funds for transportation as a hindrance to participation. The layout of camps along with their poor lighting exacerbated security risks to women, especially rape (kajok) and sexual assault. My 
findings demonstrate that there is a conspicuous difference in the security concerns of women and men IDPs. Women referred to their security (or lack thereof) regarding gender-based violence, specifically rape, whereas the male informants never used the term "rape." In contrast, the men - if they spoke of security at all (as protection against robbery or fights) - used the word sekirite, which is a more general Creole term for safety.

Haitian women are staunch proponents of the education of their children and sacrifice their personal needs to provide a better future for their children. Immediately after the 2010 earthquake, more women informants than men prioritized the basic needs of their children (e.g., food and schooling). Most women's letters and camp committee meetings centered on food and shelter for their children. After the earthquake, women lost their meager incomes and immediately sought out ways to rebuild themselves financially.

Long-term recovery for IDPs - especially for women IDPs - often depends on the distribution of resources as well as on their visibility, access to political power, and active participation in the process (Brun, 2003; Cullen \& Ivers, 2010; InternalDisplacement.org, 2017; Schuller, 2016). Very often the international press, NGOs, international agencies, and the Haitian government portrayed displaced women as passive victims, which effectively denied IDP women the opportunities to become active participants in their own long-term recovery. Many women informants referred to themseves as "moun invisibles" - reflecting their sense of voicelessness in their long-term recovery process. When asked why the use of the word "invisible," many informants reported that the Haitian government and international aid agencies treated them not as active participants 
in their recovery but rather solely as numbers or program recipients. Delving deeper into their "IDPs as numbers" perception, I found that many informants experienced NGOs or external agencies conducting surveys that probed their needs without any positive changes within the camps as a result of those surveys.

Micro-financing plays an essential part in Haiti's livelihood systems (Arend, 2012; World Bank, 2017). The formal lending processes within financial institutions and NGOs as well as the informal grassroots lending organizations contribute to the economic empowerment of Haitian women (Brun, 2012). Many women IDP informants in this study talked about the need for loans as support for opening or growing their small businesses.

The lending organization Fonkoze was founded in 1995 as a Haitian NGO and allocates microloans to groups of women. The organization is the largest microfinance institution in Haiti and supports thousands of female-run micro-sized medium enterprises (MSMEs). The goal was to target the "very poor," classified by the World Bank in 1995 as those earning less than $\$ 1$ USD per day, and to create various levels of training and lending according to the educational modules attended by the participants. The broad Fonkoze goals are for participants to achieve food security and literacy, accumulate wealth, enroll kids in school, and improve existing home structures (Fonkoze, 2018)

Once the woman business owner graduates from the first Fonkoze program, she can join the next group-lending program called $t i$ credit (small credit). This group development level creates a community of lenders whereby an initial loan of $\$ 25$ USD is allocated to an individual. Once the woman has repaid the loan, she enters a lending 
group of five people who then collaborate with five additional groups. These participants are eligible to receive loans ranging from $\$ 75$ to $\$ 1300$ USD. ${ }^{15}$

Despite Fonkoze's success, the process of acquiring a micro-loan for women has developed into a difficult one. Fonkoze's borrowing system requires the borrower to have a birth certificate. Prior to the earthquake in Haiti, the document warehousing of citizens' legal papers for example- birth certificates, land titles, and court designations was an inconsistent process; and after the 2010 earthquake, millions of documents were lost (Concannon \& Lindstrom, 2011). Haitian women took the initiative to revitalize and renew their informal credit system. When faced with new exclusionary lending (documentation) requirements, the women of Haiti created a process they called sabotaj, the Creole word for the French "sabotage" by which they practiced subversion or sustained resistance in response to the formalized process of government microloan organizations (Beasley, 2012, p. 41). They undertook this sabotaj by forming groups officially known as tontines. The members formed a tontine to grant credit, barter, or negotiate businesses with other members. A trusted woman outside the circle of borrowers and lenders safeguarded the funds until the next opportunity for members to invest. These grassroots lending systems were important to IDP women when providing for their family's needs (Hossein, 2012).

Women who felt ignored, unprotected, and marginalized created this quasi-secret community (untaxed and unrecognized by governments) of lenders and borrowers (tontines) to sustain their families and small businesses. Haitians refer to these micro-

\footnotetext{
${ }^{15}$ Repayment terms and duration depend on the size of the loan.
} 
businesses as the "informal" system - a system one of the women described as Beasley noted, "when one has no identity...when one is not taxed, and their activities are not registered by the magistrate" (Beasley, 2012, p. 11).

\section{Institutional and Policy Factors Affecting IDP Women's Participation}

Exploring the factors related to institutions and policies affecting IDP women's participation in Haiti's long-term recovery process involved seeking out and understanding IDP women's voices so that their concerns could be integrated into the ongoing post-disaster recovery process. This query also analyzed the role of public administration in the recovery process and the ways in which women were empowered or disempowered during the process. Women in the long-term recovery phase - particularly IDP women - are often denied opportunities to voice their priorities to be heard by governments, NGOs, and international agencies. The rare times IDP women exercised their voice, many reported that the exercise did not yield tangible outcomes such as improvements in camp security, healthcare, and education accessibility. My research illustrated when women did participate in recovery processes through camp committees, women's groups, or church groups, they felt people listened. However, they also reflected that the Haitian government never acted, implemented innovative programs, or even visited IDP camps. NGOs and international agencies designated most IDP camp committees as the unofficial "voice" of residents in those camps; unfortunately for women, IDP camp committee members were composed mostly of men. A Haitian government informant interviewed in 2017 noted that some camp committee members especially in the quake's immediate aftermath - used food supplies as a means of 
rewarding those close to them as well as those willing to provide services including sexual "services" to the committee members.

Both women and men informants felt abandoned by the Haitian government and by the international agencies that left the country a year or two after the earthquake. As of 2018, the absence of public sector services such as lighting, bathrooms, and bathing facilities, as well as the lack of police presence still contribute to insecurity in Haiti's IDP camps. It is interesting to note the IDP women currently regard international agencies or NGOs in higher esteem than they do the Haitian government. All (100\%) of women IDP informants felt that the international agencies should form neighborhood committees to better incorporate the camp inhabitants' priorities, especially around the process of transitioning out of the camps to permanent housing. Of the men informants, $60 \%$ did not want the international agencies or NGOs to return. They felt that they were not included as active partners with the NGOs, but rather were told what to do as though they were children. In 2018, the IDP perception of a corrupt Haitian government persisted, which is consistent with $58 \%$ of IDPs reporting that they believed the international agencies should bypass the Haitian government send aid (money) directly to the IDPs and create jobs. Although the perspectives and viewpoints of the IDP women and men were critical to this dissertation's research, equally important were the perceptions and experiences of Haitian policymakers, NGO directors, and international aid agency program directors.

\section{How Policymakers and Representatives of NGOs Can Address Needs of IDP}

\section{Women}

Addressing the question as to how policymakers and representatives of NGOs can address the unique and varied needs of women while also ensuring an equitable long- 
term post-disaster recovery process informs decision makers in the Haitian government as well as domestic and international NGOs about designing and implementing genderinformed post-disaster recovery policies and programs, helping women have a more active voice, and promoting a more equitable recovery process. I asked policymakers and international officials what they observed to be top priorities of Haitians in 2010 immediately after the earthquake and found that all agreed on three that were common to women and men. Those similar priorities were insufficient sanitation, security, and income-producing activities. According to my informants - officials, as well as IDPs the IDP camps were constructed and designed without taking into consideration diverse security and sanitation needs such as lighting and placement of latrines and showers, thereby putting women at greater risk of violence. These informants reported that women IDPs worried about and experienced more violence than did men IDPs. Most officials in this study believed that numerous NGOs downplayed or negated the reports of violence including rape in the camps, while other informants stated that NGOs report exaggerated numbers of violent incidences to induce donor assistance. The losers in this public battle were the IDP women. According to my research these same issues of inadequate reporting systems, lack of security forces, and dangerous camp environments persist in 2018 (Amnesty International, 2017; Doctors Without Borders, 2017; Haiti Libre, 2017).

My findings show according to my study informants that women - primarily IDP women - have not been regarded as essential stakeholders in the long-term socioeconomic and political reconstruction of Haiti. This finding is supported by multiple researchers on Haiti in the post-disaster context (Concannon \& Lindstrom, 2011; Haiti Libre, 2017; Gender Action Network, 2013; Schuller, 2016). In the context of Haiti, 
women IDPs have sometimes participated on a local level (e.g., within-camp committees) but have not participated in the broader political arena due to the lack of access that could support their participation (e.g., meetings were held in English, which excluded the Creole-speaking IDPs from public participation). As stated earlier, one of the informants acting as an interpreter was dismayed when she found that she was the only Creole speaker as well as the only woman in virtually all cluster and camp committee meetings. According to many of the informants, NGOs and international organizations refused to provide aid to camps unless committees were formed. When these committees did exist, self-selection and bullying led to few women on the committees, thus the IDP men became the aid power brokers. This unequal distribution of representation inhibited many women from voicing their concerns and needs.

For women to effectively participate in their communities and politics, they need to see themselves represented in Haiti's government. In Haiti, the dominant minority consists of wealthy, educated, politically connected men (Fatton, 2011; Horton, 2012; Schuller, 2012, 2016). Women occupy very few government positions in local and national government agencies. In 2016 before President Martelly left office, there were only three female ministers out of a total of 27 ministers and ambassadors. Despite the Haitian constitution's proviso that women represent $30 \%$ of all elected officials, as of January 2016, all 30 members of the Senate were male (Charles, 2016; Infoplease, 2012). In December of 2017, under current Haitian President Jovenele Moïse, 5 of the 18 cabinet ministers in the Haitian government were women (Haiti Libre, 2017). According to News Americas, as of April 2018, three of the five women ministers were replaced with men (News Americas, 2018). 
Haitian women have the knowledge, capacity, and resilience to grow their livelihoods and family wealth. What they lack, however, is the global and local financial and political support to do so. Haitians prefer to be self-sustaining and, given the opportunity, to experience economic freedom. Each of the NGO informants in this research agreed that the Haitian government needed to involve IDPs and community leaders in their long-term recovery. Researchers found when local mayors, community organizations, and IDP women and men were involved in recovery, organizations saw a higher rate of program success (Chandrasekhar, 2012; Chandrasekhar, Zhang, \& Xiao, 2014; Olshansky \& Chang, 2009).

Haiti's short-term rehabilitation needs, and long-term reconstruction processes led to the development of eight essential themed sectors: governance, the environment, disaster risk management, social sectors, infrastructure-related sectors, the production sector, a macro-economic analysis, and cross-cutting sectors (youth, gender, vulnerable persons, employment). These sectors, which were led by multi-national directors, then developed cluster teams. The cluster teams created a multi-sector review of damage and losses as well as an action plan for the identification, recovery, and rebuilding needs for the upcoming 6 months to 10 years (The Government of Haiti, 2010; World Bank, 2010). There were two critical problems with these cluster meetings. First, many high-level meetings took place in the United States or Canada, which prevented the participation of Haitian government officials. Second, local sector cluster meetings in Haiti were mainly conducted in English and thus excluded IDPs and grassroots organizations. One informant labeled this practice of limiting the Haitian participation as blandization (whitening the process). Local cluster meetings were initially designed as collaborative 
opportunities to adress short- and long-term recovery needs such as shelter, food, sanitation, and water with the Haitian government ministries, IDP camp committees, and grassroots organizations. The IDPs reported feeling that collaborative activities did not exist.

Officials in my study supported the view of the IDP informants: displaced persons in Haiti are viewed as "the other" - or in IDP words moun invisibles - and not afforded their rights as citizens, specifically their rights as outlined by the Haitian Constitution. The Haitian Constitution's Chapter II, Sections A-J states, "All Haitian citizens have the right to liberty, freedom of expression, conscience and the right to food security, work education, property, information, and security" (The Haitian Government, 1987). The above finding triangulates various findings from other researchers (Arend \& Vitale, 2013; Duramy, 2011; Eves, 2011; The Haiti Equality Collective, 2010); which is that the Haitian justice system does not guarantee the constitutional rights of its displaced citizens.

Some researchers argued that the Haitian government as well as some NGOs trampled on the rights of IDPs by relocating them to other camps or by evicting them from camps with no place to go (CEPR, 2013; Concannon \& Lindstrom, 2011; Corbet, 2014). The Haitian government and several NGOs created distinctions between official IDP camps such as Camp Corail and unofficial camps such as Canaan.

These distinctions were designed to decrease the official number of IDPs and to justify camp closures (Kushner, 2017; Richard, 2012). NGOs officially managed the formal area known as Camp Corail just north of Port-au-Prince, allowing little participation from the IDPs living within its boundaries. 
All NGO informants in this research agreed that the Haitian government needs to involve IDPs and others in the planning and implementation their long-term recovery processes. When involved in post-disaster long-term recovery, NGOs need to possess cultural competencies: to speak the local language, learn local customs, and understand that women and men - and IDPs - are not homogenous populations. Only then does the lengthy process of post-disaster recovery becomes a collaborative, participatory process for all stakeholders. The following two lists outline this study's policy recommendations.

\section{Policy Recommendations for NGOs and International Agencies:}

- Change NGOs \& International agencies' official prejudices of women IDPs as victims, prostitutes and house cleaners without legal recourse.

- Ensure aid and development employees understand the culture and employ local talent in needs assessment and program implementation.

- NGOs/International agencies should be transparent to the governments and people they serve.

- Support efforts by the Haitian Government to enforce laws which protect women's housing, land rights and legal recourse for rape and domestic violence.

- Change how officials choose and finance long-term rebuilding sites

- Funding geared towards women's issues (education, microcredit/loans, healthcare, affordable transportation).

- Ensure more women participate in local initiatives, camp committees, and programs.

- Restore citizen confidence in NGOs \& International agencies. 


\section{Policy Recommendations for the Haitian Government:}

- Focus on rebuilding the capacities of government. departments such as the Ministry for Women's Affairs and the Ministry of Education by increasing women's representation and participation in local and national governments. The Haitian government must prioritize women's representation and participation, and allocate funds for those priorities. The government can seek Public/Private funding geared towards women's issues (e.g., education, microcredit/loans, healthcare).

- Adopt an expanded grassroots approach to long-term recovery that include the hundreds of small- and medium-sized community organizations.

- Develop a "rights-based approach" to recovery, a notion advocated by an interviewee with a legal background. This rights-based approach can ensure protection of IDP civil rights, land rights, and political rights. It can also ensure that the Haitian citizens have the right to "liberty, freedom of expression, conscience and the right to food security, work education, property, information, and security" (The Haitian Government, 1987).

- Restore citizen confidence in the Haitian government by establishing a culture of transparency and accountability that deters corruption.

- Teach citizen participation in schools that emphasizes the roles women and girls play in the economic, political, and social rebuilding of their communities. 


\section{Policy Recommendations for the Haitian Government and NGOs:}

- The Haitian government and NGOs must protect and support the growth of grassroots organizations in Haiti, particularly women's organizations.

- The Haitian government and NGOs must create livelihood opportunities for all of its citizens.

- By implementing collaborative programs, the Haitian government and NGOs may engage the Haitian elite and private enterprises to create socially responsible opportunities for education and job training in Haiti.

\section{Strengths and Limitations of This Research}

The qualitative methods I used in this dissertation research helped me to explore and understand the beliefs, experiences, and perceptions of internally displaced women and men in Haiti. Their responses allowed me to identify and examine their unique opinions and viewpoints regarding the IDP experience in Haiti. The resurgence in the number of IDPs in Haiti has renewed the urgency for further research into long-term recovery priorities for people and communities who are displaced.

Despite the advantages of the qualitative methodology, it also presents some limitations. First, this study focuses on a small sample of IDPs in three neighborhoods of Port-au-Prince, Haiti; however, its findings are generalizable and can potentially contribute to the overall research and scholarship on the priorities, needs, and participation of internally displaced people, especially women. Second, the repeated displacement of 2010 study participants including changes in phone numbers posed additional challenges and prevented following up with them for this dissertation study. Third, those living in IDP camps during the 2017-2018 period may have distortions in 
their memories as to accurately recollecting what their priorities and needs were in the immediate aftermath of the earthquake, seven or eight years after the event. Fourth, as in other studies on participation, there is a mismatch between what was reported by the policymakers who were referenced by the IDPs and those whom I interviewed for the study. The researcher, however, made every effort to conduct interviews with the specific policymakers mentioned by the IDPs in the three communities; however, due to a new government, many of those policymakers were no longer in office. Finally, although the study touches upon men's perspectives on disaster recovery and participation, by design its focus is on the needs and priorities of IDP women.

This study also has several strengths. One strength is that this research locates gender amid disaster and examines its role in the long-term IDP recovery process. Destruction from Hurricanes Matthew (2016) and Irma (2017) forced about 200,000 people to migrate to Port-au-Prince, once again sending women and children to temporary shelters and camps. Another key strength is its methodology; the study compares gendered attitudes toward long-term disaster recovery from multiple perspectives: those of IDP women, IDP men, government leaders, and agency directors. The methodology also scrutinizes the processes that enable or hinder recovery of the internally displaced by utilizing content analysis. And finally, a unique and powerful strength is the longitudinal data collected through the study (from 2010 to 2018) as it repurposed and extended the data from interviews, focus groups, and observations of an earlier project (Rahill et al., 2014). My knowledge of the Haitian culture and fluency in French and Creole also enriched and strengthened this research. 


\section{Future Research Directions}

\section{IDP Men's Healthcare}

The men IDPs I interviewed in 2017 and 2018 never mentioned healthcare or the affordability of transportation. Why not? Men's general healthcare is rarely discussed in Haiti, in scholarly research journals, or within NGOs and international aid agencies except in the context of HIV/AIDS or post-traumatic stress disorder (PTSD; Cerda et al., 2013; Partners In Health, 2018). This lack of research focus on men's healthcare is disconcerting since, according to the CDC (2018), men in Haiti have a shorter life span than women: 61 years for men and 65 years for women. In Haiti’s hyper-masculine culture (Richman, 2012), men are taught from boyhood that illness is a weakness reserved for women. The 2010 Post Disaster Needs Assessment (PDNA) did not discuss men's specific health. In the book The Gendered Terrain of Disaster, Thinking About Men and Masculinities (Enarson \& Pease, 2016), various researchers describe their examinations of the excessive social, economic, and cultural costs of disaster for men. The many challenges faced by displaced men during the long-term recovery phase are overlooked.

I argue that unless we - researchers, communities, governments, and agencies assess gender-based violence and its root causes from IDP men's perspectives and experiences, we will not assist women IDPs. Questions are posed such as "Do men selfmedicate with cigarettes, alcohol, or drugs when suffering post-disaster trauma?" and "Are their feelings of financial inadequacy or of survivor guilt factors that increase domestic or partner violence?" While these questions in no way excuse violent behavior, they do suggest that if a root cause analysis of increased rape and other violence 
following a disaster is not conducted, then rape and other violence towards displaced girls and women will increase globally. The Central American NGO Puntos de Encuentro (2018) integrated the following message into their community work after Hurricane Mitch: "Violence against women is one disaster men can prevent" (para 1).

\section{LGBTQ Communities' Concerns}

The study of the LGBTQ community merits accelerated research efforts due to the global increase of IDPs (UNHCR, 2018). Gorman-Murray, McKinnon, and DomineyHowes (2014) examined the loss of community and shelter within LGBTQ communities after various disasters and how individual experiences are not homogenous. In this study, they found that during the short- and long-term recovery phases, many LGBTQ individuals avoided shelters as the designs of these spaces were viewed as unsafe. After the earthquake in Haiti, there were reports of forced transactional sex in exchange for food, as well as rape and shelter discrimination against members of LGBTQ communities in some shelters (Trudeau, 2011).

\section{The Rights of IDPs at the Haitian-Dominican Border}

Which organizations and governments will protect the rights of IDPs living along this border? Various sources (Ariza, 2017; Haiti Libre, 2017; Newland \& Salant, 2017; UN Office for the Coordination of Humanitarian Affairs [UN OCHA], 2018) reported that over 100,000 Haitians now live in displacement camps along the Haitian-Dominican border. Newland and Salant (2017) stated: "Many returnees were born in the Dominican Republic, and without knowledge of Haitian Creole or close contacts in Haiti, end up living in squalid camps along the border" (para. 11). Dominican policymakers justify the removal of naturalized Dominicans or those of Haitian descent on the grounds of national 
security, economic protection of native populations, and the need to enforce strict immigration laws. By forcibly expelling this population to Haiti, the Dominican government may be exacerbating the economic and social instability in Haiti, as witnessed by the growth of IDP camps.

\section{Other Excluded Groups in Haiti's Long-term Recovery}

The post-earthquake issues experienced by government officials and by the elite in Haiti have not been studied. Another under-researched population in Haiti are those affected by disasters in situ ${ }^{16}$ who are not displaced.

\section{Closing Thoughts}

I have profound respect and admiration for the women of Haiti "Poto Mitan" - the primary economic drivers of the Haitian economy but the last to eat and the last to reap the benefits of many global interventions. Haitian women have the knowledge, capacity, and resilience to grow their livelihoods and family wealth; what they lack is the global and local financial and political support to do so. It is vital that Haiti's inclusion of IDP voices - particularly those of displaced women - becomes an integral factor in the country's quest for citizen participation, policy efficacy, government transparency, and accountability in the long-term recovery process. Researchers have postulated that postdisaster recovery could become a successful development intervention when local and national officials overcome traditional hierarchal attitudes and discriminatory gendered policies (Lund \& Veaux, 2009; Soares \& Mullings, 2009; Yonder et al., 2009). With women in Haiti comprising over half of the country's population, the Haitian government

\footnotetext{
${ }^{16}$ Disaster victims who stay in their original homes/communities
} 
and other international organizations can ill afford to alienate them. Not addressing women's issues may risk the socioeconomic, political, and educational future of Haiti's next generation (Bell, 2012; Fatton, 2011; Schuller, 2014; UN Women, 2018). 


\section{LIST OF REFERENCES}

A Celebration of Women Organization. (2010, August 21). Haiti-Reconstruction of Projects Approved. Retrieved from acelebrationofwomen.org:

http://acelebrationofwomen.org/2010/08/haiti-reconstruction-projects-approved/

Abbott, S. e. (2014, August 14). Hidden Curriculum. Retrieved from The Glossary of Education Reform: http://edglossary.org/voice/

ACAPS. (2018, January 2). Haiti crisis analysis. Retrieved from acaps.org: https://www.acaps.org/country/haiti/crisis-analysis

Acker, J. (2006). Inequality, Regimes, Gender, Class and Race in Organizations. Gender and Society Vol. 20 \#4, 441-464.

Acker, J. (2012). Gendered Organizations and Intersectionality: Problems and Possibilities. Equality, Diversity and Inclusion: An International Journal, 214-224.

Affairs, O. U. (2018, January 12). Haiti Earthquake 8 years later. Retrieved from reliefweb.int: https://reliefweb.int/report/haiti/ha-ti-s-isme-8-ans-apr-s-des-victimesoubli-es

Ahmed, A. (2015, June 16). Haitian Workers Facing Deportation by Dominican Neighbors. Retrieved from nytimes.com:

https://www.nytimes.com/2015/06/17/world/americas/migrant-workers-in-dominicanrepublic-most-of-them-haitian-face-deportation.html

Ahmed, F. E. (2011). Review of Film "Poto Mitan". ASA-Teaching Sociology, 402-403.

Albright, M. (2003). Think Again: The UN Foreign Policy. New York: The United Nations.

Aldrich, D. (2011). Ties that Bond, Ties that Build: Social Capital and Governments in Post Disaster Recovery. Studies in Emergent Order Vol, 4., 58-68.

Ali-Mohammed, K. (2013, November 6). Building Communities-Vive Chef CoumbiteNew Masters in Post-Emancipation Haiti. Retrieved from http://scholar.library.miami.edu/emancipation/culture3.htm

Aloudat, T., \& Christensen, L. (2012). Psycho-social Recovery. In B. Wisner, J. Gaillard, \& I. Kelman, Handbook of Hazards and Disaster Risk Reduction and Management (pp. 569-579). London, N.Y.: Routledge. 
Amnesty International. (2017, December 13). Women's Rights Defender Threatened With Death. Retrieved from amnesty.org: https://www.amnesty.org/download/Documents/AMR3675982017ENGLISH.pdf

Anthem, P. (2016, October 7). Haiti: dans le sillage de l'ouragan Matthew. Retrieved from fr.wfp.org: http://fr.wfp.org/histoires/dans-le-sillage-de-louragan-matthew

AonBenefield. (2013). Global and Catastrophe Report. AonBenefield.

Apaza, C. (2015, February 10). Promoting Citizen Participation. Retrieved from PAtimes.org: http://patimes.org/promoting-citizen-participation-public-sector-reforms/

Archibald, R. C. (2014, October 24). Dominicans of Haitian Descent Cast Into Legal Limbo by the Court. Retrieved from nytimes.com:

https://www.nytimes.com/2013/10/24/world/americas/dominicans-of-haitian-descentcast-into-legal-limbo-by-court.html

Archibold, R. (2013, October 24). Dominicans of Haitian Descent Cast into Legal limbo by Court. Retrieved from nytimes.com:

https://www.nytimes.com/2013/10/24/world/americas/dominicans-of-haitian-descentcast-into-legal-limbo-by-court.html

Arend, E. (2012). IFIs \& Gender Based Violence Case Study: Haiti. Retrieved from genderaction.org: http://www.genderaction.org/publications/haitigbvcs.pdf

Arend, E., \& Vitale, L. (2013, October 31). Gender Justice Women's Rights Report-2011. Retrieved from Genderaction.org: www.genderaction.org

Ariyanbandu, M. (2009). Sex, gender, and gender relations in disasters. In E. Enarson, \& D. Chakrabarti (Eds.), Women, Gender, and Disaster: Global Issues and Initiatives (pp. 5-17). Sage.

Ariza, M. (2017, February 21). La Apatrida: Dominicans of Haitian Descent Are Deported and Forgotten. Retrieved from newtimes.com:

http://www.miaminewtimes.com/news/la-apatrida-dominicans-of-haitian-descent-aredeported-and-forgotten-9153733

Arnstein, S. (1969). A ladder of community participation. American Institute of Planners Journal 35 (4), 216-224.

Banoff, G. (2006, June 11). The Tale of the Three Pigs: Taking Another Look at Vulnerability in the Light of the Indian Ocean Tsunami and Hurricane Katrina. Retrieved from SSRC,org: http://understandingkatrina.ssrc.org/Bankoff/ 
Bardhan, P. (2002). Decentralization of Governance and Development. Journal of Economic Perspectives.

Barenstein, J. D. (2017). Post Disaster Reconstruction- Informal Settlers and the Rights to Adequate Housing. In A. Sapat, \& A.-M. Esnard (Eds.), Coming Home After Disaster (pp. 245-262). Boca Raton: CRC.

Beasley, M. (2012). Women, Sabotaj and Underground Food Economies. GastronomicaJournal of Food and Culture, 38-50. Retrieved from Gastronomica, Journal f Food.

Beasley, M. (2012). Women, Sabotaj, and Underground Food Economies. GastronomicaJournal od Food and Culture, 38-50.

Began, R., \& Schuller, M. (Directors). (2009). Poto Mitan- Women as Pillars of the Global Economy [Motion Picture].

Bell, B. (2001). Walking on Fire. Ithaca and London: Cornell University Press.

Bell, B. (2010). We bend but we don't break: fighting for a just reconstruction in Haiti. NACLA Report on the Americas 43 (4), pp. 28-31.

Bell, B. (2012). Fault Lines:Views Across Haiti's Divide. Ithaca and London: Cornell University Press.

Berger, M. T. (2004). After the Third World/ History, Destiny and the Fate of the Third World. Third World Quarterly, 9-39.

Blaikie, P., Cannon, T., Davis, I., \& Wisner, B. (2004). At Risk: National Hazards, People's Vulnerability and Disasters. London: Routledge.

Blimn- Pike, L., Phillips, B., \& Reeves, P. (2006). Shelter Life After Katrina: Visual Analysis of Evacuee Perspectives. International Journal of Mass Emergencies and Disaasters, 303-330.

Bloem M.D., C., \& Miller M.D., A. (2013). Disasters and Women's Health: Reflections from 2010 Earthquake in Haiti. Prehospital and Disaster Medicine.

Bowen, G. (2008). Naturalistic inquiry and the saturation concept: a research note. Retrieved from sagepub.com:

http://journals.sagepub.com/doi/10.1177/1468794107085301

Bradshaw, S. (2004). Socio-economic Impacts of Natural Disasters: A Gender Analysis. United Nations Women and Devlopment. Santiago, Chile: UN. 
Bradshaw, S. (2009). 'Engendering disasters: feminisation of response or a feminisation of responsibility?'. Regional Development Dialogue. 30(1). , 123-131.

Bradshaw, S. (2013). Gender, Development and Disaster. Cheltenham: Edward Elgar Publishing Inc.

Bradshaw, S., \& Fordham, M. (2013). Women and Girls in Disasters. British Department for International Development.

Broderick, E. (2012, March 9). Addressing Gender Equality and Women's Rights in Public Policy. Retrieved August 2016, from Human Rights .gov:

https://www.humanrights.gov.au/news/speeches/applying-gender-perspective-publicpolicy-what-it-means-and-how-we-can-do-it-better

Brubaker, B. (2010, September). Haiti the art of resilience. Retrieved from smithsonianmag.com: https://www.smithsonianmag.com/travel/in-haiti-the-art-ofresilience-53519464/

Brun, C. (2003). "Local Citizens or Internally Displaced Persons? Dilemmas of Long Term Displacement in Sri Lanka. Retrieved from forcedmigration.org: http://www.forcedmigration.org/research-resources/expert-guides/internaldisplacement/alldocuments

Brun, C. (2012). Identifying MSMEs in Haiti at the 2012 IDB Conference. Retrieved from Inter-American Development Bank: www.foromic2012.com-upload/panelistas/35

Bryce, H. (2009). Trust in Government: A By Product of NGO Intervention in Public Policy. International Journal of Public Administration, vol.32 \#1 1, 951-969.

Bullivant, B. M. (1989). Culture: It's Nature and Meaning for Educators. In M. a. McGee, Multicultural and Educational Issues and Perspectives (pp. 27-45). Boston: Allyn and Bacon.

Buvinic, M. (1999). "Hurricane Mitch": Women's needs and contributions. Washington D.C.: Inter-American Developent Bank- Sustainable Development Deppartment.

Cardona, O. M. (2012). Detreminants of Risk: Exposure and Vulnerability. IPCC. New York: Cambridge University Press.

Carlin, R. E., Love, g. J., \& Zechmeister, E. J. (2014). Trust Shaken: Earthquake Damage, State Capacity, and Interpersonal Trust in Comparative Perspective. Comparative Politics Vol. 46, No. 4, 419-437.

Center for Disease Control. (2018, February 6). Global Health-Haiti. Retrieved from cdc.gov: https://www.cdc.gov/globalhealth/countries/haiti/ 
Center for Economic and Policy Research (CEPR). (2013, January 7). Haiti's

Increasingly Hidden Displacement Disaster. Retrieved from Reliefweb.int:

https://reliefweb.int/report/haiti/haiti\%E2\%80\%99s-increasingly-hidden-displacementdisaster

Cerda, M., Paczkowski, M., Galea, S., Nemethy, K., Pean, C., \& Desvarieux, M. (2013). Psychopathology in the Aftermath of the Haiti Earthquake: population based study of PTSD and major depression. Depression and Anxiety Vol. 30 \# 5, 413-424.

Chakraborty, J., Tobin, G., \& Montz, B. (2005). Population Evacuation: Assessing Spatial Variability in Geophysical Risk and Social Vulnerability. National Hazards Vol. $6 \# 1,23-33$.

Chandrasekhar, D. (2012). Digging deeper: participation and non-participation in postdisaster community recovery. Community and Development Vol. 43 \# 5, 614-629.

Chandrasekhar, D., Zhang, Y., \& Xiao, Y. (2014). Nontraditional Participation in Disaster Recovery Planning: Cases from China, India, and the United States. Journal of the American Planning Association vol. 80, iss. 4, 373-384.

Charles, J. (2016, January 18). The Miami Herald.com. Retrieved from Nation-The Americas- Haiti: http://www.miamiherald.com/news/nationworld/world/americas/haiti/article55358850.html.

Charles, J. (2017, September 9). Irma mostly spared Haiti but for the stuggling farmers, the damages are devastating. Retrieved from miamiherald.com:

http://www.miamiherald.com/news/nationworld/world/americas/haiti/article172268857.html

Chen, H., Chen, Y., Au, M., Ling Feng, \& Qian Chen. (2014). , The presence of posttraumatic stress disorder symptoms in earthquake survivors one month after a mudslide in southwest China. Nursing and Health Sciences, 39-45.

Choguil, M. (1996). A ladder of community participation for underdevloped countries. Habitat International 20 (3), 431-444.

Cigler, B. (2009). Mainstreaming Emergency Management into Public Administration. Public Administration Review, 69 \#6, 1172.

CNN. (2010, January 12). Goudou Goudou. Retrieved from youtube.com: https://www.youtube.com/watch?v=Zw69AmK_mBM

Cohen, M. (2017, June 1). 5 Places Secretary of State Kelly should have seen on his trip to Haiti. Retrieved from oxfamamerica.org: 
https://politicsofpoverty.oxfamamerica.org/2017/06/five-places-secretary-kelly-shouldhave-seen-on-his-trip-to-haiti/

Col, J.-a. (2007). Managing Disasters:The Role of Local Government. Public Administartion Review;67, S1, 114-125.

Coleman Selden, S. (2006). A Solution in Search of Problem? Discrimintion, Affirmative Action, and the New Public Service. Public Administration Review, 911-915.

Comerio, M. (1997). Housing issues after disasters. Journal of Contingencies and crisis Management, 166-178.

Comerio, M. (2017). Disaster Recovery and Community Renewal:Housing Approaches. In A. Sapat, \& E. Ann-Margaret (Eds.), Coming Home After Disaster (pp. 3-20). Boca Raton: CRC Press.

Comfort, L. K., Birkland, T. A., Cigler, B. A., \& Nance, E. (2010). Retrospectives and Prospectives on Hurricane Katrina: Five Years and Counting. Public Administration Review Public Administration Review, Vol. 70, No. 5, 669-678.

Comfort, L. K., Waugh, W. L., \& Cigler, B. (2012). Emergency Management Research and Practice in Public Administration: Emergence, Evolution, Expansion, and Future Directions. Public Administration Review, Vol. 72, Iss. 4, 539-548.

Concannon, B., \& Lindstrom, B. (2011). Cheaper, Better, Longer-Lasting: A Rights Based Approach to Disaster Response in Haiti. Emory International Law Review Vol. 25, 1145-1192.

Connor, T., Rapplage, H., \& Angulo, E. (2015, January 11). What does Haiti have to show for 13Billion in earthquake aid? Retrieved from nbcnews.com: https://www.nbcnews.com/news/investigations/what-does-haiti-have-show-13-billionearthquake-aid-n281661Connor, Tracy; Rappalage, Hannah; Angi

Cook, A., \& Glass, C. (2014). Women and Top Leadership Positions: Towards an Institutional Analysis. Work and Organization vol.2 \#1.

Corbet, A. (2014). Encampment dynamics: comparison between a formal camp and an informal camp in Haiti . Cultures and Conflicts \# 93 Spring, 87-108.

Cornwall, A. (2003). Whose voices? Whose choices? Reflections on gender and participatory development. World Development, 1325-42.

country meters. (2018, March 28). Haiti. Retrieved from countrymeters.info: http://countrymeters.info/en/Haiti\#Population_clock 
Courlander, H. (1973). The drum, the hoe; the life and love of the Haitian people. Berley: University of California Press.

Cullen, K., \& Ivers, L. C. (2010). Human Rights Assessment in Parc Jean marie Vincent, Port-au-Prince, Haiti. Health and Human Rights12 (2), 61-72.

Cunningham, O. (2012). The Humanitarian Aid Regime in the Republic of NGOs- The Fallacy Of Building Back Better. The Josef Korbel Journal of Advanced International Stusdies, 102-127.

Cupples, J. (2007). Gender and Hurricane Mitch: reconstructing subjectivities after disaster. Disasters 31 (2), 155-175.

Cutter, S. (2006, June 11). The Geography of Social Vulnerability: Race, Class, and Catastrophe. Retrieved from SSRC.org: http://understandingkatrina.ssrc.org/Cutter/

Cutter, S. (2014, February 28). Building Disaster Reslience. Retrieved from Challenges of Sustainability: http://www.librelloph.com/challengesinsustainability/article/view/cis-1$2-72$

Cutter, S. B. (2003). Social Vulnerability to Environmntal Hazards. Social Science Quarterly Vol.84, No.2,, 242-260.

Cutter, S. E. (2009). Social Vulnerability to Climate Change Variablity Hazards: A Review of the Litearture. Columbia: University of South Carolina Hazards and Vulnerability Research Institute.

Cynn, C. (2008). Nous Mande Jistis (We Demand Justice) Reconstituting Community and Victimhood in Roboteau Haiti. Women's Studies Quarterly $36: 1 \& 2$.

Danes, S. M., Lee, J., Amarapurkar, S., Stafford, K., \& Haynes, G. (2009). Determinants of Family Business Resilience after a National Disaster. Journal of Develpmental Entrepreneurship Vol. 14 \# 4, 333-354.

David, E. (2008). Cultural Trauma, Memory and Gendered Collective Action: The Case of the Women of the Storm Following Hurricane Katrina. The NWSA Journal Vol. 20 No.3, 138-162.

David, E. (2010). "Studying Up" On Women and Disaster: An Elite Women's Group Following Hurricane Katrina. International Journal of Mass Emergencies and Disasters, 246-269.

De Cicco, G. (2016, July 25). Post Earthquake Reconstruction: Another pending matter for the Chilean Government. Retrieved from AWID.org: http://www.awid.org/news-andanalysis/post-earthquake-reconstruction-another-pending-matter-chilean-government 
Desvarieux, J. (2010, June 6). Haiti's Latest Problem. Clearing Away the Rubble. Retrieved from time.com:

http://content.time.com/time/world/article/0,8599,1994544,00.html

Doctors Without Borders. (2017, July 12). Against Their Will: Sexual and Gender based Violence Against Young People in Haiti . Retrieved from doctorswithoutborders.org: https://www.doctorswithoutborders.org/article/against-their-will-sexual-and-genderbased-violence-against-young-people-haiti

Dodd, P., \& Espinosa, R. (2010, January 31). U.N. sets up women only food aid in Haiti. Retrieved from independent.co.uk:

https://www.independent.co.uk/news/world/americas/un-sets-up-women-only-food-aidin-haiti-1884361.html

Domonoske, C. (2016, August 18). UN admits role in Haiti Cholera Outbreak That Killed Thousands. Retrieved from www.npr.org: https://www.npr.org/sections/thetwoway/2016/08/18/490468640/u-n-admits-role-in-haiti-cholera-outbreak-that-has-killedthousands

Donais, T. (2015). Bringing the Local Back In: Haiti, Local Governance and the Dynamics of Vertically Integrated Peacebuilding. Journal of Peacebuilding and Development, vol.10 no.1, 40-55.

Dubois, L. (2012). Haiti: The Aftershocks of History. New York: Metropolitan Books.

Dupuy, A. (2010, July/August). Report on Haiti.

Duramy, B. F. (2011). Women In the Aftermath of the 2010 Haitian Earthquake. Emory International Law Review vol.25.

Eade, D., \& Williams, S. (1995). The Oxfam Handbook of Development and Relief. OXFAM publications.

Eagly, A., \& Karau, S. (2002). Role Congruity Theory of Prejudice Toward Female Leaders. Psychology Review vol.109 \#3, 573-598.

Edmonds PhD., K. (2012). Beyond Good Intentions-The Structural Limitations of NGOs in Haiti. Journal of Critical Sociology, 404-424.

EERI Special Earthquake Report. (2010). Learning from Earthquakes: The Mw 8.8 Chile Earthquake of 2010, Social Impacts, Response and Recovery. National Science Foundation Grant \#CMMI 1034831.

Elliot, J. P. (2006). Race, Class, and Hurricane Katrina: Social Differences in Responses to Disaster. Social Science Research Vol. 35, 295-321. 
Elmhirst, R. (2011). Introducing new feminist ecology. Geoforum \#42, 129-132.

Embassy of the Republic of Haiti. (2017). Haiti at a glance. Retrieved from haiti.org.: http://haiti.org/haiti-at-a-glance/

Enarson, E. (2007). Identifying and Addressing Social Vulnerabilities. In W. L. Waugh, \& E. (. Tierney, Emergency Management: Prnciples and Practices for Local Government (pp. 257-278). Washington D.C.: ICMA Press.

Enarson, E. (2009, October). Women, Gender \& Disaster: Men \& Masculinities. Retrieved from gdnonline.org: https://www.gdnonline.org/resources/GDN_GenderNote3_Men\&Masculinities.pdf

Enarson, E., \& Fordham, M. (2001). From Women's Needs to Women's Rights. Environmental Hazards Vol. 3, 134-136.

Enarson, E., \& Meyreles, L. (2004). International Perspectives on Gender and Disaster: Differences and Possibilities. International Journal of Sociology and Social Policy Vol 24 Iss 10/11, 49-93.

Enarson, E., \& Morrow, B. H. (1998). Toward Gendered Disaster Policy, Practice and Research. In E. Enarson, \& B. H. Morrow (Eds.), The Gendered Terrain of Disaster: Through Women's Eyes (pp. 225-250). Indiana: Praeger.

Enarson, E., \& Morrow, B. H. (1998). Why Gender? Why Women? An Introduction to Women and Disaster. In E. Enarson, \& B. H. Morrow (Eds.), The Gendered Terrain of Disaster: Through Women's Eyes (pp. 1-10). Indiana: Praeger.

Enarson, E., \& Pease, B. (2016). The Gendered Terrain of Disaster, Thinking about Men and Masculinities. In E. Enarson, \& B. Pease (Eds.), Men, Masculinities and Disaster. New York: Routledge.

Enarson, E., Fothergill, A., \& Peek, L. (2006). Gender and Disaster:Foundations and Directions. In H. edited by Rodriguez, E. Quarantelli, \& R. Dynes, The Handbook of Disaster Research (pp. 130-146). New York: Springer.

Esnard, A. M. (2017). Displacement, Return, and Relocation: Housing and Commuity Recovery Considerations. In A. Sapat, \& A.-M. Esnard (Eds.), Coming Home After Disaster (pp. 37-48). Boca Raton: CRC.

Esnard, A.-M., \& Sapat, 1. (2014). Displaced by Disaster: Recovery and Resilience in a Globalizing World. Routledge. 
Everest, G. (2011, May 25). NGOs in Haiti:Caught in an Aid Worker Bubble. Retrieved October 9, 2013, from http://www.e-ir.info/2011/10/05/ngos-in-haiti-caught-in-an-aidworker-bubble/

Eves, C. (2011). Haiti IDP Camp Policy: The Management of Vulnerability. Retrieved from Advocate Forum: http://ssa.uchicago.edu/haitis-idp-camp-policy-managementvulnerability

Fan, L. (2013, November). Disaster as Opportunity-Building Back better in Aceh, Myanmar and Haiti. Retrieved from Overseas Development Institute: /www.odi.org/hpg

Farmer MD., P. (2012). Haiti After the Earthquake. New York: Public Affairs.

Farooqui, M., Quadri, S., Suriya, S., Khan, M., Ovais, M., Sohail, Z., . . Hassan, M. (2017). Post-traumatic stree disorders: a serious post-earthquake complication. Trends in Psychiatry Psychotherapy 39(2), 135-143.

Fatton, R. (2011). Haiti In the Aftermath of the Earthquake: The politics of Catastrophe. Journal of Black Studies, 158-185.

Fatton, R. (2011). Haiti's unending crisis of governance: Food, the constitution and the struggle for power. In J. Heine, \& A. S. Thompson, Fixing Haiti: MINUSTAH and beyond (pp. 41-65). Tokyo: United Nations University Press.

Federal Emergency Management Agency (FEMA). (2018). Strategic Plan 2018-2022 : Helping People.Together. Retrieved from fema.gov/media-library-data: https://www.fema.gov/media-library-data/152173607776789fc0afeacb7a93bd7b6a1091aaeba2b/strat_plan.pdf

Finch, C., Emrich, C., \& Cutter, S. (2010). Disaster disparities and differential recovery in New Orleans. Poplular Environs 31, 179-202.

Fischer, S. (2009). Srilankan Women's Organizations- Responding to Post- Tsunami Violence. In E. C. Enarson, Women, Gender, and Disaster- Global Issues and Initiatives (pp. 232-249). Los Angeles: Sage Publications.

FONKOZE. (2018, July 13). Why Microfinance-Financial INclusion and Poverty Alleviation. Retrieved from fonkoze.org: https://fonkoze.org/why-microfinance.html

FONKOZE-About Us. (2013, November 8). Retrieved from FONKOZE .org: www.fonkoze.org

Food Security Portal Home. (2012). Retrieved October 20, 2013, from Food Security Portal: www.foodsecurityportal.org 
Fook, A. (2011, April). Gender Justice Women's Rights. Retrieved October 12, 2013, from Gender Action.org: www.genderaction.org

Fordham, M. (2012). Gender, Sexuality and Disaster. In B. Wisner, J. Gaillard, \& I. Kelman, Handbook of Hazards and Disaster Risk Reduction and Management (pp. 424435). London, N.Y.: Routledge.

Fothergill, A. (2002). The Neglect of Gender in Disaster Work: An Overview of the Literature. Perspectives on Gender and Disaster, 12-24.

Fothergill, A. (2004). Heads Above Water: Gender, Class, and Family in the Grand Forks Flood. Albany: State University of New York Press.

Fothergill, A., \& Peek, L. (2015). Children of Katrina. Austin: University of Texas Press.

Franz, P. (Producer), \& Franz (Director). (2010). A Teacher's Passion for change [Motion Picture]. Haiti. Retrieved March 23, 2018, from http://www.haitiedstories.org/

Franz, P. (2010, September). Rebuilding Haiti's Education System for the Ground Up. Retrieved from pulitzercenter.org: https://pulitzercenter.org/projects/caribbean/rebuilding-haiti-education-systemearthquake

Gammage, S. (2004). Exercising Exit, Voice and Loyalty: A Gender perspective on Transnationalism in Haiti. Develoment and Change vol. 35 (4), 743-771.

Ganapati, N. E. (2012). In Good Company: Why Social Capital Matters For Women During Disaster Recovery. Public Administration Review Vol. 72 Iss. 3, 419-427.

Ganapati, N. E., \& Ganapati, S. (2009). Enabling Participatory Planning in Post-Disaster Contexts; A Case study of World Bank's Housing Reconstruction in Turkey. Journal of the American Planning Association 75 (1), 41-59.

Ganapati, N., \& Ganapati, S. (2008). Planning After Disasters: A Case Study of the World Bank's Housing Reconstruction in Turkey. Journal of the American Planning Association 75:1, 41-59.

Ganapti, N. E., \& Mukherji, A. (2014). Out of Sync: World Bank Funding for Housing Recovery, Postdisaster Planning and Participation. Natural Hazards Review 15 (1), 5873.

Garnett, J., \& Moore, M. (2010). Enhancing Disaster Recovery: Lessons from Exemplary International Disaster Management Practices. Journal of Homeland Security and Emergency Management Vol.7 Issue 1, Article 40 pp. 1-40. 
Gender Action Network. (2013). Building Back by Half : Gender Issues in IFI investments in Post-earthquake Haiti. Washington D.C.: Gender Action Network.

George, N. (2013). It was a town of friendship and mud. Australian Journal of Communication 40.1, 41-46.

Georges, J. (2004, June). Trade and Disappearance of Haitian Rice. Retrieved from Trade and Environmental Studies: http://www1.american.edu/TED/haitirice.htm

Germain-Gros, J. (2012). State Failure, Underdevelopment, and Foreign Intervention in Haiti. Routledge.

Ghosh, B. (2010, January 27). Titanyen-Haiti's Mass Graveyard of Old and New Nightmares. Retrieved from Time.com:

http://content.time.com/time/specials/packages/article/0,28804,1953379_1953494_19572 48,00.html

Global Food Security. (n.d.). Retrieved October 10, 2013, from Food Security Index: www.foodsecurityindex.eiu.com/Home/Methodolofy

Goldscheid, J. (2007). Women and Disaters: Imagining Recovery Programs from the Victim's Perspective. Women Rights Law Reporter Vol.28 No. 1, 15-19.

Goodman, A. (2016). In the Aftermath of Disasters: The Impact on Women's Health. Critical Obstetrics and Gynecology Vol. 2 \# 6:29, 1-5.

Google Maps. (2018, June 3). Populations and Neighborhoods of Haiti. Retrieved from google.com:

https://www.google.com/maps/search/populations + of + Haiti + neighborhoods, + Delmas,$+C$ anape+Vert+and+Petionville/@18.5357745,-72.3253388,15z/data=!3m1!4b1

Gordon, L. (2013). Preserving family and community: women's voices from the Christchurch earthquakes. Disaster Prevention and Management, 22.

Gorman-Murray, A., McKinnon, S., \& Dominey-Howes, D. (2014). Queer Domicide:LGBT Displacement and Home Loss in Natural Disaster Impact, Response and Recovery. Home Cultures Vol. 11 \# 2, 237-262.

Government of Haiti. (2018, March 31). Haiti's Ministers. Retrieved from primature.gouv.ht: http://primature.gouv.ht/?page_id=28\#

Green, R., Havelin, T., \& Zitleman, K. (2011). NGO's address Structural Racism After the Storm in New Orleans. Springer Science and Business Media, 311-325. 
Guo, H. (., \& Neshkova, M. I. (2012). Citizen Input in the Budget Process: When does it matter most? The American Review of Public Administration 43(3), 331-346.

Haiti. (2017, December). Retrieved from https://www.globalpartnership.org/country/haiti

Haiti and Economic Growth and Trade. (2013, October 27). Retrieved from USAID.gov: www.usaid.gov/haiti/economic-growth-and-trade

Haiti Libre. (2011, August 17). Haiti reconstruction. Retrieved from haitilibre.com: http:/www.haitilibre.com/en/news-3606-haiti-reconstruction-78-million-for-the-16neighborhoods-6-camps-project.html

Haiti Libre. (2017, August 3). Haiti - Social : Facts and figures on the situation of women in Haiti. Retrieved from Haiti Libre.com: http://www.haitilibre.com/en/news20301-haiti-social-facts-and-figures-on-the-situation-of-women-in-haiti.html

Haiti Libre. (2017, July 7). Haitians turned back from the border. Retrieved from Haiti Libre: http://www.haitilibre.com/en/news-21499-haiti-flash-more-than-140-000-haitiansturned-back-at-the-dominican-border.html

Haiti Libre. (2017, March 14). Who are the new ministers. Retrieved from haitilibre.com: http://www.haitilibre.com/en/news-20358-haiti-flash-who-are-these-new-ministers.html

Haiti Ministre de l'Economie et de Finances. (2015, March). Institut Haitien de Statitique et Informatique. Retrieved from ihsi.ht:

http://www.ihsi.ht/pdf/projection/Estimat_PopTotal_18ans_Menag2015.pdf

Haiti Observer. (2017, June 12). The Reasons Why Roads in Haiti Kill and Cause Harm. Retrieved from www.haitiobserver.com: http://www.haitiobserver.com/blog/the-reasonswhy-roads-in-haiti-kill-and-cause-harm.html

Haiti Reconstruction Fund. (2012). AFTER RELOCATING 11000 FAMILIES AND CLOSING 50 CAMPS, THE 16/6 PROGRAM FOCUSES ON THE NEIGHBORHOODS REHABILIATION. Retrieved from Haiaitreconstructionfund.org: http://www.haitireconstructionfund.org/node/171

Haiti, T. R. (2010). Haiti Earthquake PDNA: Assessment of damage, losses, general and sectoral needs. Port-au-Prince: Government of Haiti.

Haiti-Gender Equity and Women Empowerment. (2012). Retrieved from USAID.gov: http://www.usaid.gov/haiti/gender-equity-and-womens-empowerment

Hallward, P. (2010). Damming the Flood: Haiti, Aristide and the Politics of Containment. London: Verso Books. 
Hamelin, T. (2007, December 6). Community organizer with peoples organizing committee. (K. Mosby, Interviewer)

Happel, E., \& Yaffe, N. (2017, October 17). Extraordinary Conditions: A Statutory Analysis of Haiti's Qualification for TPS. Retrieved from chrgj.org: https://chrgj.org/wpcontent/uploads/2017/10/171025_Global-Justice-Clinic-Haiti-TPS-Report-webversion.pdf

Healey, P. (2007). The new institutionalism and the transformative goals of planning. (N. Verma, Ed.) Amsterdam: Elsiever.

Hetherington, M. J. (1998). The Political Relevance of Political Trust. American Political Science Review, 92, 791-808.

Hetherington, M. J., \& Husser, J. A. (2012). How Trust Matters: The Changing Political Relevance of Political Trust. American Journal of Politcal Science Vol.56, No. 2, 312325.

Hirschman, A. O. (1970). Exit, Voice, and Loyalty : Responses to Decline in Firms, Organizations and States. Cambridge Mass.: Harvard Uiversity Press.

Hoeffler, A., Honore, J. G., \& Gage, A. (2017). Domestic Violence in Haiti. Retrieved from Copenhagen Consensus Center:

http://www.copenhagenconsensus.com/publication/haiti-priorise-domestic-violencehoeffler

Horton, L. (2012). After the Earthquake: Gender Inequality and Transformation in Postdisaster Haiti. Gender \& Development, 20:2, 295-308.

Hossein, C. S. (2012). The Politics of Microfinance- A Comparative Study of Jamaica, Guyana and Haiti. PhD.Thesis. Toronto, Canada: Caroline Shenaz Hossein.

Hossein, C. S. (2013). The Black Social Economy-Perseveranve of Banker Ladies in the Slums. Annals of Public and Cooperative Economics, 423-442.

Hoy, P. (1998). Players and Issues in International Aid.

Hsieh, H.-F., \& Shannon, S. E. (2005). Three Approaches to Qualitative Content Analysis. Qualitative Health Research Vol. 15 \#9, 1277-1288.

Human Rights Watch. (2018, July 1). Haiti Events of 2017. Retrieved from hrw.org: https://www.hrw.org/world-report/2018/country-chapters/haiti

Hummon, D. (n.d.). Place Identities: Localities of the self. In C. a. Saile (Ed.), Purposes in built form and culture (pp. 34-37). Lawrence: University of Kansas Press. 
Hutchinson, J., \& Mann, H. (2006). Gender anarchy and the future of feminism in public administration. Administrative Theory and Praxis vol. 28 \#3 , 399-417.

Hyndman, J. (2008). Siting Conflict and Peace in Post-Tsunami Sri Lanka and Aceh.

Hyndman, J., \& Alwis, M. (2003). Beyond Gender- Towards a Feminist Analysis of Humanitariansim and Development in Sri Lanka. Women's Studies Quarterly \#3\&4, 212228.

IADB.org. (2017, July 18). Un techo para Haiti. Retrieved from iadb.org: https://www.iadb.org/es/noticias/articulos/2010-07-13/un-techo-para-haiti\%2C6968.html

Ianiello, M., Iacuzzio, S., Fdele, P., \& Brusati, L. (2018). Obstacles and Solutions on the Ladder of Citizen Participation: a systematic review. Public Management Review.

Ikeda. (1995). Gender differences in human loss and vulnerability in natural disasters. Indian Journal of Gender Studies Vol.2, 171-193.

Infoplease. (2012). Haiti. Retrieved from World Leaders: http://www.infoplease.com/world/leaders/haiti.html

Institute for Justice and Democracy in Haiti \& Bureau des Avocats Internationaux. (2010). Our Bodies are Still Trembling: Haitian Women's fight Against Rape. Boston: IJDH \& BAI.

Institute for Justice and Democracy (IJDH). (2012, July 5). Haiti's Housing Crisis: Relocated Families Live in Worse Conditions. Retrieved from IJDH.org: http://www.ijdh.org/2012/07/topics/housing/haitis-housing-crisis-relocated-families-livein-worse-conditions/

Inter-Agency Standing Committee. (2017). The Gender Handbook for Humanitarian Action. Retrieved from interagencystandingcommittee.org: https://interagencystandingcommittee.org/system/files/2018iasc_gender_handbook_for_humanitarian_action_eng_0.pdf

Interanational Organization for Migration. (2016, August 8). Haiti 2016. Retrieved from IOM Humanitarian Compedium: http://humanitariancompendium.iom.int/haiti/2016

Internal Displacement Monitoring Centre. (2017, June). Human Rights Watch. Retrieved from internal displacement,org: www.internal-displacement.org/countries/haiti

Internal Displacement Organization. (2017). Haiti. Retrieved from internaldisplacement.org: http://internal-displacement.org/countries/haiti 
Internal Displacement.org. (2017). Internal Displacement Global Report- On the Grid. Retrieved from Internal Displacement.org: http://www.internal-displacement.org/globalreport/grid2017/pdfs/2017-GRID-part-1.pdf

International Federation of Red Cross and Red Crescent Societies. (2011). Breaking the Waves-Impact analysis of coastal afforestation for disaster risk reduction in VietnamCross. Geneva: International Red Cross and Red Crescent Societies.

International Organization for Migration. (2011). You Tube. Retrieved from Voice of the Voiceless: https://www.youtube.com/watch?v=hYTWp3kCaiw

International Organization for Migration. (2018, May 10). International Organization for Migration. Retrieved from ion.int: https://www.iom.int/

Irvin, R., \& Stanbury, J. (2004). Citizen participation in decision making: Is it woth the effort? Public Aministration Review, 64(1), 55-65.

J/P Haitian Relief Organization. (2018, January 2). Camp and Relocations. Retrieved from jphro.org: http://jphro.org/our-programs/camp-and-relocations/

J/P Haitian Relief Organization. (2018). Programs and camp relocations. Retrieved January 10, 2018, from jphro.org: http://jphro.org/our-programs/camp-and-relocations/

Janse, H. (2012). Urban Emergencies Case Study of Haiti. Amsterdam: Delft university.

Jenkins, P. (2015, August). 10 Years After Katrina: Women Heroes of the Recovery. Retrieved from Women's Media Center: http://www.womensmediacenter.com/feature/entry/ten-years-after-katrina-womenheroes-of-the-recovery

Jigyasu, R. (2012). Socio-economic Recovery. In B. Wisner, J. Gaillard, \& I. Kelman, The Handbook of Hazards and Disaster Risk Reduction and Management (pp. 580-590). London, N.Y.: Routledge.

Johnson, J. W. (1920). Self-Determining Haiti. Washington D.C.: NAACP.

Katz, C. (2008). Bad Elements: Katrina and the scoured landscape of social reproduction. Journal of Feminist Geography Vol. 15 \# 1, 15-29.

Katz, J. (2013). The Big Truck That Went By-How The World Came to Save Haiti and Left a Disaster. New York: Palgrave Macmillian.

Katz, J. M. (2016, August 17). U.N. Admits Role in Cholera Epidemic in Haiti. Retrieved from nytimes.com: https://www.nytimes.com/2016/08/18/world/americas/united-nationshaiti-cholera.html 
Kaussen, V. (2011, April 8). State of Exception- Haiti's IDP Camps. Monthly review, 3742. Retrieved from IJDH.org: http://www.ijdh.org/2011/04/topics/housing/states-ofexception $\%$ E2\%80\%94haiti\%E2\%80\%99s-idp-camps-monthly-review/

Keiser, L. R., Wikins, V. M., Meir, K. J., \& Holland, C. A. (2002). Gender and Representative Bureaucracy Lipstick and Logarithms: Gender, Institutional Context and Representative Bureaucracy. American Political Science Review \#96, 3, 553-565.

Keiser, L., Wilkins, V., Meier, K. J., \& Holland, C. A. (2002). Lipstick and Logarithyms:Gender, Institutional Context and Representative Bureaucracy. American Politcal Science Review 96,3, 553-565.

Kennedy, J. A. (2008). The meaning of "build back better" evidence from post-tsunami Aceh and Sri Lanka. Journal of Contingencies and Crisi Management Vol. 16 No. 1, 2436.

Kenney. (2005). Reconstruction in Aceh:Building Whose Capacity.

Kermmiyage, K., \& Piyatadsannon, P. (2013). Achieving Success in Post Disaster Resettlement Programmes Through Better Coordintion Between Spatial and Socioeconomic /Cultural Factors. International Journal of Disaster Resilience and the Built Environment, 352-372.

Kim, J., \& Oh, S. S. (2014). The virtuous Circle in Disaster Recovery: Who Returns and Stays in Town After Disaster Evacuation. Journal of Risk and Research vol, 17 \#5, 665682.

Kingsley, D. J. (1944). Representative Bureaucracy: An Integration of the British Civil Service. Yellow Springs, Ohio: Antioch Press.

Kirsch, T., Wadhwani, C., Sauer, L., Doocy, S., \& Catlett, C. (2012). Impact of the 2010 Pakistani floods on rural and urban populations at six months. PLOS Currents Disasters Ed. 1, 1-8.

Klarreich, K., \& Polman, L. (2012, October 31). The NGO Republic of Haiti. Retrieved from The Nation.com: https:/www.thenation.com/article/ngo-republic-haiti/

Klein, N. (2005). The Shock Doctrine:The Rise of Disaster Capitalism. New York:

Picador-Henry Holt and Company.

Klein, N. (2007). The New Economy of Catastrophe. Harper's Bazar.

Klein, N. (2013, October 27). Review of Shock Doctrine. Retrieved from Naomi Klein .org: http://www.naomiklein.org/shock-doctrine 
Knox, R. (2015, January 12). 5 Years After Haiti's Earthquake, Where Did the 13.5 Billion Go. Retrieved from NPR.org:

http://www.npr.org/sections/goatsandsoda/2015/01/12/376138864/5-years-after-haiti-searthquake-why-aren-t-things-better

KOFAVIV. (2011). Beyond the Mountain- KOFAVIV. Retrieved from youtube.com: https://www.youtube.com/watch?v=pAU0Ffp8VDU

Korstanje, E. (2011). Reconnecting with Poverty, New Challenges of Disaster Management. Interntional Journal of Disaster Reilience in the Built Environment, 166177.

Kurin, R. (2011). Saving Haiti's Heritage: Cultural Recovery after the Earthquake. Washington D.C: The Smithsonian Institute.

Kushner, J. (2012, January 14). Haitian Farmers Undermined by Food Aid. Retrieved October 9, 2013, from Truth Out .org: http://www.truth-out.org/news/item/6101:haitianfarmers-undermined-by-food-aid

Kushner, J. (2017, April 14). Haiti: They Call it Canaan. Retrieved from pulitzercenter.org: http://pulitzercenter.org/reporting/haiti-they-call-it-canaan

Kweit, M. G., \& Kweit, R. (2004). Citizen Corruption and Citizen Evaluation in Disaster Recovery. American Review of Public Administartion Vol. 34 No. 4, 354-373.

Labadie. (2008). Auditing of Post-Disaster Recovery and Reconstruction Activities. Disaster Prevention and Management Vol. 17 , 575-586.

Lappe-Osthege, T. (2013, August 29). Do No harm-Revisting Post Earthquake Haiti. Retrieved October 9, 2013, from http://www.e-ir.info/2013/08/29/do-no-harm-revisitedassessing-the-challenges-of-its-relevancy-in-post-earthquake-haiti/

Laudisio, G. (1993). Disaster Aftermath: Redefining Response- Hurrican Andrew's Impact on I \& R. Alliance of Information and Referral Systems 15, 13-32.

Lauterbach, C. (2012, September). Haiti's National Housing Policy: Will It Work for Women? Retrieved from Gender Action.

Lawy, M. (2016, July 26). Women's Response to Chile Earthquake Immediate and Ongoing. Retrieved from Women's Media Center:

http://www.womensmediacenter.com/feature/entry/womens-response-to-chileearthquake-immediate-and-ongoing

Leger, J. (1907). Haiti: Her History and Her Detractors. New York: Neale Publishing. 
L'Etang, G. (2012, May 2). Haiti after the earthquake:camps,shanty towns and housing shortages. Retrieved January 2018, from metro politiques.eu:

http://www.metropolitiques.eu/Haiti-after-the-earthquake-camps.html?lang=fr

Lewis, D., \& Nazneen, K. (2009). Non Governmental Organizations and Development. Retrieved October 11, 2013, from Routledge Developmental Series: http://personal.lse.ac.uk/lewisd/images/NonGovernmental\%20Organizations\%20and\%20Development\%20vouchers.pdf

Lizzardde, G., Fayazi, M., Kikan, F., \& Thomas, I. (2017). Meta Patterns in Post-Disaster Housing Reconstruction and Recovery. In A. Sapat, \& A.-M. Esnard (Eds.), Coming Home After Disaster (pp. 229-244). Boca Raton: CRC.

Louvri, Y. J. (2012). Reducing Vulnerability to Sexual Violence in Haiti's IDP Camps. New York: NYU SChool of Law.

Luft, R. (2008). Looking for Common ground:Relief Work in Post-Katrina New Orleans as an American Parable of Race and Gender . WSA Journal Vol. 20 No.3, 5-31.

Luke, J. (2012). The gendered nature of disasters: Women survivors in post-tsunami Tamil Nadu. Indian Journal of Gender Studies vol.19 (1), 1-29.

Lund, F., \& Vaux, T. (2009). Work Focused Responses to Disasters- India's SelfEmployed Women's Association. In E. Enarson, \& P. D. Chakrabarti, Women, Gender and Disaster- Global Issues and Initiatives (pp. 212-223). Los Angeles: Sage Publications.

Luzencourt, K., \& Gulbrandson, J. (2010). Education and Conflict in Haiti- Rebuilding the Education Sector after the 2010 Earthquake. Washington D.C.: United States Institute of Peace.

MADRE. (n.d.). Retrieved from https://www.madre.org/press-publications/article/fouryears-after-earthquake-haitian-women-continue-feel-impact

Malbranche, S. (2015). Delmas 32: A Post disaster Planning Experience in Haiti. In S. Malbranche, I. E. Brisson, \& A. E. Soo Chun (Eds.), Ground Rules for Humanitarian Design (pp. 240-264). Hoboken, N.J.: Wiley and Sons Ltd.

Mannakkara, S., \& Wilkinson, S. (2014). Re-conceptualizing "Build Back Better" to improve post-disaster recovery. International journal of Managing Projects in Business Vol. 7\#3, 327-341.

Marlowe, L. (2010, January 10). Just this once the stricken capital's biggest slum was comparatively lucky. Retrieved from The Irish Times: 
https://www.irishtimes.com/news/just-this-once-the-stricken-capital-s-biggest-slum-wascomparatively-lucky-1.1270583

Marquart-Pyatt, S. P. (2007). Trust, the Democrtic Process, and Involvement in a Rural Community. Rural Sociology 73 (2), 250-274.

Marshall, C., \& Rossman, G. (2011). Designing Qualitative Research. Thousand Oaks: Sage.

Marshall, J. T., LaGrange, A., \& Ann-Margaret, E. (2017). Anticipating and Overcoming Regulatory and Legal Barriers During Rebuilding and Resettlement. In A. Sapat, \& A.M. Esnard (Eds.), Coming Home After Disaster (pp. 293-306). Boca Raton: CRC.

Maxime, S. (2017, September 9). Haiti expels 300 NGOs. Retrieved from Haiti Sentinel: http://sentinel.ht/2017/09/06/haiti-govt-bans-300-ngos-operating-country/

McEntire, D. (2001). Triggering Agents, Vulnerabilities and Disaster Reduction Towards a Holistic Paradigmn. Disaster Prevention and Management, 189-196.

McEntire, D. (2012). Understanding and Reducing Vulnerabiity from the Approach of Liabilities and Capabilities. Disaster Prevention and Management Vol. 21, 206-225.

McEntire, D., Sadiq, A.-A., \& Gupta, K. (2012). Unidentified Bodies and Mass-Fatality Management in Haiti: A Case Study of the 2010 Earthquake with a Cross-Cultural Comparison. International Journal of Mass Emergencies and Disasters (Vol.30, NO.3), 1-43. Retrieved from http://ijmed.org/articles/608/

McNabb, D. E. (2012). Research Methods in Public Administration and Non Profit Management. Armonk, New York, London: M.E. Sharpe.

McVeigh, T. (2011, January 1). Letters from Haiti. Retrieved from The Haiti Observer: https://www.theguardian.com/world/2011/jan/01/letters-from-a-broken-land-haiti

Mellor, M. (1997). Feminism and Ecology. Cambridge, UK: Blackwell Publisher ltd.

Michels, A., \& DeGraaf. (2017). Examining citizen participation: local participatory policymaking and democracy revisited. Local Government Studies 43(6), 875-881.

Mileti, D. S. (1999). Disasters by Design:assessment of Natural Hazards in the United States. Washington D.C.: Joseph Henry Press.

Morse, J. (1995). The Significance of Saturation. Qualitative Health Research Vol. 5 \# 2 , 147-149. 
Moss, D. (2014, June). Building Back Haitian Government Responsiveness: The Power and Limitations of Grassroots Advocacy. Retrieved from ijdh.org:

http://www.ijdh.org/wp-content/uploads/2015/04/Daniel-Moss-Advocacy-Report.pdf

Nations, U. (2013). Regional Perspectives on Post-2015 UNDP Agenda. New York: UNDP.

Nations, U. (2014, Aril 22). Millenium Goals. Retrieved from United Nations.org: www.un.org/milleniumgoals

Newland, K., \& Salant, B. (2017, December). Increased Focus on Forced Return of Migrants and Asylum Seekers Puts Many in Peril. Retrieved from reliefweb.int:

https://reliefweb.int/report/world/increased-focus-forced-return-migrants-and-asylumseekers-puts-many-peril

Newsamericas. (2018, April 26). Haiti Governemnt names new ministers. Retrieved from newsamericasnow.com: https://www.newsamericasnow.com/caribbean-news-haitigovernment-names-new-ministers/

Norweigan Refugee Council. (2017, February). Haiti. Retrieved from internal displacement.org: http://internal-displacement.org/countries/haiti

Nussbaum, M. C. (2000). Women and Human Development. New York, New York, USA. Retrieved August 2016, from www.cambridge.org/9780521660860

Olshansky, R., \& Chang, S. (2009). Planning for disaster Recovery: Emerging research needs and challenges. Progress in Planning 72 (4), 200-209.

Olshansky, R., Johnson, L., Horne, J., \& Nee, B. (2008). Longer view: Planning for the rebuilding of New Orleans. Journal of the American Planning Association 74 (3), $273-$ 287.

Ott, S. (2016, March 21). Haiti Earthequake: A new start in Canaana for survivors. Retrieved from aljazeera.com: https://www.aljazeera.com/indepth/features/2016/03/haitiearthquake-start-canaan-survivors-160308083308750.html

PADF and Root Project. (2017). The Root Project. Retrieved from padf.org: https://www.padf.org/rootproject/

Padgett, A., \& Warnecke, T. (2011). Diamonds in the Rubble:The Women of Haiti, Institutions, Gender Equity and Human Development in Haiti. Journal of Economic issues, 527-557.

Pamuk, A. (2006). Mapping Global Cities GIS Methods in Urban Analysis. Redlands, CA.: ESEI Press. 
Partners In Health. (2018). Partners in Health in Haiti. Retrieved March 20, 2018, from pih.org: https://www.pih.org/country/haiti

Paton, D., Selway, K., \& Seadon, L. (2013). Community Resilience in Christchurch: Adaptive responses and Capacities During Earthquake Recovery. Christchurch: GNS Science Report.

Patterson, M. (2018, February 22). Are NGOs in Haiti Doing More Harm Than Good. Retrieved from americanmaazine.org: https:/www.americamagazine.org/politicssociety/2018/02/22/are-ngos-haiti-doing-more-harm-good

Peek, L. F. (2009). Using Focus Groups: Lessons from Studying Daycare Centers 9/11, and Hurricane Katrina. Qualitative Research, 31-59.

Peet, R. (1999). Econmic Theories of Growth and Devlopment. In R. Peet, Theories of Devlopment.

Petrozziello, A. J., \& Wooding, B. (2013). Borders, buscones, brothels, and bi-national markets:Haitian women negotiate how to get through. Cultural DynamicsVol. 25 \#2, 183205.

Phillips, B. D. (1996). Homelessness and the social construction of places:The Loma Prieta earthquake. Humanity and Society 19 (4), 95-101.

Phillips, B. D. (2009). Disaster Recovery. Boca Raton: Taylor and Francis.

Phillips, B. D. (2017). Post-Disaster Housing Vulnerability: Getting People Back Home. In A. Sapat, \& A.-M. Esnard (Eds.), Coming Home After Disaster (pp. 21-36). Boca Raton: CRC.

Pierre, Y.-F., Glen, S., \& Tardieu, J.-F. (2009, November). Lost Childhoods in Haiti, Quantifying Child trafficking, Restaveks and Victims of violence. Retrieved from b.3cdn.net: https://b.3cdn.net/padf/d0b483e2777248284b_mlbrz311l.pdf

Pierre-Louis, F. (2011). Earthquake, Nongovernmental Organiztions and Governance in Haiti. Journal of Black Studies Vol.42 \#2, 186-202.

Pierre-Louis, F. (2011). Earthquakes, nongovernmental organizations, and governance in Haiti. Journal of Black Studies 42 (2), 186-202.

Platt, S. (2017). Factors Affecting the Speed and Quality of Post-disaster Recovery and Resilience. In R. Rupakhaty, \& S. Olafsson (Eds.), Earthquake Engineering and Structural Dynamics in memory of Professor Raynar Sigbjornsson. 
Puntos de Encuentro. (2018, July 1). Violencia contra las mujeres. Retrieved from puntosdeencuetro.org: http://www.puntosdeencuentro.org/

Pyles, L. (2015). Participation and Other Ethical Considerations in Participatory Action Research in Post-Earthquake Haiti. International Social Work vol. 58(5), 628-645.

Quarantelli, E. (1982). General and Particular Observations on Sheltering and Housing in American Disasters. Shelter and Housing in American Disasters Vol.6 No.4, 277-281.

Quarantelli, E. (1999). The Disaster Recovery Process, What We Know and Do Not Know from Research. Delaware: University of Delaware Disaster Research Center.

Quarantelli, E. (2006). A Heuristic Approach to Future Disasters and Crisis: New, Old and In Between Types. In Q. D. Rodriguez, Handbook of Disaster Research (pp. 16-41). Springer.

Quigley, B., \& Ramanauskas, A. (2016, August 18). Seven places where Haiti's earthquake money did and did not go. Retrieved from haiti-liberte.com: http://haitiliberte.com/archives/volume5-25/Seven\%20Places.asp

Quigley, M. (2016). The Earthquakes Keep Coming. Retrieved from The Conversation: http://theconversation.com/the-earthquakes-keep-on-coming-for-christchurch-54804

Rahill, G. J. (2014). Re-housing urban Haiti after the earthquake: The dual role of social capital. . Disasters, 38(S1, S73-S93.

Rahill, G. J., \& Ganapati, N. E. (2017). Early Post-Disaster Shelter Recovery After the 12 January 2010 Haiti Earthquake. In A. Sapat, \& A.-M. Esnard (Eds.), Coming Home After Disaster (pp. 161-174). Boca Raton: CRC.

Rahill, G. J., Ganapati, N. E., \& Mukerji, A. (2014). Shelter recovery in urban Haiti after the earthquake: the dual role of social capital. Disaster 38 (S1), S73-S93.

Ramachandran, V., \& Walz, J. (2013, January 14). Haiti's earathquake generated $9 b n$ response, where did the money go? Retrieved from theguardian.com: https://www.theguardian.com/global-development/poverty-matters/2013/jan/14/haitiearthquake-where-did-money-go

Ramachandran, V., \& Walz, J. (2015). Haiti: Where Has All The Money Gone? The Journal of Haitian Studies, Volume 21 No.1, 27-65.

Raskin, M., Kjar, S. A., \& Butt, J. (2008). What is seen and unseen on the Gulfcoast. International Journal of Social Economics Vol. 35 \#7, 490-500. 
Rastoje, N. (2010, January 26). Haiti's Environmental Aftermath. Retrieved from SLATE.com:

http://www.slate.com/articles/health_and_science/the_green_lantern/2010/01/haitis_envir onmental_aftermath.html

Razafimbahiny, H. R. (2017, April 4). Haiti Inc: The Next Frontier. Retrieved from linkedin.com: https://www.linkedin.com/pulse/haiti-inc-next-frontier-herve-rakotorazafimbahiny

Regnier, P. N. (2008). From Emergency Relief to Livelihood Recovery. Disaster Prevention and Management Vol. 17 No, 3, 410-429.

Régnier, P., Neri, B., Scuteri, S., \& Miniati, S. (2008). From Emergency Relief to Livelihood Recovery. Disaster Prevention and Management Vol. 17 \#3, 410-429.

Reini, J. (2010, July 13). In Haiti the Rich look down on the Poor. Retrieved from The National: https://www.thenational.ae/world/the-americas/in-haiti-the-rich-look-down-onthe-poor- 1.511828

Relief Web International. (2016, April 6). Haiti Humanitarian Needs and Key Figures. Retrieved from reliefweb.int: http://reliefweb.int/report/haiti/haiti-humanitarian-needsoverview-2016

Restavek Foundation. (2011, October). Restavek: The Persistence of Child Labor and Slavery. Retrieved from ijdh.org: http://www.ijdh.org/wp-content/uploads/2011/03/HaitiUPR-Restavek-Report-FINAL.pdf

Richman, K. (2012). Male Migration, Female Perdition- Narratives of Economic and Reproductive Impotence in a Haitian Transnational Community. Anthropoliogica 54, 2, 189-197.

Rocheleau, D., Thomas-Slayter, B., \& Wangari, E. (Eds.). (1996). Feminist Political Ecology: Global Issues and Local Experience (Vol. One). London and New York: Routledge. Retrieved 2016

Rodriguez, H. T. (2006). Rising to the Challenges of a Catastrophe: The Emergent and Prosocial Behavior following Hurricane Katrina. Annals of the American Academy of Political and Social Science Vol.604, 82-101.

Rodriguez, H., Wachtendorf, T., \& James, K. T. (2006). A snapsot of the 2004 Indian Ocean Tsunami: Societal Impacts and Cosequences. Prevention and Management Vol. 15 No. 1, 163-177.

Rousseau, J. J. (1762). Du Contrat Social ou Principes du Droit Politique. Paris. 
Rubin, C. B. (2009). Long Term Recovery from Disasters- The Neglected Component of Emergency Management. Journal of Homeland Security and Emergency Management Vol.6 No.1.

Sany PhD., J. (2013, October 3). USAID FUNDS AND LOCALS OWN: LOCAL OWNERSHIP OF PROJECTS IN SITUATIONS OF FRAGILITY AND INSTABILITY. THE CASES OF IDEJEN IN HAITI AND BUILDING PEACE AND PROSPERITY IN CASAMANCE, SENEGA. Retrieved from George Mason University: www.Sany_gmu_0883E_10287

Sapat, A., \& Esnard, A.-M. (2012). Displacement and Disaster Recovery: Tansnational Governance and Socio-legal Issues Following the 2010 Haiti Earthquake. Risk, Hazards and Crisis in Public Policy vol (1), 1-24.

Schein, E. (2004). The Concept of Organizational Culture: Why Bother? In E. Schein, Organizational Culture and Leadership 3rd. ed. (pp. 3-23). San Francisco: Jossey-Bass.

Schein, E. (2014, March 3). Culture fundamentals from Edgar Schein. (h. (. Keppler), Interviewer)

Schuller, M. (2010, December 13). Journal of Humanitarian Assistance. Retrieved from site.tufts.edu: $\mathrm{http}: / /$ sites.tufts.edu/jha/archives/869

Schuller, M. (2010). Unstable Foundations: Impact of NGO's on Human Rights for Portau-Prince's Internally Displaced People. New York: CUNY.

Schuller, M. (2012). Genetically Modified Organizations: Understanding \& Supporting Civil Society in Urban Haiti. The Journal of Haitian Studies, Volume 18 No. 1, 50-74.

Schuller, M. (2012). Killing with Kindness Haiti, International Aid, and NGOs. New Jersey: Rutgers University Press.

Schuller, M. (2014, April 19). Haiti's Disaster after the Disaster: The IDP Camps and Cholera. Retrieved from Tufts University: www.sites.tufts.edu/jha/archives/869

Schuller, M. (2016). Humanitarian Aftershocks in Haiti. Rutgers University Press.

Schuller, M. (2018, February 22). Haiti's Latest Indignity at the Hands of Dogooders, Oxfam's Sex Scandal. Retrieved from counterpunch.org: https://www.counterpunch.org/2018/02/22/haitis-latest-indignity-at-the-hands-ofdogooders-oxfams-sex-scandal-2/

Schulz, D. E., \& Marcella, G. (1994). Reconciling the Irreconcilable:The Trobled Outlook for U.S. Policy Towards Haiti. Crlisle Barracks, PA: Strategic Studies Institute. 
Schwartz, T. (2016, September 25). Polygyny in Haiti. Retrieved from timothyschwartzhaiti.com: https://timothyschwartzhaiti.com/polygyny-in-haiti/

Schwartz, T. (2018, May 12). Scaling up and Estimating Rape in Post- Earthquake Haiti. Retrieved from timothyschwartzhaiti.com: https://timothyschwartzhaiti.com/scalingestimating-rape-post-earthquake-haiti/

Schwartz, T. T. (2012). Travesty in Haiti. Smashwords.

Schwartz, T. T. (2017). The Great Haiti Humanitarian Aid Swindle. Createspace Independent platform.

Seager, J. (2009). The Penguin Atlas of Women in the World. New York: Penguin Books.

Sen, A. (1999). Development As Freedom. Oxford: Oxford Uiversity Press.

Shah, S. A. (2012). Gender and Building Homes in Disaster in Sindh, Pakistan. Gender and Development Vol.20 No.2, 249-264.

Skutsch, M. (2004). Mainstreaming gender into the climate change regime. Retrieved from wecf.eu: http://www.wecf.eu/cms/download/20042005/Gender_climhange_COP10.pdf

Smith, A. (2010, January 24). Haiti and the Aid Racket. Retrieved October 9, 2013, from Counterpunch: www.counterpunch.org/2010/02/24/haiti-and-the-aid-racket/

Smith, A. (2010, January 26). NGOs in Haiti: the Handmaidens of Imperial Domination. (M. Whitney, Interviewer)

Stivers, C. (1990). The public agency as polis: active citizenship in the administrative state. Adminstration and Society 22 (1), 86-105.

Suhrke, A. (1999). The Global Crisis of Internally Displaced Persons, The Case of the Forsaken People: Case Studies of the Internally Displaced. (R. Cohen, \& F. Deng, Eds.) Human Rights Quarterly 21 (2), pp. 541-544.

The Embassy of Haiti in Washington D.C. (2017, August 10). Parlement Haitien Republique D'Haiti. Retrieved from leparlementhaitien.info: http://www.leparlementhaitien.info/

The Embassy of Haiti in Washington D.C. (2017, August 10). The Judicial branch of Haiti. Retrieved from Haiti.org: http://haiti.org/the-judicial-branch/

The Government of Haiti and the World Bank. (2010, March 24). Haiti Earthquake PDNA. Retrieved November 10, 2017, from worldbank.org: 
https://siteresources.worldbank.org/INTLAC/Resources/PDNA_Haiti2010_Working_Document_EN.pdf

The Guardian. (2016, October 6). Hurricane Matthew in Haiti. Retrieved from The Gurdian.com: https://www.theguardian.com/world/2016/oct/06/hurricane-matthew-haitirescuers-battle-reach-remote-areas

The Haiti Equality Collective. (2010). The Haiti Gender Shadow Report: Ensuring Haitian Women's Participation in Post Earthquake Reconstruction. Retrieved from Gender Action .org: http://www.genderaction.org/publications/2010/gsr.pdf

The Haitian Government. (1987). The Haitian Constitution. Retrieved from wipo.in: http://www.wipo.int/wipolex/en/text.jsp?file_id=217598\#LinkTarget_1445

The Humanitarian Academy of Harvard. (2018, August 20). The Protection of Internally Displaced Persons. Retrieved from atha.se: http://atha.se/content/protection-internallydisplaced-persons

The Lost Children of Haiti (2010). [Motion Picture]. Retrieved March 23, 2018, from https://www.cbsnews.com/news/the-lost-children-of-haiti-19-03-2010/

The Mission Haiti. (2018). Haiti scholarship Fund. Retrieved from themissionhaiti.com: https://www.themissionhaiti.com/

The Office of the UN High Commission for Refugees. (2018, January). Study highlights under reported humanitarian crisis. Retrieved from UNHCR.org: http://www.unhcr.org/en-us/news/latest/2018/1/5a65a0ea4/study-highlights-underreported-humanitarian-crises-2017.html

The World Bank. (2017, October 20). Rapidly Assessing the Impact of Hurricane Matthew in Haiti. Retrieved from woldbank.org: http://www.worldbank.org/en/results/2017/10/20/rapidly-assessing-the-impact-ofhurricane-matthew-in-haiti

The World Bank. (2018, August 18). Country Statistics-Haiti. Retrieved from data.worldbank.org: https://data.worldbank.org/indicator/SP.POP.TOTL?locations=HT

Torgman, A. L. (2012). Haiti; A Failed State? Democratic Process and OAS Intervention. Retrieved from University of Miami Interamerican Law Review: http://repository.law.miami.edu/umialr/vol44/iss1/7

Torro, M. C. (2009). The Rise of the Social Economy in Haiti:Constructing Solidarity or Survival Strategies in a Country in Crisis. Cadenas de Estudios Latino-Americano, 60-70. 
Trudeau, M. (2011, April 7). Human Rights Sexual Orientation and Gender Identification in Haiti. Retrieved from hrbrief.org: http://hrbrief.org/2011/04/human-rights-sexualorientation-and-gender-identity-haiti/

U.N. Human Rights Council. (2009, June 10). U.N. expert on slavery expresses concern over restavek system in Haiti. Retrieved from reliefweb.int:

https://reliefweb.int/report/haiti/un-expert-slavery-expresses-concern-over-restaveksystem-haiti

UN Education Scientific and Cultural Organization. (2017). UNESCO and the Philippines Typhoon Haiyan. Retrieved March 23, 2018, from unesco.org: www.unesco.org/new/en/unesco/themes/pcpd/special-pages/philippines-typhoon-haiyan/

UN General Assembly. (2010, June 10). UN Resolution- Education in Emergencies. Retrieved from amazonaws.com: http://s3.amazonaws.com/ineeassets/resources/UN_Resolution_Education_in_Emergencies.pdf

UN Office for the Coordination of Humanitarian Affairs. (2018, February 28). HaitiHumanitarian Snapshot. Retrieved from reliefweb.int:

https://reliefweb.int/report/haiti/haiti-humanitarian-snapshot-28-february-2018

UN Women. (2018, February 12). Background Briefing to the Executive Board 2018, Operational Response at Country Level: Haiti.

UNDP- Governance for Sustainable Governance. (2014, April 22). Integrating Governance in Post 2015 Development Framework. Retrieved from UNDP.org: www.undp.org/sustainablegovernance

UNDP, I. R. (2011). IRP/UNDP Guidance on Recovery Document-Livelihood Systems. Retrieved from UNDP: http://www.in.undp.org/content/india/en/home/knowledge-andsolutions/guidance-notes-and-training-modules.html?page831027148=2/UNDP

UNESCO. (2011, April 19). Haiti-Making Culture a Motor for Reconstruction. Retrieved from whc.unesco.org: http://whc.unesco.org/uploads/events/documents/event-725-10.pdf

UNESCO. (2017, March 23). Crisis and Transition Responses. Retrieved 2018, from unesco.org: http://www.unesco.org/new/en/unesco/themes/pcpd/education-inemergencies/nine-reasons/

UNESCO. (2017). Gender and Science. Retrieved from UNESCO.org: http://www.unesco.org/new/en/natural-sciences/priority-areas/gender-and-science/crosscutting-issues/gender-equality-and-disaster-risk-reduction/facts-and-figures/

UNICEF-Access to Food-Haiti. (2012, March). Retrieved October 21, 2013, from UNICEF: 
www.unicef.org/evaldatabase/files/UNICEF_HRBAP_Final_Report_vol_I_11June_copy -edited_translated_pdf

UNISDR. (2015, August 28). Hurricane Katrina raised the Bar for Disaster Risk

Reduction. Retrieved from UNISDR,org: https://www.unisdr.org/archive/45571

UNISDR. (2016, June 18). Sendai Framework for Disaster Risk Reduction 2015-2030. Retrieved from Prevention web:

www.preventionweb.net/files/43291_sendaiframeworkfordrren.pdf

United Nation Development Programme. (2011, October 12). Haitians clear half of quake rubble. Retrieved from undp.org:

http://www.undp.org/content/undp/en/home/presscenter/pressreleases/2011/10/12/haitian s-clear-half-of-quake-rubble.html

United Nations Development Group. (2017). UN Haiti Cholera Response Mult Partner Fact Sheet. Retrieved from mptf.undp.org: http://mptf.undp.org/factsheet/fund/CLH00

United Nations Development Program. (2014, April 22). Haitian Women Rebuild Their Lives One Brick at a Time. Retrieved from UNDP.org:

www.undp.org/undp/en/home/overwork/crisisprevntionandrecovery/successstories/haitia n-women-rebuild-their-lives-one-brick-at-a-time

United Nations Office for Disaster Risk Reduction. (2016, July 23). UNISDR

Terminology. Retrieved from United Nations Office for Disaster Risk Reduction: https://www.unisdr.org/we/inform/terminology

United Nations Office for Disaster Risk Reduction. (2017, February 2). Report on Disaster Risk Reduction. Retrieved from unisdr.org: https://www.unisdr.org/we/inform/publications/51748

United Nations Women. (2018, June 24). Facts and Figures: Leadership and Political Participation. Retrieved from unwomen.org: http://www.unwomen.org/en/what-wedo/leadership-and-political-participation/facts-and-figures

United States Department of State. (2017, June). Trafficking in Persons Report. Retrieved from state.gov: https://www.state.gov/documents/organization/271339.pdf

USAID. (2017, March). Education in Haiti. Retrieved from usaid.gov: https://www.usaid.gov/sites/default/files/documents/1862/FINAL_EducationMarch2017. pdf

USAID. (2017, July). Haiti- Gender Equity and Women Empowerment. Retrieved from usaid.gov: https://www.usaid.gov/haiti/gender-equity-and-womens-empowerment 
USAID. (2017, March). Haiti-Education. Retrieved from usaid.gov:

https://www.usaid.gov/sites/default/files/documents/1862/FINAL_EducationMarch2017. pdf

USAID. (2018, March 10). Housing and Settlements. Retrieved from usaid.gov:

https://www.usaid.gov/haiti/shelter-and-housing

USAID and Programs to empower Haitian Women. (2013, October 25). Retrieved from USAID.gov: www.usaid.govhaiti/gender-equity-and-womens-empowerment

Verderbe, S. (2009). The Unbuilding of Historic Neighbourhoods in Post Katrina New Orleans. Journal of Urban Design Vol. 14 \#3, 257-277.

What We Do-Food security-Haiti. (2013, May 31). Retrieved October 20, 2013, from Care International: www.care-international.org/where-we-work/haiti.aspx

White, S. C. (1996). Depoliticising development: the uses and abuses of participation. Development in Practice Vol. 6 \#1, 6-15.

World Bank. (2011). Interim Strategy Note For the Republic of Haiti. Washington, D.C.: The World Bank.

World Bank. (2011). Supporting Primary Education in Post-Earthquake Haiti. Retrieved from worldbank.org: http://www.worldbank.org/en/results/2016/09/30/supportingprimary-education-post-earthquake-haiti

World Bank. (2013). World Bank-Haiti. Retrieved October 19, 2013, from data.WorldBank.org:

www.data.worldbank.org/country/haiti/data/views/reports/tableview.aspx

World Bank. (2017). Haitian Cities: Actions For Today With An Eye On Tomorrow. (N. Lozano-Garcia, \& M. Garcia Lozano, Eds.) Retrieved March 28, 2018, from worldbank.org: http://documents.worldbank.org/curated/en/709121516634280180/pdf/122880-V1-WPP156561-OUO-9-FINAL-ENGLISH.pdf

World Bank. (2018, June 27). Haiti overview. Retrieved from worldbank.org: http://www.worldbank.org/en/country/haiti/overview

World Bank FAO and IFAD. (2009). Agriculture and Rural development: Gender in agriculture. World Bank.

World Bank Local Economic Development. (2013, November 7). Retrieved from Worlld Bank.org: http://go.worldbank.org/EA784ZB3F0 
World Health Organization. (2016, April 6). WHO, Zika Virus, Microcephaly and Guillein-Barre Syndrome. Retrieved from reliefweb.net:

http://reliefweb.int/report/world/who-zika-virus-microcephaly-and-guillain-barrsyndrome-situation-report-31-march-2016

World Population Review. (2018, June 3). Haiti Population. Retrieved from worldpopulationreview.com: http://worldpopulationreview.com/countries/haitipopulation/

Yumarni, T., Amaratunga, D., \& Haigh, R. (2014). Assessing gender vulnerability postearthquake reconstruction: case study from Indonesia. Procedia Economics and Finance Vol. 28, 763-771.

Yunus and You Haiti. (2013, November 26). Retrieved from Grameen Creative Lab: www.yyhaiti.org

Zidor, K. (2012, August 17). In Haiti's land of Canaan, a promised land empty of promises. Retrieved from caribjournal.com: https://www.caribjournal.com/2012/08/17/inhaitis-land-of-canaan-a-promised-land-empty-of-promise/\# 


\section{Appendix A}

Interview Guide

\section{The Gendered Long-term Recovery Priorities of Internally Displaced Persons in Post-Earthquake Haiti}

\section{INDIVIDUAL GUIDE (Women and Men)}

Version: 2017

\begin{tabular}{|l|l|}
\hline Moderator: & \\
\hline Date: & \\
\hline Place: & \\
\hline Starting Time: & \\
\hline $\begin{array}{l}\text { Community (Pétion-Ville, Delmas, } \\
\text { Canapé vert) : }\end{array}$ & \\
\hline
\end{tabular}

\section{A. PARTICIPANT DEMOGRAPHICS}

In this section, I will ask you a few questions about you and your household.

A1. Where were you born?

$\square$ Port-au-Prince

$\square$ Other (Please specify):

A2. How old are you?

$\begin{array}{llll}\square \quad 18-25 & \square & 46-50 \\ \square \quad 26-30 & \square & 51-55 \\ \square & 31-35 & \square & 56-60 \\ \square \quad 36-40 & \square & 61-65 \\ \square \quad 41-45 & \square & \text { Above } 65\end{array}$

A3. What is your gender?

$\square$ Male

$\square$ Female

A4. What is your marital status?

$\square$ Single

$\square$ Married
Separated

Widowed 
Cohabit (partner lives in household)

$\square$ Cohabit (partner lives outside of household)

A5. Are you currently employed?

$\square$ Yes $\quad \square$ No

A6. What is the highest grade of school or degree you have completed?

$\square \quad$ Less than Secondary school

$\square \quad$ Bachelor's or License degree

$\square$ Secondary school

$\square$ Graduate degree

$\square \quad$ College level without degree

$\square \quad$ Do not know

$\square$ Other (please specify)

A7. What is your religion?

$\square$ Roman Catholic

$\square \quad$ Protestant

$\square \quad$ None

$\square \quad$ Other (please specify):

A8. Are you a member of an organization?

$\square \quad$ Yes

$\square \quad$ No

If yes, which ones? (please specify)

A9. Where are you currently staying?

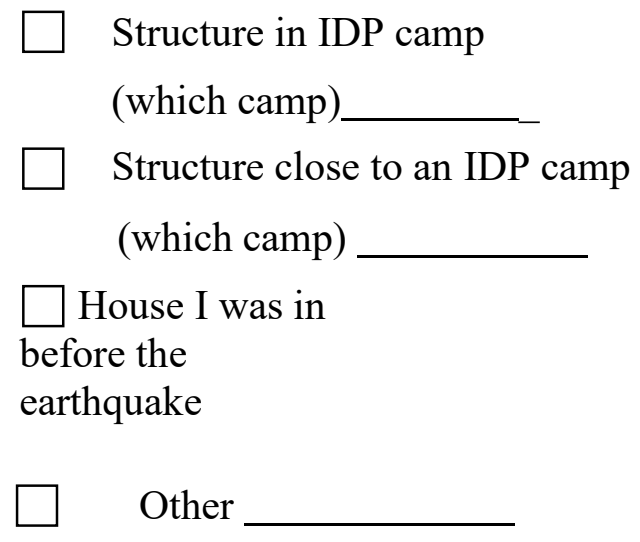

A10. How many do you currently have in the household? 
A11. How many children do you have in the household? What are their ages?

0- 4

$\square$ 5-10

$\square 11-16$

$\square 17$ and older

A12. Do they attend school? yes or no

$\square$ child 1

$\square$ child 2

$\square$ child 3

child 4

A13. Who is the breadwinner in your household?

$\square$ Myself

$\square$ Partner

$\square$ Children

$\square$ Other

\section{B. POST-EARTHQUAKE PRIORITIES AND PARTICIPATION (WITHIN THE FIRST YEAR)}

In this section, I will ask you questions about your top recovery priorities within the first year of the earthquake and about how you informed the authorities about your top priorities.

B1. What was your top recovery priority within the first year of the earthquake?

B2. Please explain why this was important to you at the time.

B3. In what ways did the Haitian government address your top recovery priority at that time?

B4. In what ways did the international agencies address your top recovery priority at that time?

B5. Did you inform the Haitian government or the international agencies about your top recovery priority at that time?

\section{Continue to B6 if YES, move to Question B9 if NO}

B6. Who did you inform about your top recovery priority (e.g., the international agency or the Haitian government)? 
B7. Please tell me why you wanted to inform them about your top recovery priority (e.g., the international agency as opposed to the Haitian government).

B8. How did you inform them about your top recovery priority (e.g. by writing a letter, attending a meeting, arranging a meeting or through a community-based organization)?

B9. Please tell me why you decided not to inform them about your top recovery priority.

B10. When you spoke, did anyone listen within the first year of the earthquake?

Probes: Within the household, within your community, within the Haitian government and within international aid agencies.

\section{POST-EARTHQUAKE PRIORITIES AND PARTICIPATION (NOW)}

In this section, I will ask you questions about your top recovery priorities now and about how you inform the authorities about your top priorities.

$\mathrm{C} 1$. What is your top recovery priority now?

C2. Please explain why this is important to you now.

C3. In what ways is the Haitian government addressing your top recovery priority now?

C4. In what ways are the international agencies addressing your top recovery priority now?

C5. Have you informed the Haitian government or the international agencies about your top recovery priority?

\section{Continue to C6 if YES, move to Question C9 if NO}

C6. Who have you informed about your top recovery priority (e.g., the international agency or the Haitian government)?

C7. Please tell me why you wanted to inform them about your top recovery priority (e.g., the international agency as opposed to the Haitian government).

C8. How have you informed them about your top recovery priority (e.g. by writing a letter, attending a meeting, arranging a meeting or through a community-based organization)?

C9. Please tell me why you decided not to inform them about your top recovery priority.

C10. When you spoke, does anyone listen?

Probes: Within the household, within your community, within the Haitian government and within international aid agencies. 


\section{DIFFERENCES BETWEEN PRIORITIES}

In this section, I will ask you questions about the differences between women's and men's recovery priorities.

D1. Do you think women and men have different or similar recovery priorities?

D2. Why do you think women and men have different or similar recovery priorities?

Please explain why you think this way.

\section{E. POLICY ACTIONS FOR THE HAITIAN GOVERNMENT}

I would like to ask you a few questions on what you believe the Haitian government needs to do.

E1. What do you think the Haitian government needs to do to better understand your top recovery priorities?

E2. What do you think the Haitian government needs to do to better address your top recovery priorities?

E3. What do you think the Haitian government needs to do to better understand Haitian women's (or men's) top recovery priorities in general?

E4. What do you think the Haitian government needs to do to better address Haitian women's (or men's) top recovery priorities in general?

\section{F. POLICY ACTIONS FOR INTERNATIONAL AGENCIES}

I would like to ask you a few questions on what you believe the international agencies need to do.

F1. What do you think the international agencies need to do to better understand your top recovery priorities?

F2. What do you think the international aid agencies need to do to better address your top recovery priorities?

E3. What do you think international agencies need to do to better understand Haitian women's (or men's) top recovery priorities in general?

E4. What do you think international agencies need to do to better address Haitian women's (or men's) top recovery priorities in general?

Is there anything else you would like to share that we have not yet touched upon? 


\section{Appendix B}

\section{Consent Form in French}

Consentent verbal à participer dans une étude

\section{Les Priorités À Long Terme De Rétablissement Du Genre Des Personnes Déplacées À L'intérieur D'Haïti Après Le Tremblement De Terre.}

Nous vous invitons à participer à une étude dirigée par le Dr Emel Ganapati d'Université internationale de Floride à

Miami, en Floride. L'étude est sur les différences dans les priorités de récupération à long terme des femmes déplacées contre hommes déplacés en Haïti ; et les processus qui soutiennent ou entravent la participation des femmes déplacées dans le processus de récupération à long terme. Vous avez été choisi parce que vous vécu/vivre dans une des trois régions touchées par le séisme, Pétion-ville, Canapé Vert et Delmas. Le but de cele étude est au bénéfice des femmes déplacées en Haïti en exprimant leurs préoccupations et en aidant les aborder les questions qui comptent pour eux dans le cadre de post-catastrophe.

Si vous décidez d'être dans cette étude, vous serez un des quatre-vingts 80 personnes dans cele étude. La participation à cette étude prendra une heure (1) à une heure et demie $(1 \mathrm{l} / 2)$ de votre temps. Si vous acceptez d'être dans l'étude, je vais vous poser questions basées sur vos expériences après le

tremblement de terre en 2010 et votre expérience maintenant en 2017. Si vous approuvez, je voudrais enregistrer ceLe conversation. Il n'y a aucun coût ni le paiement à vous. Au cours de l'entrevue, nous pouvons arrêter chaque fois que vous avez des questions. Si vous vous sentez mal à l'aise répondant à

des questions vous pouvez arrêter à tout moment. II n'y a aucun risques prévisibles ou les avantages

pour vous, pour avoir participé à cette étude. II est prévu que cette étude peut-être bénéficier la société en fournissant des informations utiles aux ONG, gouvernements et organismes internationaux œuvrant pour les personnes vivant dans des camps, tandis que les individus reconstruire leurs communautés et leurs moyens de subsistance.

Vous resterez anonyme et vos réponses seront partagés avec d'autres personnes lorsque vous nous donnez la

permission. Dans n'importe quel genre de rapport, nous pourrions publier, nous n'inclurons pas les renseignements qui permeLraient de vous identifier comme un sujet. Dossiers de recherche seront stockés en toute sécurité et que l'équipe de chercheurs auront accès aux enregistrements. Si vous avez des questions pour l'un des chercheurs menant cette étude, vous pouvez contacter le Dr Emel Ganapati à (305)348-0436 [email : ganapat@fiu.edu] ou Nicki Fraser au (786) 351-6033 ou [nfras001@fiu.edu]. Si vous souhaitez parler avec quelqu'un sur vos droits d'être sujet à cette étude de recherche ou sur les problèmes éthiques avec cette étude de recherche, vous pouvez communiquer avec le bureau FIU d'intégrité de la recherche par téléphone au 305-348-2494 ou par courriel à ori@fiu.edu. Votre participation à cette recherche est volontaire, et vous ne sera pas pénalisé ou perdez des avantages si vous refusez de participer ou de décider d'arrêter. Vous consentez à participer à ce projet? 


\section{Appendix C \\ Introduction Letter in English \\ \begin{tabular}{l|l|l|} 
FLORIDA \\
INTERNATIONAL \\
UNIVERSITY
\end{tabular}}

Dear

My name is Nicki Fraser, and I am a Ph.D. candidate at Florida International University in Miami, Florida. My dissertation is The Gendered long-term recovery priorities of internally displaced persons in post-earthquake Haiti. This study is about the differences in the long-term recovery priorities of internally displaced women versus internally displaced men in Haiti; and the processes that support or hinder internally displaced women's participation in the long-term recovery process. It is expected that this study may benefit society by providing useful information to NGOs, governments and international agencies working to support individuals living in camps while those individuals rebuild their communities and livelihoods.

I am sending you this letter to ask for your participation in this study. Due to your role as I would appreciate the opportunity to conduct an in-depth interview (duration of 1hour-1 $1 / 2 \mathrm{hr}$.) with you about the various aspects of the recovery efforts in Haiti since January 12, 2010, earthquake. Your responses will be kept fully confidential (by removing your name and identifying comments from the raw data). This interview can be done via telephone or Skype at your convenience.

I would appreciate your participation which will help me conduct this research study.

Please feel free to send me any questions you may have regarding the study.

Regards,

Nicki Fraser

Ph.D. Candidate Public Affairs at F.I. U 
VITA

NICKI FRASER

Born, Port-au-Prince, Haïti

2011

Bachelor's in Public Administration

Florida International University

Miami, Florida

2013 Master's in Public Administration

Florida International University

Miami, Florida

2013-2016 NSF Foundation Fellow

2016-2018 Doctoral Candidate in Public Policy and Administration Florida International University

Miami, Florida

\section{PUBLICATIONS AND PRESENTATIONS}

Fraser, N. (2017). Best practices for non-profit managers. Panel member at American Society for Public Administration (ASPA) South Florida Conference.

Fraser, N. (2017). The role of public administration in IDP women's participation during the long-term recovery phase in Haiti after the 2010 earthquake. Paper presented at the Southeastern Conference for Public Administration (SECoPA).

Fraser, N. (2016). The gendered priorities of internally displaced persons in postearthquake Haiti. Paper presented at oral dissertation competition, Florida International University (FIU) Graduate School.

Fraser, N. (2016). Citizens' trust in their own government: Haiti before and after the January 12 earthquake. Paper presented at the American Society for Public Administration (ASPA) National Conference.

Fraser, N. (2015). The role of Black micro businesses in transforming Miami's urban core. Paper presented at the American Society for Public Administration (ASPA) National Conference.

Fraser, N. (2015). The role of Black micro businesses in transforming Miami's urban core. Paper presented at the International City/County Management Association (ICMA) Conference. 
Fraser, N. (2014). Femmes c'est Poto Mitan: The role of women-owned micro-businesses in Haiti. Paper presented at the Florida International Women's Conference.

Fraser, N. (2013, 2014). Cross-cultural competence and the emotional labor of aid workers after the 2010 Haiti earthquake, Paper presented at the American Society for Public Administration (ASPA) National Conference. 